Aus der Klinik für Psychiatrie und Psychotherapie

(Prof. Dr. J. Wiltfang)

im Zentrum Psychosoziale Medizin

der Medizinischen Fakultät der Universität Göttingen

\title{
Untersuchung der LTP-artigen Plastizität über dem linken M1 nach anodaler tDCS bei Patienten mit einer Schizophrenie
}

\author{
INAUGURAL - DISSERTATION \\ zur Erlangung des Doktorgrades \\ der Medizinischen Fakultät der \\ Georg-August-Universität zu Göttingen
}

vorgelegt von

Bettina Rein

aus

Quedlinburg

Göttingen 2014 
Dekan:

I. Berichterstatter:

II. Berichterstatter/in:

III. Berichterstatter/in:

Tag der mündlichen Prüfung: $\quad 22.09 .2015$
Prof. Dr. rer. nat. H. K. Kroemer

Prof. Dr. T. Wobrock

Prof. Dr. M. Nitsche

Prof. Dr. M. Oppermann 


\section{Inhaltsverzeichnis}

Verzeichnis der Abkürzungen .......................................................................................................5

1 Einleitung ............................................................................................................................ 8

1.1 Neuroplastizität und Langzeitpotenzierung ……………………………….... 10

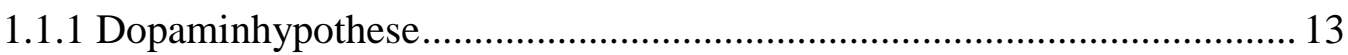

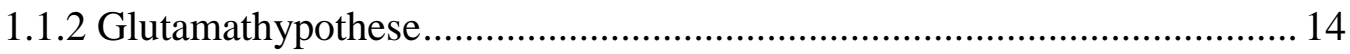

1.1.2.1 Einfluss GABAerger Neurotransmission .......................................... 15

1.1.3 Einfluss sekretorischer Proteasen............................................................... 16

1.2 Longitudinale Veränderungen im Verlauf der Schizophrenie ........................... 17

1.2.1 Klinische Merkmale und Veränderungen im Verlauf der Schizophrenie. 17

1.2.2 Strukturelle Veränderungen neuronaler Strukturen im Verlauf der

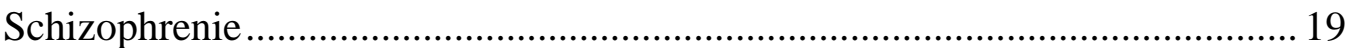

1.2.3 Die histopathologischen Veränderungen im Verlauf der Schizophrenie... 21

1.3 Transkranielle Magnetstimulation (TMS)...................................................... 21

1.3.1 Allgemeine Aspekte der TMS.............................................................. 21

1.3.1.1 TMS-Einzelpulsmessungen........................................................... 22

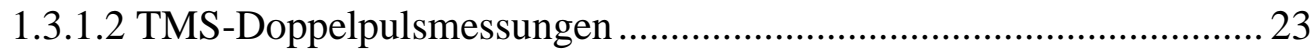

1.3.2 Evaluation der kortikalen Erregbarkeit mittels TMS bei Patienten mit einer

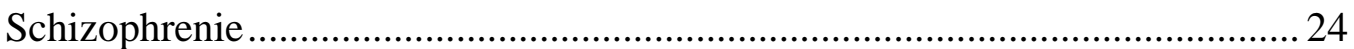

1.4 Transkranielle Gleichstromstimulation (tDCS) ………………………….... 25

1.5 Zielsetzung der Arbeit............................................................................ 28

2 Material und Methoden ...................................................................................................... 29

2.1 Probandenkollektiv ................................................................................ 29

2.2 Versuchsaufbau und Versuchsdurchführung ……………………………........ 35

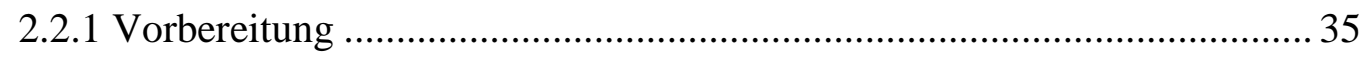

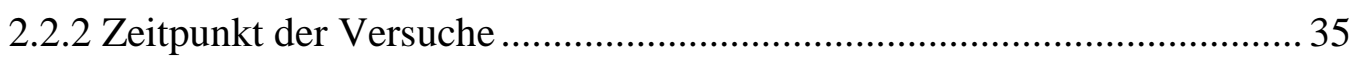


2.2.3 Transkranielle Magnetstimulation 36

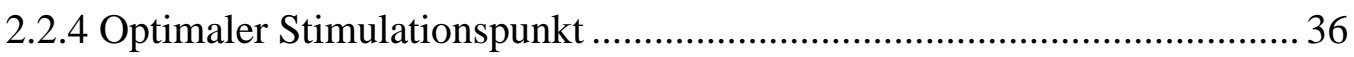

2.2.5 Messparameter und Versuchsdurchführung....................................... 37

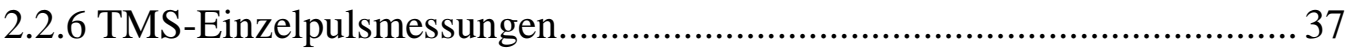

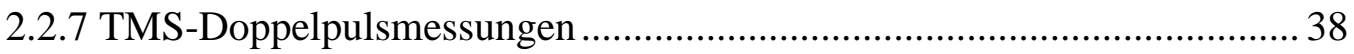

2.2.8 Transkranielle Gleichstromstimulation (tDCS) ..................................... 40

2.2.9 Zusammenfassung der Versuchsprotokolle (Flow Chart)....................... 41

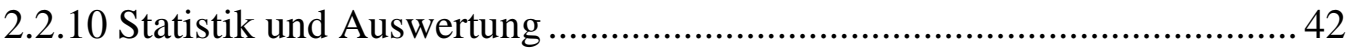

3 Ergebnisse

3.1 Soziodemographische und klinische Merkmale ............................................. 45

3.2 Bahnung der MEPs mittels anodaler tDCS ................................................ 47

3.3 Gruppenunterschiede der kortikalen Erregbarkeit vor tDCS ........................ 50

3.4 Gruppenunterschiede kortikaler Erregbarkeit nach tDCS............................ 53

3.5 Analyse der entsprechend des Alters gematchten Unter-gruppen (Gesunde

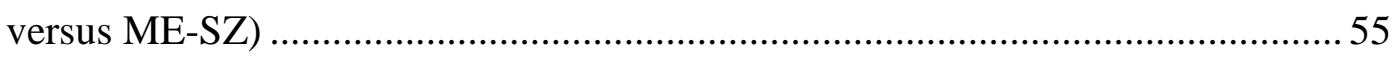

3.6 Einfluss klinischer Faktoren und Antipsychotika auf die TMS-Parameter ..... 56

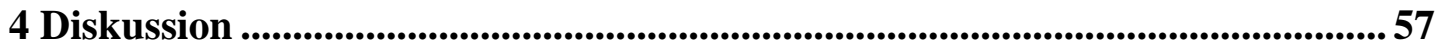

4.1 LTP-ähnliche Plastizitäts-Defizite bei Schizophrenie ...................................5 57

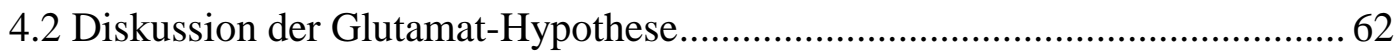

4.3 Progression der Defizite im Verlauf bei Patienten mit einer Schizophrenie ... 65

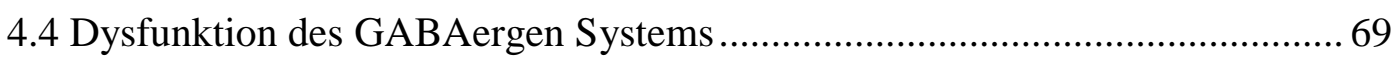

4.4.1 SICI als inhibitorischer Parameter ……................................................. 70

4.4.2 CSP als inhibitorischer Parameter......................................................... 72

4.4.3 ICF als fazilitatorischer Parameter .......................................................... 73

4.5 Einordnung des Ergebnisses in die Dopamin-Hypothese ............................... 74

4.6 Beurteilung der funktionellen Relevanz der Befunde .................................. 75

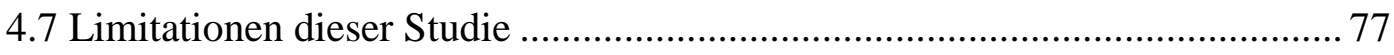


5 Zusammenfassung und Ausblick. .82

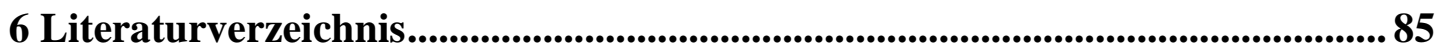




\section{Verzeichnis der Abkürzungen}

Ag

$\mathrm{AgCl}$

AMPA

AMT

ANOVA

BDNF

CGI

$\mathrm{cm}^{2}$

$\mathrm{CPZ}$

CSP

$\mathrm{D}_{1}$

$\mathrm{D}_{2}$

DGPPN

FDI

GABA

GAD67

GAF

$\mathrm{Hz}$

ICD-10

ICF

ISI

$\mathrm{kHZ}$

LTD

LTP

$\mathrm{mA}$

MEP
Silber

Silberchlorid

a-Amino-3-hydroxy-5-methyl-4-isoxazol- Propionsäure

aktive motorische Schwelle (active motor threshold)

Varianzanalyse (analysis of variance)

Wachstumsfaktor (brain-derived neurotrophic factor)

Clinical Global Impressions

Quadratzentimeter

Chlorpromazin-Äquivalent

kortikale kontralaterale Silent Period

$\mathrm{D}_{1}$-Rezeptor

$\mathrm{D}_{2}$-Rezeptor

Deutsche Gesellschaft für Psychiatrie, Psychotherapie und Nervenheilkunde

Musculus interosseus dorsalis I

Gamma-Aminobuttersäure

Glutamat-Decarboxylase 67

Global Assessment of Functioning

Hertz

International Statistical Classification of Diseases and Related

Health Problems

intracortical fascilitation

Interstimulusintervall

Kilohertz

Langzeitdepression (long-term depression)

Langzeitpotenzierung (long-term potentiation)

Milliampère

Muskelsummenaktionspotential 


\begin{tabular}{|c|c|}
\hline ME-SZ & $\begin{array}{l}\text { Patienten mit mehreren psychotischen Episoden } \\
\text { (multi-episode schizophrenia) }\end{array}$ \\
\hline $\mathrm{mg}$ & Milligramm \\
\hline mGlu3 & metabotroper Glutamatrezeptor 3 \\
\hline mRNA & messenger RNA (Ribonukleinsäure) \\
\hline MRS & Protonen-Magnetresonanzspektroskopie \\
\hline MRT & Magnetresonanztomographie \\
\hline $\mathrm{ms}$ & Millisekunde \\
\hline $\mathrm{mV}$ & Millivolt \\
\hline $\mathrm{n}$ & Anzahl der Probanden \\
\hline NMDA & N-Methyl-D-Aspartat \\
\hline $\mathrm{p}$ & Signifikanzniveau \\
\hline PANSS & Positive and Negative Syndrome Scale \\
\hline PAS & paarig-assoziative Stimulation \\
\hline PCP & Phenylcyclidin \\
\hline PET & Positronen-Emissions-Tomographie \\
\hline RO-SZ & $\begin{array}{l}\text { Patienten mit nur einer psychotischen Episode } \\
\text { (recent-onset schizophrenia) }\end{array}$ \\
\hline RM-ANOVA & $\begin{array}{l}\text { Varianzanalyse mit Messwiederholungen } \\
\text { (repeated-measures ANOVA) }\end{array}$ \\
\hline RMT & motorische Ruheschwelle (resting motor thershold) \\
\hline S1 & konditionierender Reiz \\
\hline $\mathrm{S} 2$ & Testreiz \\
\hline $\mathrm{S} 1 \mathrm{mV}$ & 1 Millivolt-Intensität \\
\hline SICI & short-interval intracortical inhibition \\
\hline $\mathrm{tDCS}$ & $\begin{array}{l}\text { transkranielle Gleichstromstimulation (transcranial direct } \\
\text { current stimulation) }\end{array}$ \\
\hline TMS & transkranielle Magentstimulation \\
\hline$\mu \mathrm{V}$ & Mikrovolt \\
\hline
\end{tabular}




\section{Einleitung}

Die Schizophrenie ist eine schwerwiegende psychische Erkrankung, bei der sich sowohl das innere Erleben als auch die äußere Wahrnehmung der Patienten stark verändert.

Die Lebenszeitprävalenz der Schizophrenie liegt weltweit zwischen 0,6 und 1,5 Prozent (Jablensky 1995) und stellt somit eine häufige Erkrankung in der Psychiatrie dar. Männer und Frauen sind in etwa gleich häufig betroffen, wobei das Ersterkrankungsalter der Männer im Durchschnitt etwas geringer ist. Zudem weisen Patienten mit einer Schizophrenie im Vergleich zur Normalbevölkerung eine reduzierte Lebenserwartung (excess mortality) auf, was auf das vermehrte Vorkommen von körperlichen Erkrankungen und Suiziden zurückzuführen ist (Laursen et al. 2007; Large et al. 2011).

Die Schizophrenien sind eine Erkrankungsgruppe mit komplexem Phänotyp. Im Allgemeinen leiden die betroffenen Patienten an so genannten Positivsymptomen wie Wahn, Halluzinationen, Ich- und Denkstörungen und an den Negativsymptomen wie Affektverflachung, Anhedonie und Apathie (siehe Tabelle 1). Typischerweise ist der Verlauf gekennzeichnet durch akute psychotische Episoden sowie eine mögliche Chronifizierung mit Rezidiven und Symptompersistenz (Ciompi 1980; DGPPN 2005). Der Symptomkomplex der Schizophrenie führt häufig zu einer deutlichen Beeinträchtigung der Lebensqualität der betroffenen Patienten sowie zu einer gravierenden Belastung für die Angehörigen (Deutsche Gesellschaft für Psychiatrie, Psychotherapie und Nervenheilkunde DGPPN 2005). Zudem leiden die Patienten zunehmend an komorbiden Störungen, die wahrscheinlich bedeutende Auswirkungen auf die Erkrankung und den Alltag der betroffenen Patienten haben (Wobrock et al. 2005). 
Des Weiteren ist die Schizophrenie als eine der schwerwiegendsten und häufigsten Erkrankungen unter allen psychiatrischen Erkrankungen mit sehr hohen direkten und indirekten Behandlungskosten vergesellschaftet (DGPPN 2005; Gustavsson et al. 2011).

\section{Leitsymptome der Schizophrenie nach ICD-10}

1 Gedankenlautwerden, -eingebung, -entzug, -ausbreitung (Ich-Störungen)

2 Kontroll- oder Beeinflussungswahn, Gefühl des Gemachten bezüglich Körperbewegungen, Gedanken, Tätigkeiten, Empfindungen;

Wahnwahrnehmungen

3 Kommentierende oder dialogische Stimmen

$4 \quad$ Anhaltender, kulturell unangemessener oder völlig unrealistischer Wahn (bizarrer Wahn)

$5 \quad$ Anhaltende Halluzinationen jeder Sinnesmodalität

6 Gedankenabreißen oder -einschiebungen in den Gedankenfluss

$7 \quad$ Katatone Symptome wie Erregung, Haltungsstereotypien, Negativismus oder Stupor

$8 \quad$ Negative Symptome wie auffällige Apathie, Sprachverarmung, verflachte oder inadäquate Affekte

\footnotetext{
Tabelle 1: Leitsymptome der Schizophrenie nach ICD-10 (Deutsche Gesellschaft für Psychiatrie, Psychotherapie und Nervenheilkunde DGPPN 2005).

Für die Diagnose Schizophrenie ist mindestens ein eindeutiges Symptom (zwei oder mehr, wenn weniger eindeutig) der Gruppen $1-4$ oder mindestens zwei Symptome der Gruppen 5 - 8 erforderlich. Diese Symptome müssen fast ständig während eines Monats oder länger deutlich vorhanden gewesen sein.
} 
Trotz einer Vielzahl von molekularbiologischen, neuropathologischen, elektrophysiologischen und bildgebenden Studien sind die neurobiologischen Grundlagen dieser Erkrankung weiterhin nur in Ansätzen verstanden.

Eines der ältesten Modelle zum pathophysiologischen Verständnis der Schizophrenie ist die Dopamin-Hypothese. Basierend auf den Beobachtungen und der Wirkung dopaminantagonistischer Antipsychotika (Carlsson 2006) beschreibt diese eine gestörte dopaminerge Neurotransmission bei Patienten mit einer Schizophrenie (Howes und Kapur 2009).

Des Weiteren werden Alterationen zusätzlicher Neutransmittersysteme wie das noradrenerge, serotonerge und das GABAerge System als ursächlich für die Entstehung der Schizophrenie diskutiert (Olney und Farber 1995; Weinberger 1999; Benes und Berretta 2001). Im Folgenden werden diese Hypothesen und deren theoretische Grundlagen und die jeweiligen Pathomechanismen erläutert.

\subsection{Neuroplastizität und Langzeitpotenzierung}

Unter dem Begriff der neuronalen Plastizität versteht man die Fähigkeit neuronaler Strukturen sich zu reorganisieren, das heißt, sich veränderten Umweltbedingungen sowohl in der Struktur als auch in der Funktion anzupassen (Bliss und Lomo 1973; Daskalakis et al. 2008a).

Bereits 1949 beschrieb Donald Olding Hebb synaptische Plastizität als aktivitätsabhängige Änderung der Stärke der synaptischen Übertragung und folglich als zelluläres und molekulares Substrat von Lernen und Gedächtnis (Hebb 1949). Die durch synaptische Transmission vermittelten Lernprozesse entsprechen lang anhaltenden Erregbarkeitszunahmen. Ein wesentlicher Mechanismus dieser veränderten synaptischen Aktivität ist die Langzeitpotenzierung (LTP) (Bliss und Lomo 1973; Fritsch et al. 2010). Hierbei kommt es mittels afferenter Einflüsse zu einer Aktivierung neuronaler Verbindungen und folglich $\mathrm{zu}$ einer im entsprechend aktivierten Netzwerk lang anhaltenden Verstärkung der Informationsübertragung. 
Somit stellt die Langzeitpotenzierung eine molekulare Grundlage von neuronaler Plastizität dar.

Ein zentraler Baustein für die Entstehung von neuronaler Plastizität und LTP sind die glutamatergen Rezeptoren. Vor allem der N-Methyl-D-Aspartat-Rezeptor (NMDARezeptor) spielt eine wesentliche Rolle bei der Induktion von Neuroplastizität. Durch Entfernung des Magnesium-Blocks (mittels Bindung von Glutamat am postsynaptischen Rezeptor) öffnet sich der NMDA-Rezeptor und Kalzium strömt in die Zelle. Folglich steigt die intrazelluläre Kalziumkonzentration. Diese wiederum führt zu einer Phosphorylierung des postsynaptischen AMPA-Rezeptors ( $\alpha$-Amino3-hydroxy-5-methyl-4-isoxazol- Propionsäure) und somit $\mathrm{zu}$ einer erhöhten Öffnungswahrscheinlichkeit. Es resultiert eine gesteigerte synaptische Übertragung (Malenka und Bear 2004).
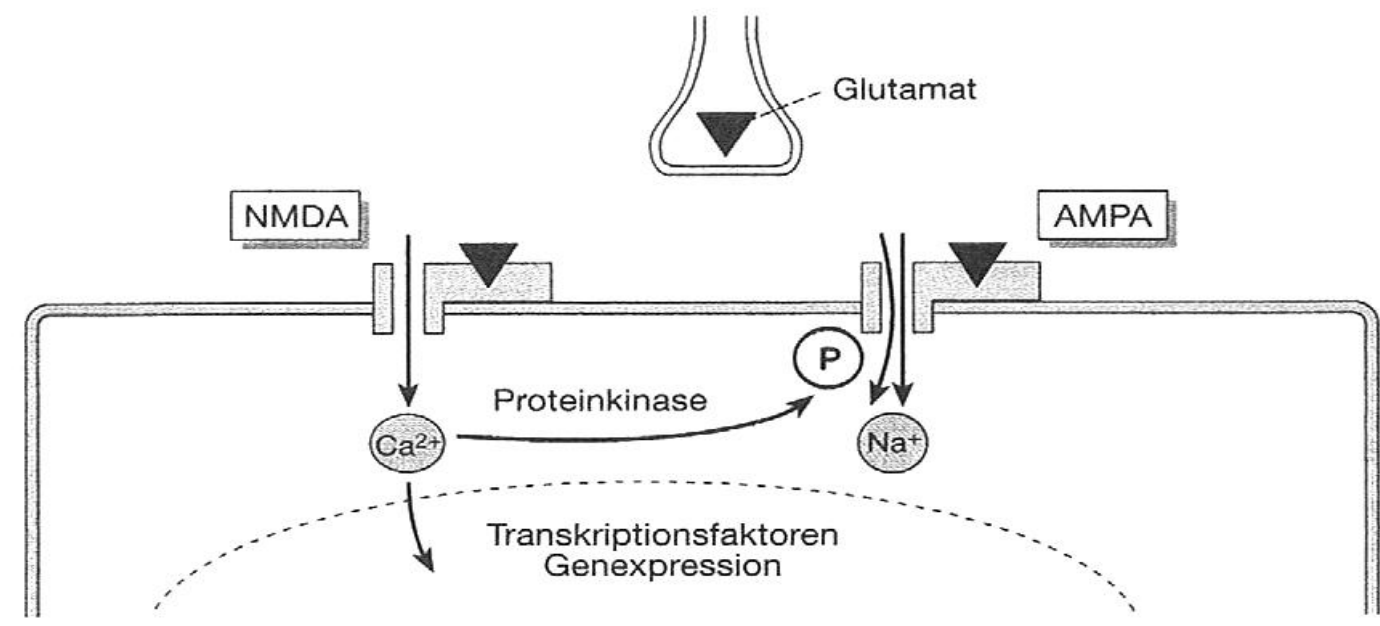

Abbildung 1: Neurotransmitter, Rezeptoren und Plastizität am Beispiel einer nozizeptiven Synapse des Rückenmarks (Grafe 2005, Seite 84).

Die Verwendung von Abbildung 1 erfolgt mit freundlicher Genehmigung des Elsevier-Verlags. 
Zusätzlich beeinflusst der Neurotransmitter Dopamin die NMDA-Rezeptoren und trägt somit zur Entstehung der Langzeitpotenzierung bei. So ist zum Beispiel der $\mathrm{D}_{1^{-}}$ Rezeptor zur Dopaminkontrolle für die Regulation des NMDA-Rezeptors und somit für die Induktion synaptischer Plastizität von wesentlicher Bedeutung (Gurden et al. 2000).

Generell wird dem Neurotransmitter Dopamin eine besondere Bedeutung in der Regulation und der Expression glutamaterger Rezeptoren und bei der Entstehung von Neuroplastizität beigemessen (Manahan-Vaughan und Kulla 2003; Wolf et al. 2003).

Weitere Studien haben gezeigt, dass die GABAerge ( $\gamma$-Aminobuttersäure) Neurotransmission eine wichtige Bedeutung bei der Entstehung der LTP darstellt (Davies et al. 1991). So konnte anhand von Untersuchungen TMS-induzierter, anwendungsabhängiger synaptischer Plastizität am motorischen Kortex gesunder Probanden gezeigt werden, dass die Verabreichung von $\mathrm{GABA}_{\mathrm{A}}-$ Rezeptor-Agonisten (zum Beispiel Lorazepam) eine Reduktion der synaptischen Plastizität bedingt (Bütefisch et al. 2000). Indessen erbrachten weitere Untersuchungen, dass es in Folge einer Amputation der unteren Extremität zu einer verminderten GABAergen Inhibition im entsprechenden motorischen Kortexareal kam und somit eine Reorganisation (neuronale Plastizität) induziert wurde (Chen et al. 1998).

Zum einen spiegelt sich die klinische Bedeutung neuronaler Plastizität in der Wiederherstellung von Hirnfunktionen wider, wie zum Beispiel nach einem Schlaganfall. Zum anderen werden pathologische Veränderungen der neuronalen Plastizität bei verschiedenen Erkrankungen des zentralen Nervensystems wie Morbus Alzheimer, Epilepsie oder eben bei der Schizophrenie (zum Beispiel kognitive Störungen, gestörte Informationsverarbeitung Reizoffenheit und vieles mehr) diskutiert. 


\subsubsection{Dopaminhypothese}

Die am längsten bestehende Untersuchung zum Verständnis des Pathomechanismus der Schizophrenie ist die Dopaminhypothese, die einen engen Zusammenhang zwischen dem Neurotransmitter Dopamin und der Schizophrenie beschreibt. Bereits 1966 wurde diese Hypothese aufgestellt mit der Annahme von hyperaktiven dopaminergen Bereichen im Gehirn von psychotischen Patienten (Van Rossum 1966). Diese Erkenntnisse basierten hauptsächlich auf dem antipsychotischen Erfolg der Dopamin-Rezeptor-Antagonisten. Mit dem Nachweis der antipsychotischen Wirksamkeit der antidopaminergen Antipsychotika wurde die Hypothese unterstützt und es bestand erstmals eine erfolgsversprechende Therapieoption (Carlson 2006; Dollfus und Petit 1991).

Im Laufe der Jahre gab es immer wieder Studien, die diese Hypothese unterstützten, aber auch entkräfteten. Anhand von Post-mortem- und Tierstudien wurde die Hypothese der dopaminergen Hyperfunktion erweitert (Howes und Kapur 2009). Mittels PET konnten kortikale Bereiche dargestellt werden, die sowohl einen gesteigerten als auch einen reduzierten Dopaminmetabolismus aufwiesen. Daraus resultierte die Hypothese, dass bei Patienten mit einer Schizophrenie eine vor allem im präfrontalen Kortex dopaminerge Hypofunktion kompensatorisch $\mathrm{zu}$ einer dopaminergen Hyperfunktion subkortikaler Strukturen, vor allem des Striatums, führt (Theorie der regionalen Spezifität). Dies zeigte sich in den entsprechenden bildgebenden Verfahren durch einen gesteigerten striatalen Dopamin-Metabolismus und eine erhöhte $\mathrm{D}_{2}$-Rezeptor-Dichte (Pycock et al. 1980; Chen et al. 2013). Daraus ergibt sich das Modell der dopaminergen, vor allem präsynaptischen Dysregulation als eine der Grundlagen pathophysiologischer Mechanismen psychotischer Episoden (Howes et al. 2009). 
Zusammenfassend gibt es Grund zur Annahme eines dopaminergen Ungleichgewichtes, welches klinisch wahrscheinlich zum einen die Positivsymptome (mesolimbische dopaminerge Hyperaktivität) und zum anderen die kognitiven Defizite und Negativsymptome (frontale dopaminerge Hypoanktivität) pathogenetisch in Teilen erklärt (Perez-Costas et al. 2010).

Mit der Weiterentwicklung der Forschung wurde auch diese Hypothese in den letzten zwei Jahrzehnten erweitert. Es ist davon auszugehen, dass die striatale dopaminerge Hyperaktivität zusätzlich durch gewisse Risikofaktoren, wie zum Beispiel die Genetik, verschiedene Umweltfaktoren, sowie die psychotischen Episoden selbst mit verursacht wird. Die pathophysiologischen Mechanismen des dopaminergen Ungleichgewichtes scheinen somit nicht von nur einer isolierten Störung bedingt zu sein, sondern vielmehr von einem Zusammenspiel multipler Fehlfunktionen verschiedener Transmitter- und neuronaler Systeme (Howes und Kapur 2009).

\subsubsection{Glutamathypothese}

Ein weiterer Neurotransmitter, das Glutamat und dessen gestörte Neurotransmission, stellen einen zusätzlichen Kernaspekt der Pathophysiologie der Schizophrenie dar (Klär et al. 2010; Coyle 2006).

Glutamat ist einer der wichtigsten und am häufigsten vorkommenden exzitatorischen Neurotransmitter des zentralen Nervensystems, der unter anderem für die Entstehung von Langzeitpotenzierung von wesentlicher Bedeutung ist.

In-vivo-Messungen der Aktivität des glutamatergen Systems mittels MRS (ProtonenMagnetresonanzspektroskopie) beschreiben sowohl eine Hyperaktivität, zum Beispiel im anterioren Zingulum, als auch eine Hypoaktivität, wie zum Beispiel im Hippocampus und im rechten präfrontalen Kortex bei Patienten mit einer Schizophrenie (Gallinat 2007; Tebartz van Elst et al. 2005). Als Ursache für diese unterschiedlichen Glutamataktivitäten werden dementsprechend unterschiedliche Rezeptorfunktionen vermutet. Es konnte gezeigt werden, dass einzelne Subtypen ionotroper Glutamatrezeptoren in den verschiedenen Bereichen des Gehirns unter- 
schiedliche Aktivitäten aufweisen. Während bei Patienten mit einer Schizophrenie präfrontal eine gesteigerte Dichte der Kainat-Rezeptoren nachgewiesen werden konnte, zeigte sich hippocampal eine verminderte Dichte an Kainat-Rezeptoren und AMPA-Rezeptoren (Gallinat und Gudlowski 2008).

Hinsichtlich der metabotropen Glutamatrezeptoren wie dem mGlu3 (metabotroper Glutamatrezeptor 3) konnte gezeigt werden, dass es wahrscheinlich eine Assoziation zwischen der Existenz des mGlu3-Gens und einem erhöhten SchizophrenieErkrankungsrisikos gibt (Mössner et al. 2008).

Der im Allgemeinen als dysregulierte Glutamattransmission $\mathrm{zu}$ beschreibende Zustand kann neurotoxisch wirken und zu einer Reduktion der NMDA-RezeptorAktivität und somit zu einer Beeinträchtigung neuronaler Plastizität führen (Konradi und Heckers 2003; Coyle 2006; Paz et al. 2008).

Es besteht die Vermutung, dass eine gestörte Langzeitpotenzierung klinisch $\mathrm{zu}$ neurokognitiven Defiziten im Lernen und Gedächtnis bei den Patienten mit einer Schizophrenie führt (Heinrichs und Zakzanis 1998). Zurückzuführen sind diese Annahmen unter anderem auf die Ergebnisse klinisch-neurophysiologischer Untersuchungen, die eine Korrelation zwischen einer reduzierten Langzeitpotenzierung und den Defiziten im motorischen Lernen bei Patienten mit einer Schizophrenie zeigten (Frantseva et al. 2008; Daskalakis et al. 2008a).

\subsubsection{Einfluss GABAerger Neurotransmission}

Post-mortem-Studien haben Veränderungen in einem Enzym, der GlutamatDecarboxylase (GAD67), welches für die Synthese von GABA verantwortlich ist, eine verminderte Anzahl von GABAergen Interneuronen bei Patienten mit einer Schizophrenie aufgezeigt (Benes et al. 1991; Benes 1998; Benes et al. 2007; Benes 2011; Lewis et al. 2005). Bemerkenswerterweise konnte zudem dargestellt werden, dass GABA-abhängige Transkriptionen und mRNA in vielen kortikalen Arealen, somit auch im motorischen Kortex, bei Patienten mit einer Schizophrenie reduziert 
sind (Hashimoto et al. 2008). Ferner ist ein Zusammenhang zwischen der verminderten GABAergen Funktion und den NMDA-Rezeptor-Veränderungen bei Patienten mit einer Schizophrenie anzunehmen, seitdem Post-mortem-Studien eine verminderte Dichte an GABAergen Interneuronen nachweisen konnten, welche für die Expression bestimmter NMDA-Rezeptor-Untereinheiten verantwortlich sind (Coyle 2006; Woo et al. 2004).

Zusammenfassend gesehen scheint ein gestörtes Zusammenspiel zwischen NMDARezeptoren und GABA-Rezeptoren zumindest teilweise für die beschriebenen kortikalen Plastizitätsdefizite bei Patienten mit einer Schizophrenie verantwortlich zu sein (Coyle 2006).

\subsubsection{Einfluss sekretorischer Proteasen}

Zusätzlich wurden in den letzten Jahren veränderte Aktivitäten von sekretorischen Proteasen wie Dysbindin (Straub et al. 2002), Neuregulin-1 (Stefansson et al. 2004) und Reelin (Eastwood und Harrison 2006) bei der Schizophrenie beschrieben. Diese Proteasen sind wichtig für die Induktion neuronaler Plastizität und somit mögliche Teilaspekte für die Erklärung der Defizite psychotischer Patienten. Am Beispiel des Reelins ist bekannt, dass dieses Neuroprotein komplexen Einfluss auf die bereits pränatale Entwicklung und Funktion des Gehirns hat (Lakatosova und Ostatnikova 2012). Es reguliert sowohl pränatal als auch postnatal die neuronale Migration und das Wachstum von Synapsen und Axonen. Daraus resultiert der bedeutende Einfluss der Proteasen auf die Entstehung neuronaler Plastizität, die wichtig ist für das Lernen und die Gedächtnisfunktion (Rogers et al. 2011; Lakatosova und Ostatnikova 2012). Es konnte gezeigt werden, dass verschiedene sekretorische Proteasen, wie zum Beispiel Reelin, bei Patienten mit einer Schizophrenie vermindert sind (Eastwood und Harrison 2006; Habl et al. 2012). 


\subsection{Longitudinale Veränderungen im Verlauf der Schizophrenie}

Eine weitere wichtige Theorie zum pathophysiologischen Verständnis der Schizophrenie beschreibt die Hypothese, dass es sich bei diesem Krankheitsbild um eine progressive Erkrankung mit Zunahme der neurobiologischen und klinischen Defizite handelt. Einige Autoren diskutieren dabei einen neurodegenerativen Aspekt als weiteres Erklärungsmodell für die Schizophrenie (Perez-Neri et al. 2006; Csernansky 2007; Archer 2010). Laut Definition handelt es sich bei einer neurodegenerativen Erkrankung um eine chronische und progressive Störung des Nervensystems (Hardy und Gwinn-Hardy 1998). Hierfür finden sich auch bei der Schizophrenie Hinweise, was zunächst klinisch, später neurobiologisch mit Hilfe von bildgebenden Verfahren wie MRT und PET, pathophysiologisch, sowie mittels Postmortem-Studien imponiert, wenn auch die genauen Mechanismen noch unbekannt sind (Lieberman 1999). Ferner manifestiert sich die Annahme, dass sowohl eine Störung der Entwicklung des Nervensystems als auch progressive Veränderungen wesentliche Aspekte im pathophysiologischen Verständnis des Krankheitsbildes der Schizophrenie darstellen (Gupta und Kulhara 2010). Neben der Diskussion dieser neurodegenerativen Aspekte, hat sich zunehmend die Hypothese einer Neuroentwicklungsstörung etabliert.

Im Folgenden werden die longitudinalen Veränderungen bei Patienten mit einer Schizophrenie sowohl unter klinischem als auch unter morphologischem und histopathologischem Aspekt erläutert.

\subsubsection{Klinische Merkmale und Veränderungen im Verlauf der Schizophrenie}

Es ist davon auszugehen, dass es bereits prä- oder perinatal durch Störfaktoren (firsthit) wie Stress, Infektionen, Traumata oder Drogenabusus der Mutter während der Schwangerschaft $\mathrm{zu}$ fortschreitenden neuronalen Veränderungen kindlicher Gehirnstrukturen kommen kann, welche zu einer gesteigerten Anfälligkeit für 
Störungen in der normalen Entwicklung des Gehirns führt. Dies hat einen progressiven Verlust der grauen Substanz und der Konnektivität vor allem präfrontal zur Folge (Pantelis et al. 2005). Dies, assoziiert mit postnatal auftretenden äußeren Faktoren (Umweltfaktoren, second-hit) wie Stress (Pariante et al. 2005) oder Drogenkonsum (vor allem Cannabis) (Rais et al. 2008), scheint den Ausbruch der Erkrankung beziehungsweise das Auftreten erster psychotischer Symptome typischerweise im Jugendalter oder im frühen Erwachsenenalter zu triggern. Inzwischen ist bekannt, dass dem eigentlichem Krankheitsbeginn eine Latenz von ein bis drei Jahrzehnten sowie ein Prodromalstadium voraus geht. Dies entspricht einem Stadium, in dem noch keine klassischen Symptome der Schizophrenie vorliegen. Es handelt sich vielmehr um eine sehr variable Zeitspanne (Wochen bis Jahre), in der die ersten unspezifischen Symptome und Defizite erkennbar werden. Häufig handelt es sich hierbei um Symptome in unterschiedlicher Ausprägung wie Stimmungsschwankungen, Veränderungen der Wahrnehmung und der Kognition oder Zeichen eines sozialen Rückzuges (Klosterkötter et al. 2013). Das Stadium endet nach Auftreten erster prominenter oder persistierender psychotischer Symptome entsprechend der diagnostischen Kriterien der Schizophrenie (Tandon et al. 2012). Wichtig hierbei zu erwähnen ist, dass das Prodromalstadium des Einzelnen häufig nur retrospektiv durch eine genaue Anamneseerhebung beurteilt werden kann (Tandon et al. 2012).

Die Zunahme beziehungsweise das Vorhandensein der Positivsymptome beschreibt die Akutphase der Erkrankung, welche sich entweder progressiv steigert oder in der es zu einer Stabilisationsphase kommt (Loebel et al. 1992). Es wird vermutet, dass die Dauer und die Anzahl der psychotischen Episoden einen entscheidenden prognostischen Faktor dar stellt (Wyatt 1991). Auf der anderen Seite ist zu erwähnen, dass ein Teil der Ersterkrankten einen positiven Verlauf mit Spontanremissionen aufweisen (DGPPN 2005). 
Bei einigen Patienten kommt es $\mathrm{zu}$ einer Verschlechterung der kognitiven Leistungsfähigkeit im Verlauf der Erkrankung (Waddington et al. 1995). Allerdings sind bei vielen Patienten nach einer Ersterkrankung die kognitiven Defizite stabil (Mesholam-Gately et al. 2009), bei Wiederauftreten von psychotischen Symptomen können diese erneut zunehmen. So zeigen Patienten, die bereits mehr als zwei psychotische Episoden (ME-SZ) aufwiesen, insgesamt eine stärkere kognitive Beeinträchtigung als solche mit nu einer Episode (Hoe et al. 2012). Auch verschiebt sich im Verlauf der Erkrankung das klinische Bild insofern, dass zu Beginn der Erkrankung, wo vor allem die Positivsymptome wie Wahn, Gedankeneingebungen und Halluzinationen im Vordergrund stehen und sich später, nach mehreren psychotischen Episoden, die Negativsymptome mit Affektverflachung, sozialem Rückzug, Reduktion der Emotionalität, sowie motorische und kognitive Defizite bedeutsamer darstellen und zu einer stärkeren Beeinträchtigung führen (Green 1996).

\subsubsection{Strukturelle Veränderungen neuronaler Strukturen im Verlauf der Schizophrenie}

Dass es zu strukturellen Veränderungen des Gehirns kommt, die in allen Stadien der Erkrankung nachweisbar sind, wurde in vielen, vor allem MRT Studien beschrieben. Es konnte gezeigt werden, dass Patienten mit einer Schizophrenie im Vergleich zu gesunden Kontrollprobanden eine Volumenreduktion der grauen Substanz (vor allem hippocampal, präfrontal und temporal) (Glahn et al. 2008; Fornito et al. 2009) und eine Volumenzunahme der flüssigkeitsgefüllten Räume (vor allem Seiten- und 3. Ventrikel) des Gehirns aufweisen (Shenton et al. 1997; Wright et al. 2000; De Peri et al. 2012; Haukvik et al. 2013). In einer longitudinalen Studie, in der mittels MRT Patienten mit einer Schizophrenie gesunden Kontrollpersonen über einen Zeitraum von fünf Jahren gegenübergestellt wurden, konnte ergänzend bei den Patienten ein Volumenverlust der grauen Substanz (vor allem im linken oberen frontalen Gyrus, im linken oberen temporalen Gyrus, im rechten Nucleus caudatus und im rechten Thalamus) bestätigt werden (Van Haren et al. 2007). Metaanalysen zu Diffusions- 
Tensor-Bildgebungen konnten zudem eine reduzierte Myelinschicht vor allem links präfrontal und temporal lokalisierter Nervenfasern nachweisen und somit ergänzend $\mathrm{zu}$ den strukturellen Veränderung Hinweis für funktionelle Defekte neuronaler Netzwerke bei Patienten mit einer Schizophrenie darlegen (Ellison-Wright und Bullmore 2009).

Zusätzlich ist bekannt, dass chronisch beziehungsweise mehrfach erkrankte Patienten mit einer Schizophrenie (ME-SZ) größere Abnormalitäten der Gehirnstruktur aufweisen als Ersterkrankte und die wiederum mehr neuronale Strukturveränderungen zeigen im Vergleich zu Gesunden (Lieberman et al. 1992; Ho et al. 2011). Diese neuronalen Strukturveränderungen konnten in einer Vielzahl von Untersuchungen über mehrere Jahre wiederholt nachgewiesen werden und bestätigen eine Progredienz der Volumendefizite mit fortschreitender Krankheitsdauer (Ho et al. 2011).

Neueste MRT-Studien ermittelten einen Zusammenhang zwischen der Anzahl und Schwere der psychotischen Episoden und den morphologischen Veränderungen im Gehirn (Cahn et al. 2009). Bedingt ist diese strukturelle Gehirnveränderung und der progressive Volumenverlust der grauen Substanz (vor allem präfrontal) vermutlich durch den toxischen Effekt der psychotischen Episoden selbst (Mc Glashan 2006). Das heißt, je länger und je häufiger die akute Phase der Patienten ist, desto größer ist der Volumenverlust im Gehirn (Cahn et al. 2009). Ebenso scheint die antipsychotische pharmakologische Therapie Einfluss auf den Volumenverlust der grauen Substanz im Gehirn zu haben, so dass höhere Dosierungen mit einem stärkeren, vor allem frontalen Volumenverlust, assoziiert sind und dies unabhängig von der Krankheitsdauer (Ho et al. 2011). 


\subsubsection{Die histopathologischen Veränderungen im Verlauf der Schizophrenie}

Histopathologisch wurde dem programmierten Zelltod, der Apoptose, eine wichtige Rolle zugeschrieben. So kommt es bei der Schizophrenie hypothetisch durch einen Trigger, wie zum Beispiel einer exzessiven Glutamatausschüttung, zur Aktivierung von Caspasen und somit zum programmierten Zelltod in den Dendriten der Neurone (Margolis et al. 1994). Dies stellt eine Hypothese zur Erklärung für die neuronale Dystrophie dar (Olney und Farber 1995). Folglich kommt es durch die reduzierte Zellgröße und Neuronendichte zum Funktionsverlust der Nervenzellen (Verlust der Konnektivität) bei Patienten mit einer Schizophrenie (Goldman-Rakic und Selemon 1997). Demzufolge lässt sich der Progression der Erkrankung, als ein eigenständiger und zentraler Aspekt der Schizophrenie, große Bedeutung zuweisen (Cahn et al. 2009).

\subsection{Transkranielle Magnetstimulation (TMS)}

\subsubsection{Allgemeine Aspekte der TMS}

Die transkranielle Magnetstimulation stellt eine erst seit 1985 angewandte Methode dar, welche nicht-invasiv und schmerzlos die Untersuchung der kortikalen Exzitabilität erlaubt.

Physikalische Grundlage ist die transkranielle Induktion eines elektrischen Stromflusses in das Nervengewebe. Unter Verwendung eines Kondensators, über den ein schneller und kurzer Entladungsstrom erzeugt wird, entsteht in einer Spule ein zeitlich wechselndes Magnetfeld. Entsprechend des Faraday'schen Prinzips wird auf Grund des schnellen Richtungswechsels des Magnetfeldes ein elektrischer Stromfluss in entgegengesetzter Richtung induziert.

Bei diesem Verfahren lassen sich insbesondere die parallel zur Spule, das heißt die horizontal verlaufenden Nervenbahnen, erregen. Diesen entsprechen vor allem die Axone der Interneurone des motorischen Rindenfeldes. Mit Hilfe von 
Oberflächenelektroden am entsprechenden Zielmuskel (zum Beispiel des kontralateralen M. interosseus dorsalis I) lässt sich die zentrale Erregung ableiten, digitalisieren und vergleichen (siehe Kapitel 2.2.3) (Siebner und Ziemann 2007).

Für die Messungen der kortikalen Exzitabilität mittels TMS können verschiedene TMS-Einzelpuls- und Doppelpulsmessungen durchgeführt werden. Die theoretischen Grundlagen werden im Folgenden erläutert.

\subsubsection{TMS-Einzelpulsmessungen}

\section{Motorische Schwellen (RMT und AMT)}

Die motorische Schwelle korrespondiert mit der geringsten TMS-Intensität die erforderlich ist, um ein MEP auszulösen. Dabei entspricht die RMT (englisch: resting motor threshold) die motorischen Schwelle im ruhenden Muskel und die AMT (englisch: active motor threshold) die motorische Schwelle im mit 20 - $30 \%$ der maximalen Muskelkraft voraktivierten Muskel. Physiologische Grundlage der neuronalen Membranaktivität (Chen 2000) und der Erregbarkeit kortikokortikaler Axone und Synapsen stellen die motorischen Schwellen dar (Shimazu et al. 2004).

Innerhalb pharmakologischer Studien an gesunden Probanden konnte zum Beispiel membrangebundenen Natriumkanälen als Einflussfaktoren auf die motorischen Schwellen eine wichtige Bedeutung zugeschrieben werden (Ziemann 2004).

\section{MEP-Amplitude}

Die Messung der Amplituden motorisch-evozierter Potentiale stellt eine weitere Möglichkeit zur Untersuchung kortikaler Erregbarkeit dar. Dabei besteht ein gleichsinnig sigmoidaler Zusammenhang zwischen der Stimulusintensität und der Größe der MEPs (Devanne et al. 1997). Die Untersuchung der MEPs vor und nach der Induktion von kortikaler Plastizität stellt eine etablierte Methode zur 
Verlaufsuntersuchung der Veränderungen der kortikalen Erregbarkeit nach einer Intervention (zum Beispiel Induktion von Plastizität) dar.

\section{Kortikale Innervationsstille}

Unter der kortikale Innervationsstille (englisch: cortical silent period, CSP) wird eine durch Stimulation ausgelöste, vorübergehende relative oder absolute Minderung von EMG-Aktivität während einer tonischen Aktivierung eines Muskels verstanden (Orth und Benecke 2007). Die Messung der CSP dient der Untersuchung der kortikalen Inhibition und es wird unter anderem eine Beteiligung von inhibitorischer $\mathrm{GABA}_{\mathrm{B}^{-}}$ Rezeptoren diskutiert (Siebner et al. 1998; Werhahn et al. 1999; Ziemann 2004).

\subsubsection{TMS-Doppelpulsmessungen}

Für die Untersuchung kortikaler Erregbarkeit des primär motorischen Kortex und der entsprechenden neurophysiologischen Grundlagen hat sich in den letzten Jahren vor allem die Verwendung verschiedener Doppelpulsprotokolle etabliert. Hierbei bewirkt die Applikation eines konditionierenden Reizes als erster Stimulus eine unmittelbar eintretende Veränderung der kortikalen Erregbarkeit in Form einer Hemmung oder einer Erregung. Für die Erfassung der kortikalen Erregbarkeitsveränderungen folgt auf den ersten unterschwelligen Stimulus ein zweiter überschwelliger Stimulus bei den am häufigsten verwendeten Protokollen (SICI/ICF, siehe unten). Das hierbei erzeugte MEP gibt entsprechend der Amplitudengröße Auskunft über eine Zu- oder Abnahme der Erregbarkeit verschiedener Interneuronnetzwerke im primär motorischen Kortex (Siebner und Ziemann 2007).

\section{SICI und ICF}

Bei kurzen Interstimulusintervallen von $1 \mathrm{~ms}$ bis $5 \mathrm{~ms}$ (englisch: short-interval intracortical inhibition, SICI) ist ein inhibitorischer Effekt des konditionierenden unterschwelligen Reizes nachweisbar, derweil bei Interstimulusintervallen von $6 \mathrm{~ms}$ 
bis $25 \mathrm{~ms}$ ein exzitatorischer Effekt (englisch: intracortical fascilitation, ICF) beobachtet werden kann (Kujirai et al. 1993). Während die SICI neben weiteren Neurotransmittern und Neuromodulatoren wie Dopamin oder Acetylcholin vor allem $\mathrm{GABA}_{\mathrm{A}}$-Rezeptor vermittelt ist, scheint die ICF am ehesten Glutamat assoziiert zu sein (Kujirai et al. 1993; Ziemann 2004).

\subsubsection{Evaluation der kortikalen Erregbarkeit mittels TMS bei Patienten mit einer Schizophrenie}

Die TMS stellt eine geeignete nicht-invasive Untersuchungsmethode für die Untersuchung kortikaler Erregbarkeit bei Patienten mit einer Schizophrenie dar. Speziell für den Nachweis einer reduzierten kortikalen Inhibition hat sich dieses Verfahren etabliert.

Seit längerem werden Dysfunktionen inhibitorischer Prozesse als Teilursache der Entstehung der Schizophrenie diskutiert (Blum und Mann 2002). Rückblickend konnte mehrheitlich eine gestörte kortikale Inhibition an Patienten mit einer Schizophrenie gezeigt werden. Von wesentlicher Bedeutung scheinen hierbei ursächlich vor allem Störungen der subkortikalen dopaminergen Aktivität sowie der GABAergen Aktivität zu sein (Paz et al. 2008; Benes et al. 2007). Es gibt Grund zur Annahme, dass eine erhöhte dopaminerge Aktivität $\mathrm{zu}$ einer verminderten Aktivierung inhibitorischer kortikaler Afferenzen führt, welche vor allem über GABAerge Interneurone vermittelt sind. Folglich resultiert daraus eine erhöhte kortikale Erregbarkeit (Wobrock et al. 2007).

Mittels verschiedener TMS-Paradigmen (Einzelpuls und Doppelpuls-Verfahren) lassen sich diverse Mechanismen der kortikalen Exzitabilität bei Patienten mit einer Schizophrenie untersuchen.

In bisherigen Studien konnte gezeigt werden, dass Patienten mit einer Schizophrenie im Vergleich $\mathrm{zu}$ einer gesunden Kontrollgruppe eine niedrigere motorische Ruheschwelle aufweisen (Daskalakis et al. 2002a, Eichhammer et al. 2004), wobei 
eine Vielzahl sich anschließender Studien diese Befunde nicht reproduzieren konnten (Wobrock et al. 2007).

Unabhängig von der Medikation (Liu et al. 2009; Daskalakis et al. 2002a), der Dauer der Erkrankung (Wobrock et al. 2008; Fitzgerald et al. 2002) und den Risikofaktoren (Hasan et al. 2012b) konnten in den letzten Jahren diverse Studien eine Reduktion der SICI (englisch: short-interval intracortical inhibition) bei nahezu allen Patienten mit einer Schizophrenie zeigen (Hasan et al. 2013a).

Sehr widersprüchlich ist die Studienlage bezüglich der kortikalen Innervationsstille (CSP). Einerseits wurde gezeigt, dass Patienten mit einer Schizophrenie im Vergleich zu gesunden Probanden eine kürzere CSP aufweisen, unabhängig vom Einfluss der Medikation (Fitzgerald et al. 2002 und 2004). Daskalakis und Kollegen schränkten 2002a diese Hypothese insofern ein, als sie diese verkürzte CSP nur bei noch medikamentös unbehandelten Patienten nachweisen konnten und bei bereits therapierten Patienten sich sogar eine Verlängerung der CSP zeigte. Im Gegensatz zu diesen Ergebnissen konnte in anderen Studien gezeigt werden, dass an einer Schizophrenie erkrankte Patienten eine längere CSP aufweisen als gesunde Kontrollpersonen (Bajbouj et al. 2004). In diesem Zusammenhang wird vermutet, dass die verlängerte CSP bedingt ist durch eine kompensatorisch erhöhte $\mathrm{GABA}_{\mathrm{B}^{-}}$ Aktivität in Folge einer Hyperaktivität des dopaminergen Systems (Wobrock et al. 2009).

\subsection{Transkranielle Gleichstromstimulation (tDCS)}

Eine inzwischen gut etablierte Methode für die Induktion kortikaler Plastizität stellt die transkranielle Gleichstromstimulation (englisch: transcranial direct current stimulation, tDCS) dar (Nitsche et al. 2008; Fritsch et al. 2010). Bei diesem nichtinvasiven Verfahren erfolgt die Induktion kortikaler Erregbarkeitsveränderungen mittels einer tonischen Elektrostimulation des menschlichen Gehirns (Nitsche et al. 2008). 
Die Applikation eines schwachen Gleichstroms führt zu Veränderungen der regionalen kortikalen Erregbarkeit, der Plastizität und der neuronalen Spontanaktivität (Nitsche et al. 2003b; Nitsche et al. 2004a; Nitsche et al. 2008; Nitsche et al. 2009). Wie langanhaltend diese Effekte sind, ist vor allem von der Dauer des applizierten Gleichstroms abhängig (Nitsche und Paulus 2001; Nitsche et al. 2003b).

Wesentliche wissenschaftlich-kontrollierte Elektrostimulationsversuche mit dieser Methode erfolgten zunächst tierexperimentell unter Zuhilfenahme epiduraler und intrazerebraler Reizelektroden (Creutzfeldt et al. 1962; Purpura und McMurtry 1965). Den entscheidenden Fortschritt der letzten Jahre erzielte die Entwicklung der nicht-invasiven und somit nahezu schmerzfreien und nebenwirkungsarmen Applikation des Gleichstroms beim Menschen. Dabei werden insgesamt zwei mit Schwämmen überzogene und dadurch angefeuchtete Oberflächenelektroden direkt auf der Kopfhaut befestigt. Zur Stimulation des primär motorischen Handareals, wie es in der vorliegenden Arbeit erfolgte, eignet sich entsprechend vorherigen Studien eine Elektrodenanordnung, bei der die Stimulationselektrode (in dem Fall die Anode) präzentral über dem primär motorischen Kortex angelegt wird. Für die bestmögliche Platzierung der Stimulationselektrode erfolgte die Bestimmung des optimalen Stimulationsortes mittels TMS (Nitsche und Paulus 2000). Die andere Elektrode (in dem Fall die Kathode) wurde kontralateral präfrontal (über der Augenbraue) mit einem Gummiband befestigt. Neurobiologisch führt die tDCS zu einer Verschiebung des Ruhemembranpotentials in den Neuronen und zu einer veränderten Feuerrate der Neurone in dem stimulierten Kortexareal (Nitsche und Paulus 2007). Entscheidende Einflussfaktoren für die Stärke, Dauer und Richtung der Erregbarkeitsveränderung ist die Auswahl der Stromdichte, der Stimulationsdauer und der Stromflussrichtung. Während anodale Stimulation unter Standardbedingungen zu einer Steigerung der vor und nach tDCS ermittelten MEP-Amplituden (depolarisierende Wirkung) und somit zu einer Zunahme der globalen Exzitabiltät führt, resultiert aus einer kathodalen Stimulation eine Abnahme der MEP-Amplituden (hyperpolarisierende 
Wirkung) im Sinne einer reduzierten Exzitabilität (Nitsche und Paulus 2000; Nitsche und Paulus 2001; Nitsche et al. 2003b; Nitsche et al. 2008). Um bei einer Stromstärke von $1 \mathrm{~mA}$ langfristige Nacheffekte (mehr als eine Stunde) zu erzielen, ist bei anodaler Stimulation eine Stimulationsdauer von 13 Minuten und bei kathodaler Stimulation einer Stimulationsdauer von neun Minuten erforderlich (Nitsche und Paulus 2001; Nitsche et al. 2003b).

Zum physiologischen Verständnis dieser Nacheffekte konnten pharmakologische Studien an gesunden Probanden nachweisen, dass für die Entstehung dieser Nacheffekte NMDA-Rezeptoren und die Kalzium-Homöostase von wesentlicher Bedeutung sind. Ein Blockade der NMDA-Rezeptoren mittels NMDA-RezeptorAntagonisten ergab eine Aufhebung der lang und kurz anhaltenden Nacheffekte (Liebetanz et al. 2002; Nitsche et al. 2003c). Andernfalls führt eine Aktivierung der NMDA-Rezeptoren mittels NMDA-Rezeptor-Agonisten zu einer Verlängerung der Nacheffekte (Nitsche et al. 2004a).

Zudem konnte gezeigt werden, dass spezifische Ionenkanäle Einfluss auf die kortikalen Erregbarkeitsveränderungen haben. Pharmakologische Untersuchungen am Menschen zeigten als wesentliches Ergebnis, dass eine Blockade von CalciumKanälen, die mittels anodaler tDCS erzeugte Zunahme der Erregbarkeit, wieder abschwächt (Nitsche et al. 2003b).

Fritsch et al. untersuchten 2010 erstmals die zellulären und molekularen Mechanismen der Wirkung von tDCS am motorischen Kortex in einem tierexperimentellen Modell. Durch Applikation des Gleichstroms über dem motorischen Kortex von Mäusen konnte eine langanhaltende Modulation kortikaler Erregbarkeit induziert werden, welche polaritässpezifisch, NMDA-Rezeptorabhängig und BDNF (englisch: brain-derived neurotrophic factor)-beeinflusst ist (Liebetanz et al. 2002; Nitsche et al. 2003c, Nitsche et al. 2004b; Fritsch et al. 2010). Folglich scheinen die durch tDCS induzierten Polaritätsveränderungen den Mechanismus von LTP (anodale tDCS) zu repräsentieren. 


\subsection{Zielsetzung der Arbeit}

Ziel dieser Studie war die Untersuchung der kortikalen Plastizität (LTP-artige Plastizität) bei Patienten mit einer Schizophrenie mittels anodaler tDCS. Zentraler Schwerpunkt dabei war die Untersuchung des Einflusses des Krankheitsverlaufes im Querschnitt auf diese pathophysiologischen Mechanismen.

Die Bedeutung der Krankheit selbst, das heißt, der Einfluss der Anzahl und Dauer psychotischer Episoden auf die neuronale Plastizität von Patienten mit einer Schizophrenie, wurde in bisherigen neurophysiologische Studien nicht dezidiert untersucht. Basierend auf der Theorie eines progredienten Verlaufes der Erkrankung mit der Zunahme der Symptomschwere und des neuronalen Verlustes, wurde die Hypothese aufgestellt, dass die kortikale Plastizität im Krankheitsverlauf zunehmend defizitär wird. Des Weiteren mutmaßen wir, dass Patienten mit einer Schizophrenie eine gestörte kortikale Inhibition im Vergleich zu gesunden Kontrollprobanden haben, und dass diese mit einer gestörten Plastizität assoziiert sein wird.

Aus den Ergebnissen dieser Arbeit sollen dann weitere funktionelle Hinweise für eine gestörte neuroplastische Funktion des Gehirns bei Patienten mit einer Schizophrenie abgeleitet und diskutiert werden. 


\section{Material und Methoden}

\subsection{Probandenkollektiv}

Für die Studie wurden insgesamt 44 Probanden rekrutiert. Ein Patientenkollektiv, bestehend aus 22 Probanden mit einer paranoid-halluzinatorischen Schizophrenie, wurde mit einer gesunden Kontrollgruppe, ebenfalls bestehend aus 22 Gesunden ohne familiäre Belastung mit einer psychischen Erkrankungen, verglichen.

Bei allen Teilnehmern wurde die Händigkeit (nach dem Edinburgh Handedness Inventory (Oldfield 1971)) ermittelt.

\section{Gesunde Kontrollgruppe}

Das Durchschnittsalter der gesunden Kontrollprobanden lag bei 29,95 Jahren. Soziodemographische Details sind in Tabelle 2 dargestellt. Mittels eines ausführlichen Anamnesegespräches seitens eines die Studie betreuenden Psychiaters wurden eine aktuelle und frühere psychiatrische Erkrankung sowie eine familiäre Belastung mit psychischen Erkrankungen ausgeschlossen.

\begin{tabular}{ll}
\hline Variable & Gesunde Kontrollprobanden \\
\hline $\mathrm{n}$ & 22 \\
Alter (Jahre) & $29,95 \pm 6,4$ \\
Männlich : Weiblich & $13: 9$ \\
Rechtshänder : Linkshänder & $20: 2$ \\
\hline
\end{tabular}

Tabelle 2: Übersicht über die Verteilung innerhalb der gesunden Kontrollgruppe.

$n=$ Anzahl der gesunden Probanden (das Alter ist angegeben in Mittelwert \pm Standardabweichung) 


\section{Patientengruppe}

Die 22 Teilnehmer der Patientengruppe wurden aus dem ambulanten und stationären Bereich der Klinik für Psychiatrie und Psychotherapie der Georg-August-Universität Göttingen rekrutiert. Bei allen Patienten wurde sowohl von einem unabhängigen behandelnden Psychiater, als auch von einem die Studie betreuenden Psychiater, entsprechend der ICD-10 Kriterien die Diagnose einer paranoid-halluzinatorischen Schizophrenie (F20.0) gestellt und bestätigt. Zum Zeitpunkt der Messungen waren alle Patienten psychopathologisch stabil.

\begin{tabular}{ll}
\hline Variable & Patientenkollektiv \\
\hline $\mathrm{n}$ & 22 \\
Alter (Jahren) & $33,27 \pm 8,24$ \\
Männlich : Weiblich & $15: 7$ \\
Rechtshänder : Linkshänder & $21: 1$ \\
\hline
\end{tabular}

Tabelle 3: Übersicht über die Verteilung innerhalb des gesamten Patientenkollektivs. $\mathbf{n}=$ Anzahl der Patienten (das Alter ist angegeben in Mittelwert \pm Standardabweichung)

Entsprechend dem Krankheitsverlauf wurden zwei Untergruppen gebildet, um zwischen Ersterkrankten und chronisch kranken Patienten (mehrere Episoden, Krankheitsdauer länger als zwei Jahre) mit einer Schizophrenie zu differenzieren.

Die erste Untergruppe, bestehend aus neun ersterkrankten Patienten (Recent-Onset Schizophrenia, RO-SZ), war gekennzeichnet durch nur eine psychotische Episode mit einer Dauer von mindestens einem Monat, ohne Rezidiv und einer Krankheitsdauer von weniger als zwei Jahren (Andreasen et al. 2011). Die durchschnittliche Erkrankungsdauer der RO-SZ betrug innerhalb der vorliegenden Studie 1,17 Jahre. Unter ihnen waren sechs Männer und drei Frauen. Alle RO-SZPatienten waren Rechtshänder und im Durchschnitt 29,33 Jahre alt. 
Die zweite Untergruppe, bestehend aus 13 Patienten (neun Männer, vier Frauen), 12 Rechtshändern und einem Linkshänder, war charakterisiert durch mehr als zwei psychotische Episoden mit mindestens einem Rezidiv und einer Krankheitsdauer von mehr als zwei Jahren. Die durchschnittliche Erkrankungsdauer der ME-SZ betrug 8 Jahre. Diese Multi-Episode Schizophrenie (ME-SZ) entspricht am ehesten einem chronischen Krankheitsverlauf.

\begin{tabular}{lll}
\hline Variable & RO-SZ & ME-SZ \\
\hline $\mathrm{n}$ & 9 & 13 \\
Alter (Jahren) & $29,33 \pm 7,8$ & $36,00 \pm 8,0$ \\
Männlich : Weiblich & $6: 3$ & $9: 4$ \\
Rechtshänder : Linkshänder & $9: 0$ & $12: 1$ \\
Dauer der Erkrankung (Jahren) & $1,17 \pm 1$ & $8 \pm 3,7$ \\
\hline
\end{tabular}

Tabelle 4: Übersicht über die Verteilung innerhalb der Subgruppen des Patientenkollektivs. $\mathbf{n}=$ Anzahl der Patienten (Alter und Dauer der Erkrankung ist angegeben in Mittelwert \pm Standardabweichung)

Bei jedem Patienten wurden strukturiert mit etablierten Instrumenten die Psychopathologie (Positive und Negative Syndrome Scale, Kay et al. 1987), der Schweregrad der Erkrankung (Clinical Global Impressions; Guy and Bonato 1976) sowie das globale Funktionsniveau (Global Assessment of Functioning; Endicott et al. 1976) erhoben.

Bis auf zwei Patienten wurden alle mit Antipsychotika behandelt, davon 15 Patienten in Monotherapie (Quetiapin, neun; Risperidon, sieben; Aripiprazol, drei; Olanzapin, zwei; Flupentixol, einer; Ziprasidon, einer; Amisulprid, einer; siehe Tabelle 5). 
Im Allgemeinen erhielten die Patienten keine zusätzliche neuroaktive Begleitmedikation. Auf Grund des klinischen Bildes erhielten allerdings fünf Patienten folgende nicht-antipsychotischen Begleitmedikamente: In der RO-SZ erhielt ein Patient 15 mg Citalopram und ein Patient 10 mg Diazepam. In der ME-SZ Gruppe erhielt ein Patient 45 mg Mirtazapin, ein weiterer Patient 4 mg Biperiden und 12,5 mg Diazepam, sowie einer $4 \mathrm{mg}$ Biperiden und $2 \mathrm{mg}$ Lorazepam.

\begin{tabular}{|c|c|c|c|}
\hline Patient & Subgruppe & Medikamente & Tagesdosis [mg] \\
\hline 1 & RO-SZ & Quetiapin & 350 \\
\hline 2 & RO-SZ & Quetiapin & 125 \\
\hline 3 & RO-SZ & Quetiapin & 300 \\
\hline 4 & RO-SZ & Quetiapin & 200 \\
\hline 5 & RO-SZ & Risperidon; Diazepam & $5 ; 10$ \\
\hline 6 & RO-SZ & Olanzapin; Aripiprazol; Escitalopram & $10 ; 10 ; 15$ \\
\hline 7 & RO-SZ & Risperidon; Risperidon consta & $2 ; 75^{\mathrm{a}}$ \\
\hline 8 & RO-SZ & Risperidon consta & $50^{\mathrm{a}}$ \\
\hline 9 & RO-SZ & Unmediziert & 0 \\
\hline 10 & ME-SZ & Olanzapin & 5 \\
\hline 11 & ME-SZ & Risperidon & 3 \\
\hline 12 & ME-SZ & Risperidon; Risperidon consta & $3 ; 50^{\mathrm{a}}$ \\
\hline 13 & ME-SZ & Quetiapin & 300 \\
\hline 14 & ME-SZ & Aripiprazol; Mirtazapin & $10 ; 45$ \\
\hline 15 & ME-SZ & Quetiapin; Aripiprazol & $900 ; 10$ \\
\hline 16 & ME-SZ & Quetiapin & 25 \\
\hline 17 & ME-SZ & Risperidon & 5 \\
\hline 18 & ME-SZ & Amisulprid; Aripiprazol & $400 ; 5$ \\
\hline 19 & ME-SZ & Ziprasidon & 20 \\
\hline
\end{tabular}




\begin{tabular}{llll}
\hline 20 & ME-SZ & Risperidon; Risperidon consta; Quetiapin; & $2 ; 50$ a $; 100 ;$ \\
& & Biperiden; Lorazepam & $4 ; 2$ \\
21 & ME-SZ & Quetiapin ; Flupentixol; Biperiden; & $500 ; 17,5 ; 4 ;$ \\
& & Diazepam & 12,5 \\
22 & ME-SZ & Unmediziert & 0 \\
\hline
\end{tabular}

Tabelle 5: Übersicht über die Medikation der Patienten.

${ }^{a}$ Diese Patienten wurden alle zwei Wochen mit Risperidon consta in Form einer Depot Injektion behandelt.

Um den Einfluss der Antipsychotika auf die abhängigen Variablen (siehe unten) vergleichen zu können, wurde die Tagesdosis der Antipsychotika in ChlorpromazinÄquivalente umgerechnet (nach Woods 2003 und Müller 2001).

Alle Probanden wurden in einem ausführlichen Gespräch über den Ablauf, den Nutzen und die Risiken sowohl mündlich, als auch schriftlich durch einen Studienarzt aufgeklärt. Zudem wurden alle Probanden darauf hingewiesen, dass sie jederzeit und ohne Angaben von Gründen das Recht hatten, die weitere Untersuchung abzulehnen beziehungsweise die Einverständniserklärung zurück zu ziehen. Alle Teilnehmer erhielten die Einverständniserklärung und den Aufklärungsbogen in Kopie ausgehändigt. Die Durchführung der Studie wurde durch die Ethikkommission der Georg-August-Universität Göttingen genehmigt und unter Berücksichtigung der Deklaration von Helsinki und den "Note for Guidance on good clinical practice“ (GCP), gültig ab dem 17.01.1997, durchgeführt. Bei allen Versuchspersonen lag vor Einschluss in die Studie eine unterschriebene Einverständniserklärung vor. 
Für die Teilnahme an der Studie galten verschiedene Ein- und Ausschlusskriterien, welche im Folgenden näher erläutert werden.

Wichtiges Einschlusskriterium war, dass die Patienten die Diagnose einer paranoid halluzinatorischen Schizophrenie (F20.0 nach ICD-10) aufwiesen und sich in einem psychopathologisch stabilen Zustand befanden.

Bei Vorliegen folgender allgemeiner und spezieller Ausschlusskriterien war eine Teilnahme an der Studie nicht möglich:

1. Fehlende Einwilligungsfähigkeit

2. Herzschrittmacher

3. Intrazerebrale Metallimplantate (Platten, Clips, künstliche Hörschnecke o.ä.)

4. Gesetzliche Unmündigkeit (z.B. Betreuung)

5. Alter $<18$ oder $>65$ Jahre

6. Hinweise auf epileptische Anfälle in der Vorgeschichte

7. Vorliegen einer gravierenden internistischen oder neurologischen Vorerkrankung

8. Akute psychotische Dekompensation

9. Suizidalität

10. Schwangerschaft oder Stillperiode

Zusätzlich wurden Probanden von der Studie ausgeschlossen, bei denen Hinweise für eine dermatologische, dementielle oder neurologische Erkrankung sowie eine komorbide Substanzabhängigkeit (außer Nikotinabhängigkeit) vorlagen.

Alle Versuchspersonen wurden gebeten, Auffälligkeiten und Nebenwirkungen, die während oder nach dem Versuch auftreten, dem Studienarzt zu melden. Die Auswertung der Daten erfolgte anonymisiert und verschlüsselt, so dass alle Erfordernisse des Datenschutzes beachtet worden sind. 


\subsection{Versuchsaufbau und Versuchsdurchführung}

\subsubsection{Vorbereitung}

Alle Probanden saßen während der Versuche in einem bequemen, elektrisch beweglichen Liegestuhl mit Kopfstütze. Um eine größtmögliche Entspannung und muskuläre Relaxation während der gesamten Versuchsdurchführung zu erzielen, wurde der rechte Arm auf einer Lehne und bei Bedarf mit einem Kissen passiv unterstützt. Entsprechend des großen Repräsentationsfeldes im motorischen Kortex wurde bei allen Versuchen der Musculus interosseus dorsalis I (englisch: first dorsal interosseus, FDI) der rechten Hand als Zielmuskel verwendet. Für die Oberflächenelektromyographie wurden zwei Ag-AgCl-Elektroden mit Hilfe eines Pflasterstreifens befestigt. Die differente Elektrode wurde am Punctum maximum des Muskelbauches, die indifferente Elektrode am Sehnenansatzpunkt des entsprechenden Muskels positioniert. Eine dritte Elektrode am Unterarm diente der Erdung. Mittels eines handelsüblichen Verstärkers (Keypoint portable, Medtronic Co.; Denmark) wurden die von den Oberflächenelektronen abgeleiteten Signale vorverstärkt und von einem Bandpassfilter $(2 \mathrm{~Hz}-10 \mathrm{kHz})$ gefiltert und anschließend digitalisiert. Jedes Signal wurde in der Nachbereitung der Versuche manuell und offline analysiert. Die Elektromyogramm-Aktivität des Zielmuskels wurde zusätzlich während des gesamten Versuches durch ein visuelles Feedback per EMG überwacht, um die nötige Relaxation sicher zu stellen.

\subsubsection{Zeitpunkt der Versuche}

Um Einflüsse des zirkadianen Rhythmus auf die kortikale Exzitabilität auszuschließen (Lang et al. 2011), wurden alle Versuche in der Zeit zwischen 8 Uhr und 14 Uhr durchgeführt und es wurde ein Matching zwischen den Gruppen hinsichtlich der Uhrzeit durchgeführt. 


\subsubsection{Transkranielle Magnetstimulation}

Die transkranielle Magnetstimulation (TMS) wurde zur Erfassung der kortikalen Exzitabilität vor und nach der Gleichstromstimulation angewandt. Mittels einer achtförmigen Standard-TMS-Spule (Einzelspulendurchmesser von jeweils $70 \mathrm{~mm}$, C-B60 der Fa. Medtronic Co., Dänemark) und eines MagPro X 100 Magnetstimulators (Fa. Medtronic Co., Dänemark) wurde gezielt über der Area 4 des linken motorischen Kortex kurzzeitig ein magnetisches Feld appliziert. Der dadurch induzierte Stromfluss führte zur Depolarisation neuronaler Strukturen im motorischen Kortex und folglich zur peripheren Kontraktion des Musculus interosseus dorsalis I. Die Ableitung und Digitalisierung der motorisch evozierten Potentiale (MEP) erfolgte über das Medtronic Keypoint Modul. Während der TMS stand der Versuchsleiter hinter dem Probanden und fixierte die Spule manuell ohne weitere Hilfsmittel über dem Gebiet des linken Motorkortex.

\subsubsection{Optimaler Stimulationspunkt}

Vor jeder Messung erfolgte die Festlegung des optimalen Stimulationspunktes individuell bei jedem Probanden. Über dem zu erwartenden Repräsentationsareal des rechten Musculus interosseus dorsalis I wurde die Spule tangential zum Schädel über dem linken Motorkortex positioniert. Der Spulenschaft wurde nach postero-lateral um 45 Grad zur Sagittalebene angewinkelt und in kleinen Abständen über den motorischen Kortex der linken Hemisphäre bewegt. Diese Spulenausrichtung führt zur größten und stabilsten MEP-Antwort, abgeleitet an der Handmuskulatur (Davey et al. 1994; Mills et al. 1992). Um sicherzustellen, dass die Spule während der gesamten Versuche in ihrer Position nicht variiert, wurde mit einem roten, wasserlöslichen Filzstift die Stelle an der Kopfhaut markiert, die im Mittel die größte und stabilste MEP-Amplitude aufwies. Dieser Stimulationspunkt wurde für alle folgenden Messungen verwendet. Entsprechend dieser Spulenausrichtung ist anzunehmen, dass die durch TMS induzierten Ströme von postero-lateral nach antero-medial parallel zur Kortexoberfläche eine Stimulation der horizontal 
verlaufenden Neurone bewirken. Über kortikale Interneurone kommt es somit zu einer transsynaptischen Aktivierung der Pyramidentraktneurone (Di Lazzaro et al. 1998; Kaneko et al. 1996; Nakamura et al. 1996; Werhahn et al. 1994; Day et al. 1989).

\subsubsection{Messparameter und Versuchsdurchführung}

Für die Studie wurden verschiedene TMS-Einzelreiz- und TMS-Doppelpulsmessungen verwendet. Die jeweiligen Messprotokolle, die in identischer Abfolge vor und nach der 13-minütigen anodalen Gleichstromstimulation durchgeführt wurden, werden im Folgenden erläutert.

\subsubsection{TMS-Einzelpulsmessungen}

\section{Bestimmung der 1mV-Intensität und Messung der 1mV-MEPs}

Unter der $1 \mathrm{mV}$-Intensität $(\mathrm{S} 1 \mathrm{mV})$ versteht man die Intensität, die im Mittel eine MEP-Amplitude von 1,0 mV ( $\pm 0,3 \mathrm{mV})$ auslöst. Angegeben in Prozent, wobei $100 \%$ der maximalen Ausgangsleistung des Stimulators entspricht, dient die 1mVIntensität bei einigen Messprotokollen als Testreiz. Diese wurde individuell bei jedem Probanden zu Beginn der Versuche und nach der anodalen tDCS bestimmt. Mit der initial bestimmten S1mV wurde vor und nach der Stimulation jeweils mittels 40 TMS-Pulsen die 1mV-MEPs bestimmt.

\section{Bestimmung der Motorischen Ruheschwelle (RMT)}

Zur Bestimmung der RMT wurde der maximal relaxierte Zielmuskel zunächst überschwellig gereizt. In $1 \%$-Schritten erfolgte eine Reduktion der Stimulatorintensität, solange bis fünf von zehn aufeinander folgenden MEPs eine Amplitude von circa $50 \mu \mathrm{V}$ erreichten. Diese Intensität wurde dann als motorische Ruheschwelle festgelegt. Anschließend erfolgte zur Kontrolle eine unterschwellige Annäherung an die ermittelte Schwelle, um die RMT exakt zu bestimmen (Rothwell 
et al. 1999). Diese Bestimmung wurde individuell bei jedem Probanden vor und nach der Gleichstromstimulation neu festgesetzt.

\section{Bestimmung der kontralateralen kortikalen Innervationsstille (Cortical Silent Period, CSP)}

Am Ende jeder Versuchsreihe wurden unter tonischer Voraktivierung des Zielmuskels mit 25 - $30 \%$ der maximalen Kontraktionskraft (visuelle Kontrolle per EMG) je 10 Stimuli mit der 1mV-Intensität appliziert. Manuell erfolgte dann offline die Bestimmung der CSP-Dauer, festgelegt als Zeitspanne vom Anfang des MEPs bis zur Wiedereinstellung der Spontanaktivität (absolute CSP) (Daskalakis et al. 2003).

\section{Bestimmung der aMEP}

Unter tonischer Voraktivierung des Zielmuskels mit 25 - $30 \%$ der maximalen Kontraktionskraft wurden je 10 Stimuli mit der $1 \mathrm{mV}$-Intensität appliziert. Die aMEP wurde mittels der Größe der peak-to-peak Amplitude des MEPs erfasst.

\subsubsection{TMS-Doppelpulsmessungen}

Zwei aufeinander folgende Stimuli wurden mit unterschiedlichen Interstimulusintervallen (siehe unten) durch dieselbe Spule und über demselben Stimulationsort randomisiert appliziert. Ziel war es, den Einfluss eines konditionierenden Reizes (S1) auf einen Testreiz (S2) unter Verwendung verschiedener Interstimulusintervalle (ISI) zu untersuchen (Kujirai et al. 1993). 


\section{Messung der SICI und der ICF}

Für die Bestimmung der SICI (englisch: short-interval intracortical inhibition) und der ICF (englisch: intracortical fascilitation) wurde für S1 (konditionierender Stimulus) $80 \%$ der RMT und für S2 (Testreiz) die 1mV-Intensität festgelegt.

\begin{tabular}{llll}
\hline & S1 & S2 & ISI [ms] \\
\hline SICI & $80 \%$ RMT & $1 \mathrm{mV}$-Intensität & 3 \\
ICF & $80 \%$ RMT & $1 \mathrm{mV}$-Intensität & 12 \\
\hline
\end{tabular}

Tabelle 6: Tabellarische Zusammenfassung der verwendeten Doppelpulsparadigmen. Die genaue Darstellung der verschiedenen Messverfahren findet sich im Text.

Insgesamt wurden 80 Stimuli (siehe Tabelle 7) jeweils vor und nach der Gleichstromstimulation in drei verschiedenen Konditionen untersucht:

\begin{tabular}{lll}
\hline Kondition & Bedeutung & Häufigkeit \\
\hline 1 & Testkondition, Einzelpuls allein & 40 \\
2 & Doppelpuls, ISI $3 \mathrm{~ms}$ & 20 \\
3 & Doppelpuls, ISI $12 \mathrm{~ms}$ & 20 \\
\hline
\end{tabular}

Tabelle 7: Übersicht über die verschiedenen Konditionen jeweils vor und nach tDCS.

Für die SICI-, ICF- und CSP-Messungen wurden die RMT und die S1mV nach der tDCS adjustiert, da die Stimulation die Werte der RMT und S1mV verändert und diese Veränderungen die genauen Messungen der kortikalen Exzitabilität beeinflussen können (Fitzgerald et al. 2004, Chen 2004). Die 1mV-MEPs vor und nach Stimulation wurden hingegen mit der gleichen Intensität (S1mV vor tDCS) gemessen. 


\subsubsection{Transkranielle Gleichstromstimulation (tDCS)}

Die tDCS ist ein nicht invasives Verfahren zur nicht-invasiven Induktion kortikaler Plastizität im menschlichen Gehirn. Grundlage ist eine Verschiebung des Ruhemembranpotentials in den Neuronen, wobei eine anodale Stimulation zu einer Depolarisation und eine kathodale Stimulation zu einer Hyperpolarisation der Neurone führt (Nitsche et al. 2008).

Der Strom wurde von einem für diesen Zweck speziell entwickelten, CEzertifizierten und batteriebetriebenen Gleichstromstimulator (Eldith-ElectroDiagnostic \& Therapeutic Systems GmbH) mit einer maximalen Stromstärke von 5 mA generiert. Die über 13 Minuten applizierte Stromstärke von $1 \mathrm{~mA}$ wurde vom Stimulator automatisch reguliert, konstant gehalten und mit Hilfe eines integrierten Ampèremeters kontrolliert. Um unerwünschte Nebenwirkungen wie Hautirritationen durch Elektrolyse zu minimieren, wurden zwei plattenförmige, aus leitendem Gummi bestehende Oberflächenelektroden (Firma Eldith und neuroconn $\mathrm{GmbH}$ ) verwendet. Mit einem mit 0,9 \% - Natriumchlorid benässten Schwamm (Oberfläche $35 \mathrm{~cm}^{2}$ ) überzogen, wurde die anodale Elektrode über dem für die TMS bereits ermittelten Repräsentationsareal des rechten FDI (englisch: first dorsal interosseus) positioniert. Die kathodale Elektrode wurde über der kontralateralen Orbita ebenfalls mit einem Gummiband befestigt. Diese Anordnung ist geeignet, signifikante Veränderungen der Exzitabilität des Gehirns durch Stromapplikation zu erzeugen (Nitsche und Paulus 2000). Mit dieser Versuchsanordnung, Stimulationsdauer und -stärke können Nacheffekte bis zu einer Stunde nach Stromapplikation erzeugt werden (Nitsche und Paulus 2000; Nitsche und Paulus 2001; Nitsche et al. 2003b; Nitsche et al. 2004a). 


\subsubsection{Zusammenfassung der Versuchsprotokolle (Flow Chart)}

Die Dauer des gesamten Versuches betrug ungefähr zwei Stunden pro Proband.

1. Begrüßung und Aufklärung des Probanden

2. Einverständniserklärung durch Studienarzt

3. Test der Händigkeit (Edinburgh handeness inventory (Olfield 1971))

a. Speziell bei allen Patienten:

Evaluation

- $\quad$ eines psychopathologischen Befundes

(Positive and Negative Syndrome Scale, Kay et al. 1987),

- $\quad$ des Schweregrades der Erkrankung

(Clinical Global Impressions; Guy and Bonato 1976),

- des allgemeinen Funktionsniveaus

(Global Assessment of Functioning; Endicott et al. 1976) und

- der Dauer und Häufigkeit psychotischer Episoden.

4. Anschluss der Elektroden, EMG des rechten FDI

5. Feststellung des Hot Spots

6. Messung der 1mV-Intensität und der RMT prä-tDCS

7. TMS-Einzelreizmessungen

8. TMS-Doppelreizmessungen (SICI, ICF)

9. Messung der CSP

10. 5 Minuten Pause

11. Anschluss der Elektroden für die tDCS (Anode über Motorkortex)

12. tDCS (13 Minuten mit $1 \mathrm{~mA}$ )

13. 5 Minuten Pause, Abkabeln des Probanden

14. TMS-Einzelreizmessung (mit 1mV-Intensität prä-tDCS)

15. Messung der 1mV-Intensität und der RMT post-tDCS

16. TMS-Einzelreizmessung (mit $1 \mathrm{mV}$-Intensität post-tDCS) 


\section{TMS-Doppelreizmessungen (SICI, ICF)}

18. Messung der CSP

19. Abkabeln des Probanden, Ende.

\subsubsection{Statistik und Auswertung}

Die Auswertung der Daten aus dem Keypoint-Aufzeichnungsprogramm (Keypoint portable, Medtronic Co., Denmark) wurde manuell mittels einer Offline-Analyse durchgeführt. Für die Doppelpulsmessungen wurden die gemittelten Amplituden der MEPs vom größten bis zum kleinsten negativen Umschlagspunkt (Peak-to-PeakMessung) mit dem oben genannten Keypoint-Programm sowohl vor als auch nach der Gleichstromstimulation interindividuell ermittelt (siehe Abbildung 2).

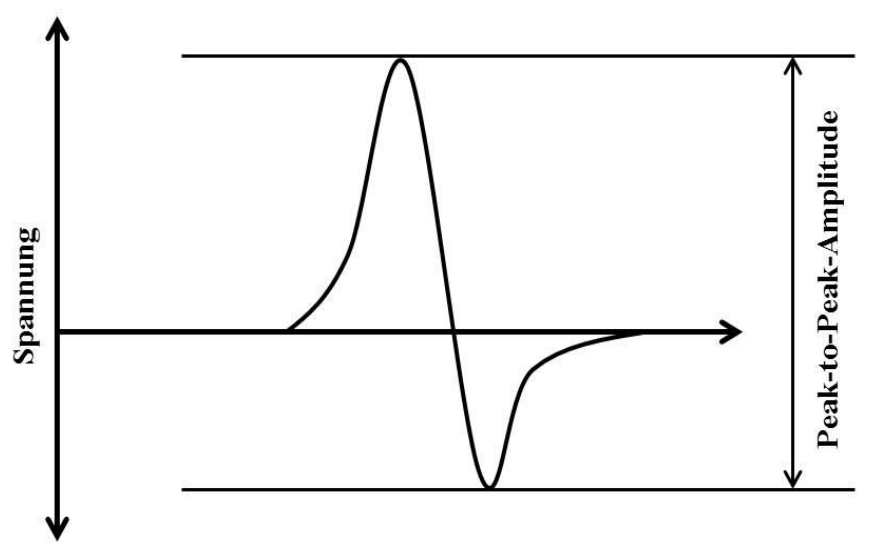

Abbildung 2: Schematische Darstellung eines MEPs nach TMS-Einfachstimulation.

Die Peak-to-Peak-Amplitude ergibt sich aus dem Abstand von Amplitudenmaximum und Amplitudenminimum.

Während eine Zunahme der Peak-to-Peak-Amplitude der MEPs im Vergleich zum Testreiz auf eine gesteigerten Exzitabilität hinweist, spricht eine Abnahme der Amplitude für eine reduzierte Erregbarkeit. 
Für die Bestimmung der aMEPs wurden mit Hilfe des Medtronic Keypoint Moduls die mittleren MEP-Amplituden aus der Messung der MEPs unter tonischer Voraktivierung genommen.

Die CSP-Dauer entsprach der Zeitspanne vom Anfang des MEPs bis zur Wiedereinstellung der Spontanaktivität (absolute CSP) (Daskalakis et al. 2003).

Die statistische Untersuchung der Daten erfolgte mit dem Programm SPSS für Windows (Version 18.0). Als Signifikanzbereich wurde für alle statistischen Analysen ein p-Wert von $<0,05$ festgelegt. Für die Variablen Geschlecht und Händigkeit wurden $\mathrm{Chi}^{2}$-Tests errechnet, um Unterschiede in der Verteilung zwischen den Gruppen zu ermitteln. Zum Vergleich des Durchschnittsalters zwischen den einzelnen Gruppen wurde eine Varianzanalyse (ANOVA, englisch: analysis of variance), in diesem Fall eine one-way-ANOVA, durchgeführt. Die Beziehung zwischen Alter und abhängige Variablen wurde mittels PearsonKorrelationskoeffizient errechnet. Bei Verletzung der Normalverteilungsannahme (Kolmogorv-Smirnov Test < 0,05) wurden die Rohdaten aus den Messungen der S1mV, RMT, SICI, ICF und deren Quotienten zunächst logarithmiert und anschließend in die Analyse eingebunden. Zum Vergleich der vor und nach anodaler tDCS ermittelten Effekte auf die abhängigen Variablen (MEP-Größe, RMT, SICI, ICF, CSP) wurden ANOVAs für Messwiederholungen (repeated-measure-ANOVA) durchgeführt. Bei diesen Messungen wurde der Inner-Subjekt-Faktor "Zeit" (vor / nach Stimulation) und der Zwischensubjekt-Faktor "Gruppe" untersucht. Die RM-ANOVA wurde zunächst zwischen den beiden Hauptgruppen (gesunde Kontrollgruppe / Patientengruppe) und in einem zweiten Schritt zwischen den drei Untergruppen (Gesunde / RO-SZ / ME-SZ) durchgeführt.

Im Falle signifikanter Interaktionen zwischen "Zeit" und "Gruppe" in den RMANOVAs wurden zweiseitige t-Tests durchgeführt (jeweils für unabhängige Stichproben für den Vergleich zwischen den Gruppen, und für gepaarte Stichproben für den Vergleich vor und nach tDCS innerhalb einer Gruppe). Mittels dieser t-Tests 
konnte ermittelt werden, ob sich die abhängigen Variablen vor und nach Gleichstromstimulation innerhalb der Gruppen oder zwischen den Gruppen unterschieden (Gesunde versus RO-SZ, Gesunde versus ME-SZ, RO-SZ versus MESZ).

Spearman-Rangkorrelationen zwischen abhängigen Variablen und den PANSS Werten, CPZ-Äquivalenten, GAF, CGI, der Psychosedauer sowie der Anzahl der psychotischen Episoden wurden für die Patientengruppen und für jeden einzelnen Patienten ermittelt. Die Daten werden, sofern nicht anders bezeichnet, als Mittelwert \pm Standardabweichung angegeben. Die stationäre Beratung erfolgte durch Herrn M.Sc. Thomas Schneider-Axmann. 


\section{Ergebnisse}

\subsection{Soziodemographische und klinische Merkmale}

Im Vergleich des Durchschnittsalters der beiden Hauptgruppen (gesunde Kontrollprobanden und gesamte Patientenkollektiv) ergab ein unabhängiger t-Test keinen signifikanten Unterschied $\left(\mathrm{t}_{(42)}=1,471 ; p=0,149\right)$.

Nach der Unterteilung des Patientenkollektivs in zwei Untergruppen (RO-SZ und ME-SZ) war hingegen ein signifikanter Altersunterschied zwischen den drei Gruppen zu erkennen (Gesunde: 29,95 Jahre \pm 6,4; RO-SZ: 29,33 Jahre \pm 7,8; MESZ: 36,00 Jahre $\left.\pm 8,0 ; \mathrm{F}_{(2,41)}=3,468 ; p=0,041\right)$. Im Einzelnen konnte gezeigt werden, dass sich das Durchschnittsalter der gesunden Kontrollprobanden nicht signifikant $(p=0,82)$ von dem der RO-SZ unterschied. Dagegen konnte ein signifikanter durchschnittlicher Altersunterschied im Vergleich zwischen dem gesunden Kontrollkollektiv und den ME-SZ nachgewiesen werden $(p=0,019)$. Ebenso konnte im Altersvergleich zwischen RO-SZ und ME-SZ ein Unterschied gezeigt werden ( $p=0,067$; statistischer Trend).

Mit dem Ziel, den Einfluss des Alters auf die Messergebnisse untersuchen und beurteilen zu können, wurde aus der gesunden Kontrollgruppe eine Untergruppe zusammengestellt, die entsprechend Alter, Geschlecht, Händigkeit und Rauchverhalten einer ME-SZ-Untergruppe exakt zugeordnet werden konnte ( $\mathrm{n}=10$ in beiden Gruppen; jeweils vier Frauen, ein Linkshänder, sechs Raucher; Alter: Gesunde: 34,20 \pm 7; ME-SZ: 34,90 $\pm 6,6 ; p=0,820$ ). Für diese beiden Gruppen wurden erneut eigenständige Analysen der Messdaten zur weiteren Untersuchung der Hypothesen durchgeführt.

Bezüglich des Einflusses des Lebensalters auf die Ergebnisse konnte in den gesamten Versuchen an allen Gruppen keine signifikante Korrelation zwischen dem Alter und den abhängigen Variablen wie der 1mV-MEP $(p>0,17)$ oder der SICI $(p>0,16$ vor und nach tDCS gezeigt werden. 
Hinsichtlich klinischer Aspekte litten die Patienten entsprechend den PANSS-Werten im Durchschnitt an moderaten Positiv- und Negativsymptomen, welche begleitet waren von einem mäßigen Schweregrad der Erkrankung (CGI) und einer leichten Beeinträchtigung des sozialen Funktionsniveaus (GAF). Im Vergleich zu RO-SZ wiesen ME-SZ einen höheren Schweregrad der Erkrankung (CGI) $(p=0,025)$, ein reduziertes soziales Funktionsniveau (GAF) $(p=0,001)$ sowie eine schwerere Psychopathologie auf $\left(\mathrm{PANSS}_{\text {Allgemein }}\right)(p=0,042)$ (weitere Details siehe Tabelle 8).

\begin{tabular}{lllll}
\hline Variable & Gesunde & RO - SZ & ME - SZ & Statistik \\
\hline N & 22 & 9 & 13 & \\
Geschlecht & $13 \mathrm{M} ; 9 \mathrm{~F}$ & $6 \mathrm{M} ; 3 \mathrm{~F}$ & $9 \mathrm{M} ; 4 \mathrm{~F}$ & $p=0,925$ \\
Alter (Jahren) & $29,95 \pm 6,4$ & $29,33 \pm 7,8$ & $36,00 \pm 8,0$ & $p=0,041$ \\
Händigkeit & $20 \mathrm{R} ; 2 \mathrm{~L}$ & $9 \mathrm{R} ; 0 \mathrm{~L}$ & $12 \mathrm{R} ; 1 \mathrm{~L}$ & $p=0,653$
\end{tabular}

\section{PANSS Score}

$\begin{array}{lclll}\text { Gesamt } & - & 52,78 \pm 11,5 & 59,75 \pm 11,5 & p=0,186 \\ \text { Positiv } & - & 11,78 \pm 4,7 & 14,75 \pm 4,9 & p=0,227 \\ \text { Negativ } & - & 17,00 \pm 3,8 & 16,17 \pm 4,7 & p=0,726 \\ \text { Allgemein } & - & 24,00 \pm 5,2 & 28,83 \pm 5,1 & p=0,042 \\ & & & & \\ \text { GAF } & - & 66,56 \pm 6,1 & 2,75 \pm 9,3 & p=0,001 \\ \text { CGI } & - & 4,67 \pm 0,9 & 3,89 \pm 0,6 & p=0,025 \\ \text { CPZ (Tagesdosis) } & - & 281,09 \pm 155,2 & 391,82 \pm 475,6 & p=0,528 \\ \text { Erkrankungsdauer } & - & 1,17 \pm 1 & 8 \pm 3,7 & p<0,001\end{array}$

(Jahren)

Tabelle 8: Übersicht über die soziodemographischen und klinischen Merkmale aller Probanden (angegeben in Mittelwert \pm Standardabweichung).

PANSS: Positive and Negative Syndrome Scale, GAF: Global Assessment of Functioning, CGI: Clinical Global Impressions, CPZ: Chlorpromazin Äquivalent 


\subsection{Bahnung der MEPs mittels anodaler tDCS}

Die Untersuchung des Einflusses der anodalen Gleichstromstimulation ergab die RM-ANOVA im Vergleich der beiden Hauptgruppen (gesunde Kontrollgruppe und Patientengruppe) einen signifikanten Haupteffekt des Faktors "Zeit" (vor und nach anodaler Stimulation) $\left(\mathrm{F}_{(1,42)}=55,22 ; p<0,001\right)$. Zwischen dem Faktor "Zeit" und dem Faktor "Gruppe" konnte jedoch keine signifikante Interaktion nachgewiesen werden $\left(\mathrm{F}_{(1,42)}=1,45 ; p=0,234\right)$.

Im Vergleich der drei Untergruppen (Gesunde, RO-SZ, ME-SZ) war sowohl der Faktor "Zeit" $\left(\mathrm{F}_{(1,41)}=53,25 ; p<0,0001\right)$, als auch die Interaktion von "Gruppe $\mathrm{x}$ Zeit $^{\text {“ }}\left(\mathrm{F}_{(2,41)}=3,518 ; p=0,039\right)$ signifikant.

Zwischen der gesunden Kontrollgruppe und den RO-SZ zeigte die RM-ANOVA einen signifikanten Effekt der "Zeit" $\left(\mathrm{F}_{(1,29)}=52,02 ; p<0,001\right)$, jedoch keine signifikante Interaktion von "Gruppe $\mathrm{x} \operatorname{Zeit}\left(\mathrm{F}_{(1,29)}=0,27 ; p=0,604\right)$. Dem gegenüber konnte ein signifikanter Effekt der "Zeit" und der "Gruppe x Zeit" Interaktion zwischen ME-SZ und Gesunden ("Zeit": $\mathrm{F}_{(1,33)}=29,99 ; p<0,001$; Interaktion "Gruppe $\mathrm{x}$ Zeit": $\left.\left(\mathrm{F}_{(1,33)}=5,03 ; p=0,032\right)\right)$, sowie zwischen ME-SZ und RO-SZ ("Zeit": $\mathrm{F}_{(1,20)}=29,90 ; P<0,001$; Interaktion "Gruppe x Zeit": $\left(\mathrm{F}_{(1,20)}=\right.$ $6,37 ; p=0,020)$ ) nachgewiesen werden.

Nachdem alle RM-ANOVAs einen signifikanten Effekt der "Zeit" zeigten und im Dreigruppenvergleich eine signifikante Interaktion zwischen Gruppe und Zeit nachgewiesen werden konnte, wurden gepaarte t-Tests durchgeführt, um den bahnenden Effekt der anodalen Gleichstromstimulation innerhalb der Gruppen zu untersuchen. Gepaarte t-Tests zeigten eine MEP-Bahnung der MEPs nach anodaler tDCS in allen Gruppen (Gesunde: $p<0,0001$; gesamte Patientenkollektiv: $p<$ 0,0001; RO-SZ: $p=0,001$; ME-SZ: $p=0,043)$.

Die vor der tDCS (Baseline) durchgeführten Messungen ergaben keinen signifikanten Unterschied in der MEP-Amplitude zwischen den drei Gruppen (unabhängige t-Tests, Gesunde versus RO-SZ: $p=0,343$; Gesunde versus ME-SZ: $p$ $=0,415 ; \mathrm{RO}-\mathrm{SZ}$ versus ME-SZ: $p=0,975)$. Nach tDCS wies die gesunde 
Kontrollgruppe im Vergleich zu den ME-SZ höhere 1mV-MEPs auf ( $p=0,016)$. Zwischen Gesunden und RO-SZ war kein signifikanter Unterschied erkennbar ( $p=0,981)$. Im Trend konnten bei RO-SZ ebenfalls höhere $1 \mathrm{mV}$-MEPs als bei den ME-SZ gezeigt werden $(p=0,084)$.

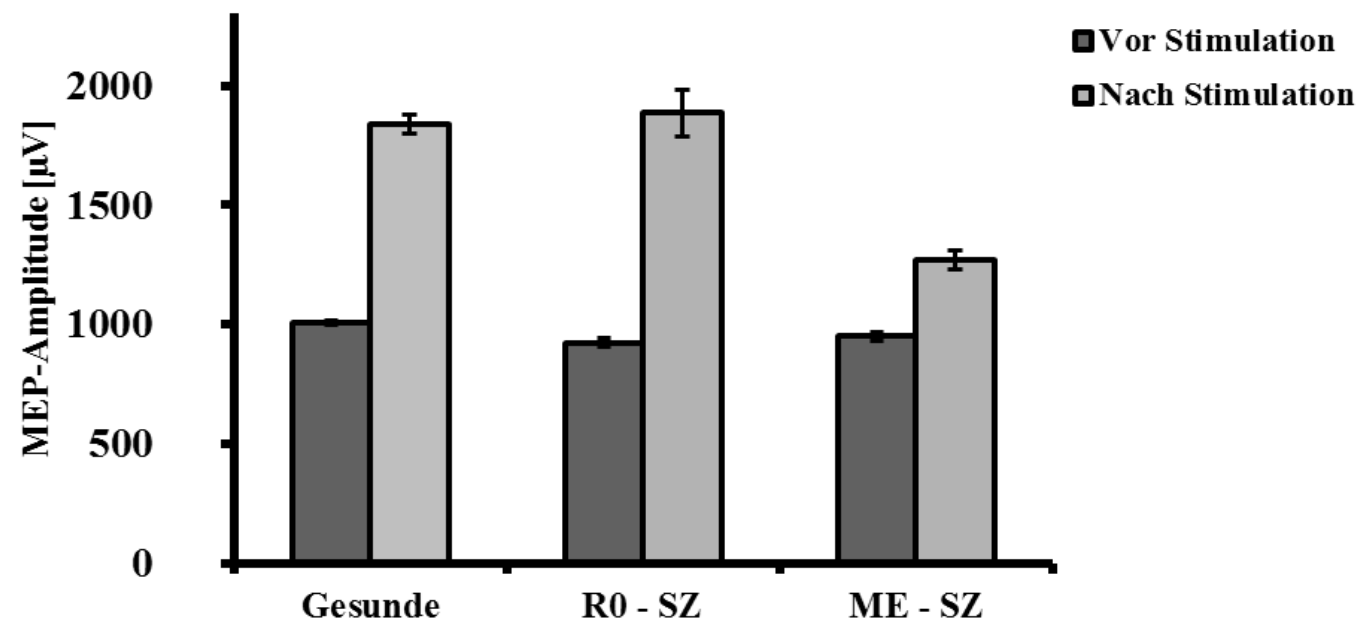

Abbildung 3: Übersicht der MEP-Amplituden $(\mathrm{S} 1 \mathrm{mV})$ in $\mu \mathrm{V}$ (Mittelwert \pm Standardfehler) vor (dunklen Balken) und nach (hellen Balken) anodaler tDCS im Drei-Gruppenvergleich. Vor tDCS zeigten unabhängige t-Tests keinen signifikanten Unterschied der MEP-Amplituden zwischen den drei Gruppen. Gepaarte t-Tests zeigten in allen Gruppen eine Bahnung der MEPAmplituden nach anodaler tDCS. Im Vergleich zu Patienten mit einer Mehrfacherkrankung (ME-SZ) wiesen Gesunde nach anodaler tDCS signifikant höhere MEP-Amplituden auf. Patienten mit einer Resent-Onset Schizophrenie (RO-SZ) zeigten im Vergleich zu Gesunden nach anodaler tDCS keinen signifikanten Unterschied der MEP-Amplituden und im Vergleich zu ME-SZ im Trend höhere MEP-Amplituden. Die Fehlerbalken zeigen den Standardfehler des Mittelwertes. 


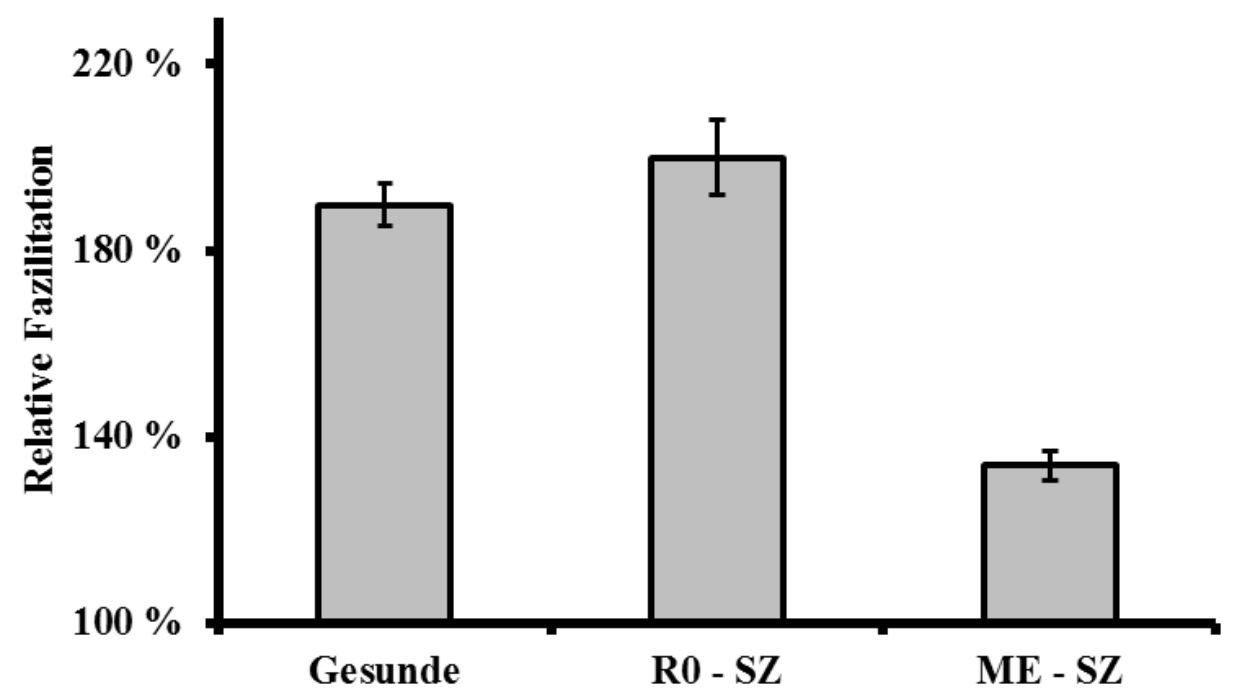

Abbildung 4: Übersicht der relativen Fazilitation nach anodaler tDCS im DreiGruppenvergleich. Für den Vergleich der unterschiedlichen plastischen Antworten des Gehirn auf die tDCS zwischen den drei Gruppen, wurden Post/Prä-Quotienten der mittels one-wayANOVA ermittelten 1mV-MEPs berechnet $(\mathrm{F}(2,41)=3,551 ; p=0,038)$. Im Vergleich zu MESZ wiesen Gesunde $(p=0,031)$ und RO-SZ $(p=0,019)$ höhere Post/Prä-Quotienten auf. Zwischen den Gesunden und den RO - SZ besteht kein signifikanter Unterschied des Post/PräQuotienten $(p=0,603)$. Die Daten sind angegeben in Prozent in Bezug zur Baseline (Mittelwert \pm Standardfehler). 


\subsection{Gruppenunterschiede der kortikalen Erregbarkeit vor tDCS}

Für die Erfassung der kortikalen Erregbarkeit der gesunden Probanden und der Patienten vor der Durchführung der anodalen Gleichstromstimulation wurden die einzelnen Gruppen entsprechend der motorischen Ruheschwelle (RMT) und der intrakortikalen Inhibition bei kurzem Interstimulusintervall (SICI) gegenüber gestellt.

Im Zweigruppenvergleich (Gesunde versus alle Patienten) ermittelte die one-wayANOVA signifikante Unterschiede sowohl für die RMT $\left(\mathrm{F}_{(1,42)}=4,25 ; p=0,046\right)$, als auch für die SICI $\left(\mathrm{F}_{(1,42)}=4,41 ; p=0,042\right)$ vor tDCS. Im Vergleich zu den Gesunden (RMT: $48 \% \pm 8 \%$; SICI: $23 \% \pm 22 \%$ ) ergab die Analyse bei den Patienten eine höhere RMT $(52 \% \pm 5 \%$, t-Test: $p=0,046)$ und eine reduzierte SICI $(31 \% \pm 19 \%$, t-Test: $p=0,044)$.

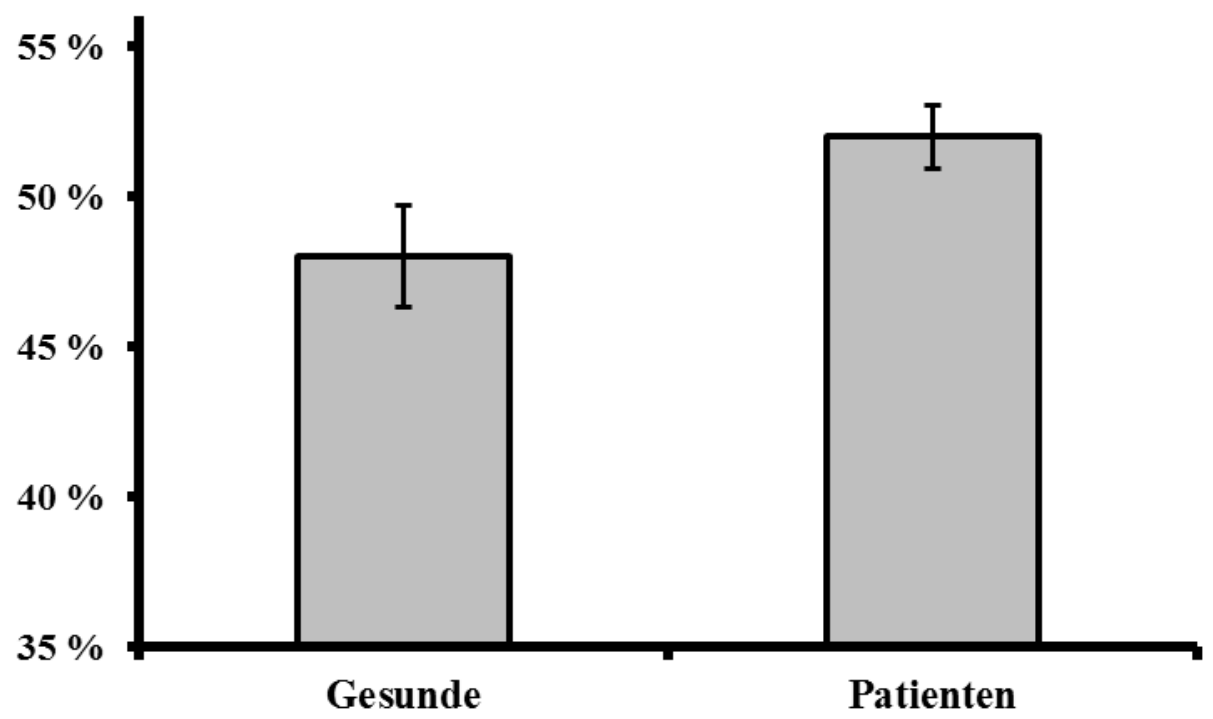

Abbildung 5: Darstellung der motorischen Ruheschwelle (RMT) vor anodaler tDCS im ZweiGruppenvergleich. Die Analyse ergab höhere motorische Ruheschwellen bei allen Patienten vor anodaler tDCS im Vergleich zu den Gesunden. Die Daten sind angegeben in Prozent in Bezug zum Testreiz (S1mV) (Mittelwert \pm Standardfehler). 


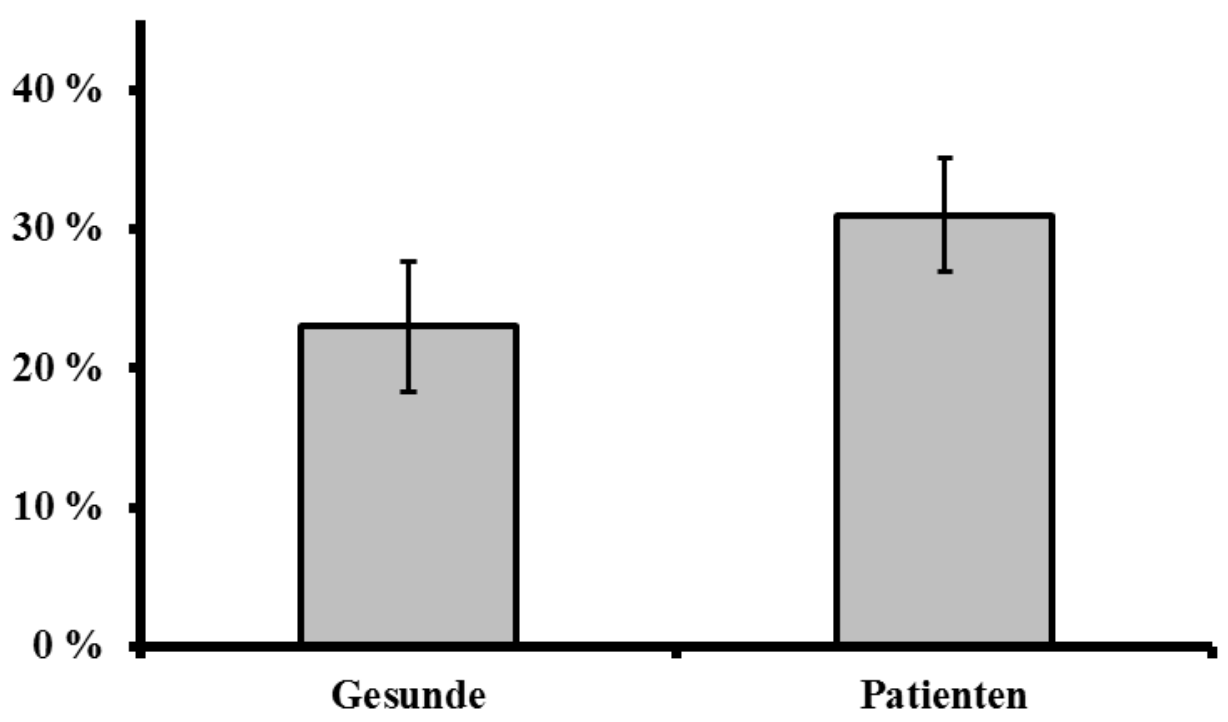

Abbildung 6: Übersicht der relativen Inhibition vor anodaler tDCS im Zwei-Gruppenvergleich. Die Analyse ergab weniger Inhibition vor anodaler tDCS (reduzierte SICI) bei dem gesamten Patientenkollektiv im Vergleich zu den Gesunden. Die Daten sind angegeben in Prozent in Bezug zum Testreiz (S1mV) (Mittelwert \pm Standardfehler). 
Im Dreigruppenvergleich zeigte eine one-way-ANOVA für den Parameter der SICI vor anodaler Gleichstromstimulation tendenziell reduzierte Werte in der Gruppe der RO-SZ im Vergleich zu den Gesunden $\left(\mathrm{F}_{(1,29)}=3,39 ; p=0,076\right)$.

Für den Parameter der RMT vor anodaler Gleichstromstimulation ergab die Analyse keinen signifikanten Gruppenunterschied $\left(\mathrm{F}_{(1,42)}=1,937 ; p=0,157\right)$.

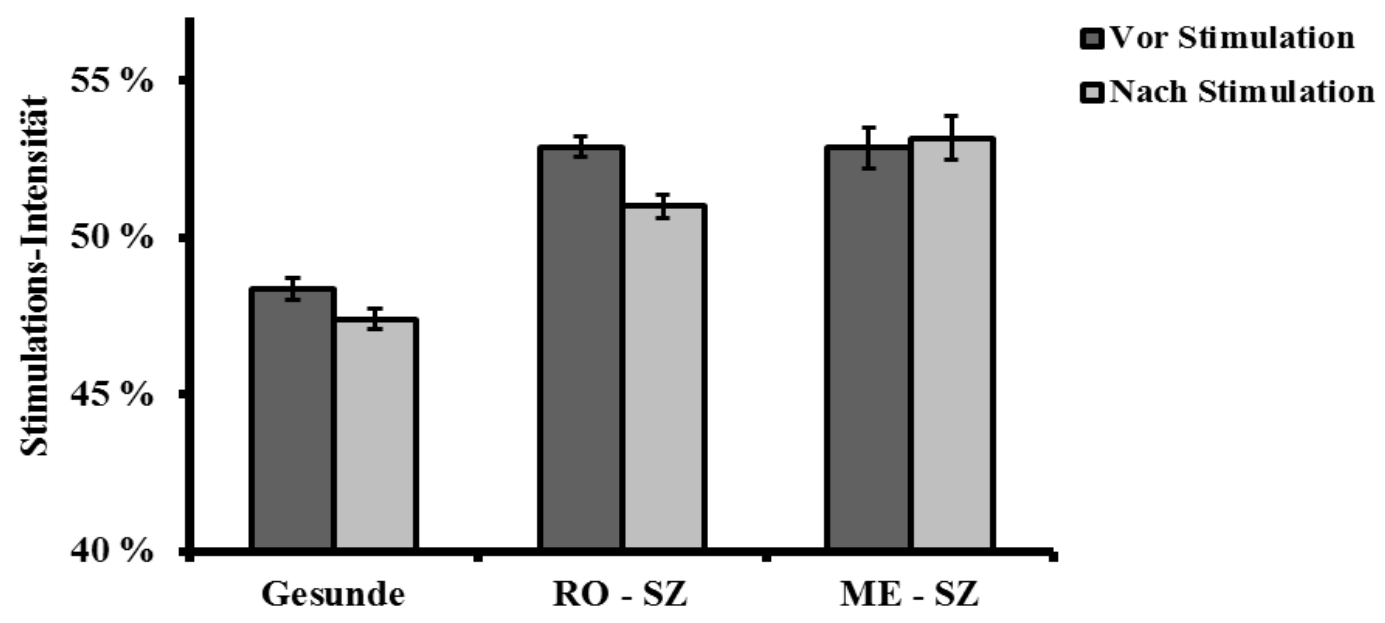

Abbildung 7: Übersicht der RMT vor und nach anodaler tDCS im Drei-Gruppenvergleich. Bezüglich der RMT zeigte sich zwischen den Gesunden, den Patienten mit einer Resent-Onset Schizophrenie (RO-SZ) und den Patienten mit einer Multi-Episode Schizophrenie (ME-SZ) kein signifikanter Unterschied.

Die Daten sind angegeben in \% der Stimulatorintensität (Mittelwert \pm Standardfehler). 


\subsection{Gruppenunterschiede kortikaler Erregbarkeit nach tDCS}

Die RM-ANOVA konnte im Vergleich zwischen den Gesunden und allen Patienten (Zwei-Gruppenvergleich) weder einen signifikanten Effekt der "Zeit" noch eine signifikante Interaktion "Gruppe x Zeit" für SICI und ICF ermitteln. Untersuchungen der CSP zeigten einen signifikanten Effekt der "Zeit" $\left(\mathrm{F}_{(1,42)}=7,265 ; p=0,010\right)$, aber keine signifikante Interaktion "Gruppe x Zeit" $\left(\mathrm{F}_{(1,42)}=0,152 ; p=0,997\right)$.

Der Drei-Gruppenvergleich (Gesunde versus RO-SZ versus ME-SZ) konnte keinen signifikanten Effekt der "Zeit" auf die SICI zeigen $\left(\mathrm{F}_{(1,41)}=0,106 ; p=0,746\right)$, aber einen Trend für eine signifikante Interaktion "Gruppe $\mathrm{x}$ Zeit" war erkennbar $\left(\mathrm{F}_{(2,41)}=\right.$ 2,486; $p=0,096)$.

Die Durchführung der RM-ANOVA konnte zwischen RO-SZ und ME-SZ keinen Effekt der "Zeit" auf die SICI $\left(\mathrm{F}_{(1,20)}=0,311 ; p=0,583\right)$, aber eine signifikante Interaktion von "Gruppe x Zeit" $\left(\mathrm{F}_{(1,20)}=5,906 ; p=0,025\right)$ nachweisen. Bei der Auswertung der ICF mittels RM-ANOVA konnte weder ein signifikanter Effekt der "Zeit", noch eine signifikante Interaktion "Gruppe x Zeit" demonstriert werden.

Eine RM-ANOVA der CSP ergab im Vergleich der drei Gruppen einen signifikanten Effekt der "Zeit" $\left(\mathrm{F}_{(1,41)}=6,861 ; p=0,012\right)$, jedoch keine signifikante Interaktion von "Gruppe $\mathrm{x}$ Zeit" $\left(\mathrm{F}_{(1,41)}=0,208 ; p=0,813\right)$.

Die Auswertung der SICI vor und nach tDCS ergab nur bei den RO-SZ eine Zunahme der SICI nach tDCS (gepaarter t-Test: $p=0,028$ ), während sich dieser Parameter bei den Gesunden und bei den ME-SZ nicht signifikant veränderte. Im Vergleich zwischen den gesunden Kontrollprobanden und dem gesamten Patientenkollektiv zeigte sich, dass, ebenso wie vor tDCS, die Gesunden nach tDCS höhere Werte für die SICI (mehr Inhibition) aufwiesen als die Patienten $\left(\mathrm{F}_{(1,42)}=4,1\right.$; $p=0,042)$.

Für alle anderen Parameter ergab die RM-ANOVA keine signifikanten Ergebnisse oder Unterschiede. 


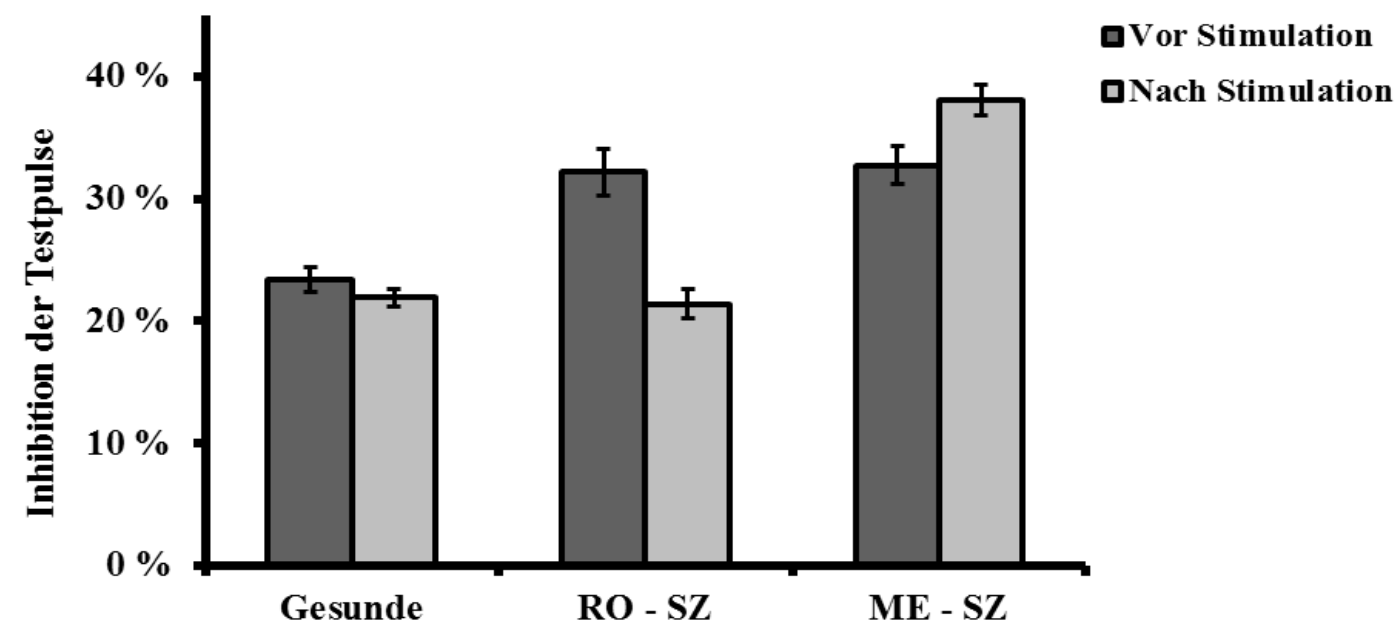

Abbildung 8: Inhibition der Testpulse (SICI) vor und nach anodaler tDCS im DreiGruppenvergleich.

Gepaarte t-Tests ermittelten bei dem Vergleich der SICI (short-interval intracortical inhibition) vor (dunkle Balken) und nach (helle Balken) anodaler tDCS nur bei den Patienten mit einer Resent-Onset Schizophrenie (RO-SZ) eine signifikante Zunahme der SICI. Bei den Gesunden und den Patienten mit einer Multi-Episode Schizophrenie (ME-SZ) zeigten sich keine signifikanten Veränderungen der SICI nach anodaler tDCS. Die Daten sind angegeben in Prozent zur 1mV-Intensität (Mittelwert \pm Standardfehler). 


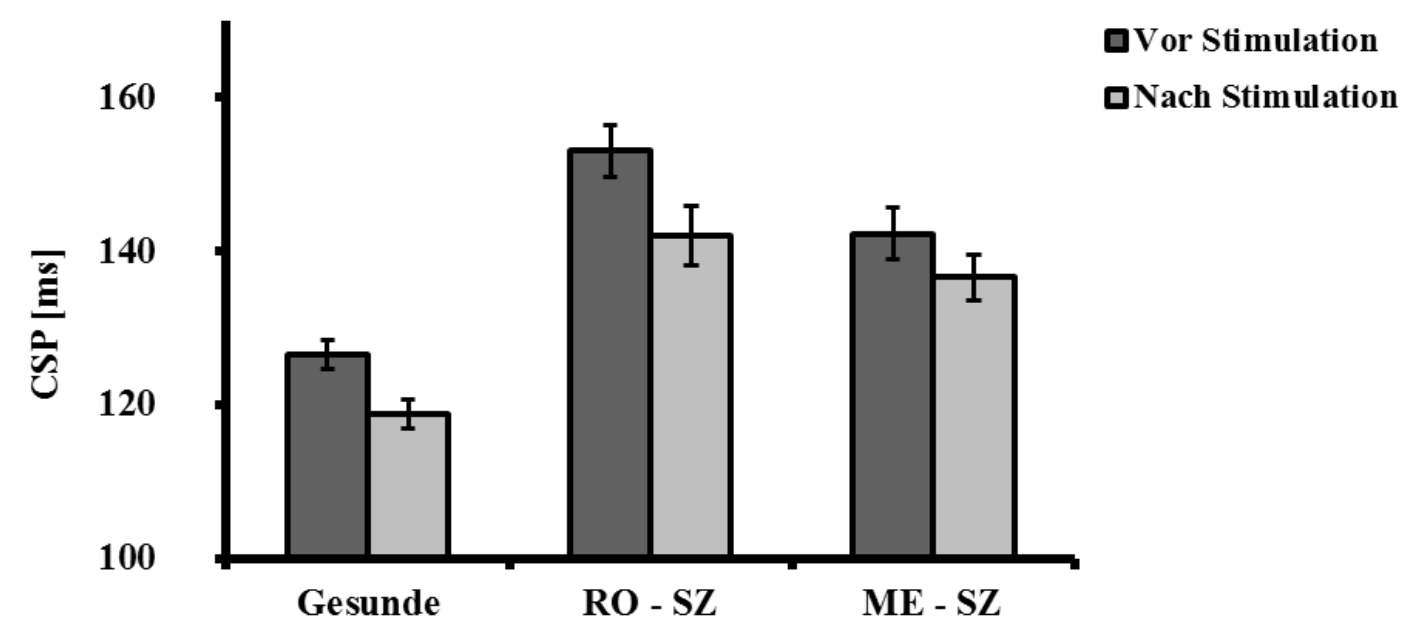

Abbildung 9: Darstellung der CSP vor und nach anodaler tDCS im Drei-Gruppenvergleich.

Der Vergleich zwischen den Gesunden, den Patienten mit einer Resent-Onset Schizophrenie (RO-SZ) und den Patienten mit einer Multi-Episode Schizophrenie (ME-SZ) ergab keine signifikanten Gruppenunterschiede bezüglich der kortikalen Silent Period (CSP) vor und nach anodaler tDCS. Die Daten sind angegeben in ms (Mittelwert \pm Standardfehler).

\subsection{Analyse der entsprechend des Alters gematchten Unter- gruppen (Gesunde versus ME-SZ)}

Die Untergruppen ME-SZ und gesunde Kontrollen wurden im Hinblick auf das Alter gematcht. Damit befanden sich in den Untergruppen jeweils 10 Personen.

Hinsichtlich der Amplitude der 1mV-MEPs ergab die RM-ANOVA im Vergleich der beiden Untergruppen einen signifikanten Effekt der "Zeit" $\left(\mathrm{F}_{(1,18)}=22,434 ; p<\right.$ $0,001)$ und eine signifikante Interaktion zwischen "Gruppe x Zeit" $\left(\mathrm{F}_{(1,18)}=4,997 ; p\right.$ $=0,038)$. Während sich die $1 \mathrm{mV}$-MEPs der beiden Gruppen vor der tDCS nicht unterschieden (unabhängiger t-Test: $p=0,244$ ), zeigten sich nach anodaler Stimulation bei den Gesunden höhere 1mV-MEPs im Vergleich zu den ME-SZ (unabhängiger t-Test: $p=0,029$ ). Alle weiteren Parameter ergaben keine signifikanten Unterschiede zwischen den beiden Gruppen. 


\subsection{Einfluss klinischer Faktoren und Antipsychotika auf die TMS-Parameter}

Für die Untersuchung klinischer Einflussfaktoren und die Bedeutung der Antipsychotika auf die Ergebnisse der vorliegenden Studie wurden SpearmanKorrelations-Analysen durchgeführt. Diese zeigten keine signifikante Korrelation zwischen CPZ-Äquivalenten und den abhängigen Variablen.

Eine one-way-ANOVA zwischen zwei unterschiedlichen Medikamentengruppen (Quetiapin versus Risperidon) konnte im Vergleich der beiden Gruppen keinen Unterschied für alle abhängigen Variablen nachweisen. Spearman KorrelationsAnalysen zeigten keine Korrelation zwischen den abhängigen Variablen und den PANSS-Werten, der CGI, der GAF, der Psychosedauer (in Jahren) und der Anzahl der psychotischen Episoden. 


\section{Diskussion}

Das Ziel der vorliegenden Arbeit war die Untersuchung der durch anodale tDCSinduzierten motor-kortikalen Plastizität (LTP-ähnlicher Plastizität) bei Patienten mit einer Schizophrenie im Vergleich zu gesunden Kontrollprobanden.

Der zentrale Schwerpunkt innerhalb dieser Studie beinhaltete die Erhebung von möglichen Plastizitätsunterschieden zwischen Patienten mit nur einer psychotischen Episode und damit frühen Krankheitsverlauf (RO-SZ, recent-onset schizophrenia) und Patienten mit mehr als einer psychotischen Episode und längerem Krankheitsverlauf (ME-SZ, multiple-episode schizophrenia) im Querschnitt.

Die durchgeführten Untersuchungen konnten zeigen, dass Patienten mit mehr als einer psychotischen Episode im Vergleich zu Patienten mit nur einer psychotischen Episode und Gesunden eine signifikant reduzierte Antwort des motorischen Kortex nach anodaler tDCS im Sinne einer Reduktion LTP-artiger Plastizität aufwiesen.

Des Weiteren konnte im Vergleich zu den Gesunden bei allen Patienten mit einer Schizophrenie eine reduzierte kortikale Inhibition nachgewiesen werden.

Resultierend aus den Ergebnissen der vorliegenden Studie besteht die Annahme, dass sich die Defizite der LTP-artiger Plastizität im Krankheitsverlauf der Schizophrenie zunehmend entwickeln.

\subsection{LTP-ähnliche Plastizitäts-Defizite bei Schizophrenie}

Als Ergebnis der vorliegenden Arbeit präsentierten sich signifikante Defizite der LTP- artiger Plastizität bei Schizophreniepatienten mit mehr als einer psychotischen Episode (ME-SZ). Erfasst wurde dieses Ergebnis durch die geringere Fazilitation der MEP-Amplitude nach anodaler tDCS bei den chronisch Kranken im Vergleich zu den gesunden Kontrollprobanden und den Patienten im frühen Erkrankungsstadium. Zwischen den Gesunden und den RO-SZ zeigten sich keine signifikanten Unterschiede bezüglich einer Zunahme der MEP-Amplitude nach anodaler tDCS. 
Des Weiteren zeigte sich unter Betrachtung des gesamten Patientenkollektivs eine signifikante kortikale Disinhibition der Patienten mit einer Schizophrenie vor anodaler tDCS (Baseline) im Vergleich zu den gesunden Kontrollpersonen. Dies konnte anhand der reduzierten kortikalen Inhibition bei kurzem Interstimulusintervall (SICI) im Patientenkollektiv verdeutlicht werden. Während eine Zunahme der Inhibition nur bei den RO-SZ nachweisbar war, zeigte sich bei den ME-SZ keine signifikante Zunahme der SICI nach anodaler tDCS.

Neben der vorliegenden Studie beschäftigte sich die Arbeitsgruppe um Daskalakis in zwei Studien mit der Untersuchung LTP-artiger Plastizität am motorischen Kortex bei Patienten mit einer Schizophrenie (Daskalakis et al. 2008a; Frantseva et al. 2008). Als entscheidender Unterschied $\mathrm{zu}$ den beiden Studien wurde in der vorliegenden Untersuchung die LTP-artige Plastizität unter Zuhilfenahme von anodaler tDCS induziert, während die anderen Studien aktivitätsabhängige Plastizität (Daskalakis et al. 2008a) beziehungsweise paarig-assoziative Stimulation (PAS) (Frantseva et al. 2008) verwendeten. Unabhängig vom genutzten Stimulationsverfahren zur Induktion kortikaler Plastizität ergaben beide Studien, analog zu der vorliegenden Arbeit, eine reduzierte Antwort auf einen externen Stimulus bei Patienten mit einer Schizophrenie (Daskalakis et al. 2008a; Frantseva et al. 2008). Im Folgenden werden die Untersuchungsmethoden und die Ergebnisse der vorliegenden Studie gemeinsam mit den oben genannten Untersuchungen detailliert beschrieben und diskutiert.

Im Rahmen der Untersuchung LTP-artiger Plastizität etablierte sich ergänzend zu bisherigen Methoden das Verfahren der PAS (gepaarte-assoziative Stimulation). Hierbei erfolgt die Stimulation zweier neuronaler Strukturen wiederholt in einem bestimmten Abstand. In Abhängigkeit von dem Stimulationsintervall zwischen den gepaarten Stimuli resultiert entweder eine Hemmung oder Bahnung der Erregbarkeit in der entsprechenden Zielregion. An gesunden Probanden konnte gezeigt werden, 
dass PAS eine langanhaltende Zunahme der M1 Exzitabilität induziert, welche NMDA-Rezeptor-abhängig ist (Stefan et al. 2002). Somit stellt dies eine weitere Methode zur Erzeugung stimulationsinduzierter Plastizität dar (Stefan et al. 2000). Erste Protokolle etablierten die Stimulation eines peripheren Nerven (N. medianus) kombiniert mit transkraniellen Kortexanteilen (kontralateraler motorischer Kortex) (Classen et al. 2004). Später erfolgte die kortikokortikale Stimulation zweier miteinander verbundener Kortexareale mit dem Resultat der Induktion von Plastizität sowie Erregbarkeitsveränderungen neuronaler Strukturen (Rizzo et al. 2009).

Im Fokus der Studie von Frantseva et al. 2008 stand die Untersuchung von LTPartiger Plastizität, welche unter Zuhilfenahme von PAS induziert wurde. Es konnte gezeigt werden, dass Patienten mit einer Schizophrenie signifikante Defizite der LTP-artigen Plastizität aufweisen (signifikante Defizite der MEP-Bahnung nach PAS im Vergleich zu Gesunden). Zusätzlich konnte in dieser Studie gezeigt werden, dass ein signifikanter Zusammenhang zwischen den Defiziten der LTP-artigen Plastizität und der Fähigkeit des motorischen Lernens besteht.

Motorische Plastizität lässt sich des Weiteren mit Hilfe anwendungsbeziehungsweise aktivitätsabhängiger Plastizität analysieren (englisch: usedependent plasticity). Durch Stimulation (TMS) eines bestimmten Areals im motorischen Kortex wird im entsprechenden kontralateralen Zielmuskel eine Bewegung induziert. Nach zusätzlichem aktivem Training des Muskels kann durch vor- und nachher TMS-Einzelpuls-Messungen die Effektivität des übungsabhängigen Lernens objektiviert werden (Bütefisch et al. 2008). Tierexperimentell konnte gezeigt werden, dass diese gezielten Bewegungen zu einer Verbesserung der Bewegungsabläufe und zu einer Vergrößerung des entsprechenden Repräsentationsareals im motorischen Kortex führen (Nudo et al. 1996). Pharmakologische Untersuchungen konnten nachweisen, dass die Effektivität dieser veränderten synaptischen Übertragung im gesunden menschlichen Motorkortex durch Aktivierung des 
NMDA-Rezeptors und durch GABAerge Hemmung verstärkt werden kann (Bütefisch et al. 2000).

Daskalakis et al. wiesen 2008a in ihren Untersuchungen anwendungsabhängiger Plastizität Defizite bei Patienten mit einer Schizophrenie nach. Diese zeigten im Vergleich $\mathrm{zu}$ gesunden Kontrollprobanden eine verminderte motorische Reorganisationsfähigkeit synaptischer Verbindungen. Die Fähigkeit der synaptischen Reorganisation ist ein wesentlicher Aspekt neuronaler Plastizität und von entscheidender Bedeutung für die Anpassung an veränderte Umweltbedingungen. So konnte gezeigt werden, dass Patienten mit einer Schizophrenie im Vergleich zu Gesunden signifikante Defizite dieser Fähigkeiten aufweisen.

Im Vergleich $\mathrm{zu}$ den beiden vorangegangenen Studien, die weder die Krankheitsursache noch die Anzahl und Dauer psychotischer Episoden berücksichtigten, beschreibt die vorliegende Arbeit einen Zusammenhang zwischen dem Krankheitsverlauf und den Veränderungen kortikaler Plastizität.

Die Ergebnisse der vorliegenden Studie, die eine Störung nicht-fokaler kortikaler Plastizität bei chronisch erkrankten Patienten sowie eine kortikale Disinhibition des gesamten Patientenkollektivs zeigten, sind mit den Ergebnissen der beiden diskutierten Studien vereinbar (sowohl die Beeinträchtigung des motorischen Lernens als auch die verminderte synaptische Reorganisationsfähigkeit) (Frantseva et al. 2008 und Daskalakis et al. 2008a). Bezüglich der unterschiedlich verwendeten Methoden soll verdeutlicht werden, dass tDCS langanhaltende und polaritätsspezifische Veränderungen der kortikalen Erregbarkeit bewirkt (Liebetanz et al. 2002; Nitsche et al. 2003a) und entsprechend tierexperimentellen Untersuchungen sich wie in der vorliegenden Studie LTP-artige Plastizität am ehesten mit Hilfe der tDCS induzieren lässt (Fritsch et al. 2010).

Allgemein betrachtet kann bei einem Patienten mit einer Schizophrenie eine Störung kortikaler fokaler und nicht-fokaler LTP-artiger Plastizität angenommen werden. 
Basierend auf diesen Befunden kann diskutiert werden, ob eine gestörte neuronale Plastizität eine wichtige pathophysiologische Ursache der Neurobiologie der Schizophrenie ist.

Ein grundlegender Mechanismus der LTP-Entstehung stellt die Funktionalität der NMDA-Rezeptoren als Vertreter der ionotropen Glutamatrezeptoren dar (Malenka 2003). Literaturübersichten mit dem Schwerpunkt der Untersuchung glutamaterger Funktionen bei Patienten mit einer Schizophrenie ergaben evidente Hinweise für die Hypothese einer Dysfunktion von NMDA-Rezeptoren infolge einer glutamatergen Unterfunktion als wichtiger pathophysiologischer Grundlage der Schizophrenie (Coyle 2006). Zusätzlich konnte gezeigt werden, dass die mittels tDCS induzierte LTP-artige Plastizität nach der Gabe von NMDA-Rezeptor-Agonisten verstärkt und nach Gabe von NMDA-Rezeptor-Antagonisten reduziert war (Nitsche et al. 2009; Nitsche et al. 2003a).

Basierend auf der Kenntnis, dass die Entstehung von LTP NMDA-Rezeptorabhängig ist, könnten glutamaterge Dysregulationen und Fehlfunktionen des NMDARezeptors die in der vorliegenden Studie nachgewiesenen Plastizitätsdefizite der chronisch kranken Patienten erklären.

Diese Ergebnisse sind von entscheidender Bedeutung für das pathophysiologische Verständnis der Schizophrenie. Speziell die Resultate der neurophysiologischen Unterschiede zwischen den Patienten mit nur einer psychotischen Episode und den chronisch kranken Patienten erlauben die Annahme eines progressiven Prozesses neuronaler Plastizität bei Patienten mit einer Schizophrenie.

Die bisherigen allgemeinen Erläuterungen zu den pathophysiologischen Grundlagen sowie den klinischen Merkmale der Schizophrenie werden im Folgenden anhand verschiedener Hypothesen detailliert beleuchtet. 


\subsection{Diskussion der Glutamat-Hypothese}

Die gestörte kortikale LTP-artige Plastizität bei Patienten mit einer chronischen Schizophrenie kann in Einklang mit der Glutamathypothese der Schizophrenie diskutiert werden.

Die Glutamathypothese unterstellt eine gestörte glutamaterge Funktion bei Patienten mit einer Schizophrenie. Vor allem Dysfunktionen des glutamatergen NMDARezeptors werden als von wesentlicher Bedeutung für das pathohysiologische Verständnis dieser Hypothese beschrieben (Paz et al. 2008). Während zunächst eine Hypofunktion des NMDA-Rezeptors im Fokus der Untersuchungen stand, werden aktuell Dysfunktionen der glutamatergen Neurotransmission als ätiologisches Modell diskutiert. Es besteht Grund zur Annahme einer regionalen Zunahme des Glutamats und einer konsekutiven Reduktion des entsprechenden NMDA-Rezeptors (Paz et al. 2008). Ursprünglich wurde diese Theorie anhand von pharmakologischen Beobachtungen entwickelt. Die Gabe des Glutamatantagonisten PCP (Phenylcyclidin) bewirkte die Induktion von Symptomen einer Schizophrenie beim Menschen (Luby et al. 1959).

Pharmakologische Untersuchungen an gesunden Probanden konnten zeigen, dass vor allem die tDCS-induzierten Nacheffekte vermeintlich NMDA-Rezeptor abhängig sind (Liebetanz et al. 2002; Nitsche et al. 2003a). Entsprechend der Funktion des Rezeptors als Kalzium-permeablem-Ionenkanal und ionotropem Glutamatrezeptor ist die Konzentration von Kalzium und Glutamat von wesentlicher Bedeutung für die oben genannten Effekte.

Im Folgenden werden die Bedeutung, der Zusammenhang und der Einfluss von Glutamat und Calcium auf die beschriebenen Defizite LTP-artiger Plastizität diskutiert.

In aktuellen Studien an Patienten mit einer Schizophrenie wird kontrovers diskutiert, ob die NMDA-Rezeptor-Defizite eher durch eine glutamaterge Überfunktion oder 
durch eine Unterfunktion bedingt sind (Paz et al. 2008; Coyle 2006; Misonou et al. 2004). Während bei den Patienten, die erst eine psychotische Episode durchlebten und medikamentös noch unbehandelt waren, präfrontal eher eine glutamaterge Hyperfunktion nachweisbar war, zeigte sich im Gegensatz dazu bei den bereits medikamentös behandelten chronisch Erkrankten eher eine glutamaterge Hypofunktion im präfrontalen Kortex (Paz et al. 2008). Dieses Ungleichgewicht der glutamatergen Neurotransmission scheint aus einer regionalen glutamatergen Überfunktion verbunden mit einer Abnahme der entsprechenden NMDA-Rezeptoren zu resultieren (Paz et al. 2008; Klär et al. 2010).

Bezüglich der Wechselwirkung zwischen der glutamtergen Neurotransmission und dem Einfluss auf die Aktivität, Funktionsfähigkeit und Ausprägung der NMDARezeptoren könnte zum Einen eine Zunahme der NMDA-Rezeptor-Expression eine glutamaterge Hypofunktion ausgleichen. Zum anderen könnte eine Abnahme der NMDA-Rezeptor-Expression Folge einer glutamatergen Hyperfunktion sein (Paz et al. 2008; Coyle 2006). Im Falle einer Hypofunktion des NMDA-Rezeptors beziehungsweise einer reduzierten NMDA-Rezeptor-Dichte wäre der CalciumEinstrom nach anodaler tDCS vermindert, und es käme zu einer Abnahme der plastischen Antwort.

Für den Fall einer Hyperfunktion des NMDA-Rezeptors beziehungsweise einer erhöhten NMDA-Rezeptor-Dichte würde es zu einem massiven Kalziumeinstrom in die Zelle nach anodaler tDCS kommen (Malenka und Bear 2004; Misonou et al. 2004). Folge wäre eine aktivitätsabhängige Translokation von spannungsabhängigen Kalium-Kanälen in der Zellmembran, was zu einem gesteigerten Kaliumausstrom im Sinne eines Ausgleiches des Konzentrationsverhältnisses führen würde (Misonou et al. 2004). Unter physiologischen Umständen dient dieser Mechanismus bei gesunden Menschen zum Ausgleich eines Kalzium-Überschusses (Misonou et al. 2004). Eine Dysregulation dieses Mechanismus, wie zum Beispiel bei Patienten mit einer Schizophrenie, könnte folglich zu Dysregulationen des Kalziumhaushaltes führen. 
Kalzium ist ein molekularer Botenstoff, welcher wesentlichen Einfluss auf die Induktion langanhaltender synaptischer Veränderungen hat und für die Effektivität synaptischer Stärke mit verantwortlich ist (Lisman 1989; Malenka 1991). Dabei scheint die Menge des einströmenden Kalziums abhängig von dem Grad der postsynaptischen Depolarisation zu sein und bestimmt somit das Ausmaß und die Richtung synaptischer Plastizität (Schiller et al. 1995; Larkum et al. 1999; Nevian und Sakmann 2006). Es konnte gezeigt werden, dass die Anzahl und die Frequenz postsynaptischer Aktionspotentiale mit dem Anstieg des postsynaptischen Kalziums und dem Ausmaß an LTP korreliert (Nevian und Sakmann 2006). Dem entgegengesetzt scheint ein geringer und langsamer postsynaptischer Kalziumanstieg eine Zunahme der LTD zu bedingen (Hansel et al. 1996). Außerdem gibt es Hinweise für ein gewisses postsynaptisches Kalziumlevel, welches einem so genannten „No-Mans-Land“ entspricht, einem Level, welches zu hoch ist für die Induktion von LTD und zu niedrig für LTP-Induktion (Lisman 2001).

Ergänzend sei zu erwähnen, dass bei Patienten mit einer Schizophrenie Störungen exzitatorischer Regulationen entsprechend der Glutamathypothese unweigerlich assoziiert sind mit Dysfunktionen inhibitorischer Funktionen wie dem GABAergen System (Coyle 2006) (Weitere Befunde zu Dysfunktionen des GABAergen Systems folgen im Kapitel 4.4).

Letztendlich könnten sowohl die Dysfunktionen des NMDA-Rezeptor-Systems und folglich die Störungen des Kalziumhaushaltes als auch eine fehlerhafte glutamaterge und GABAerge Neurotransmission die Reduktion der LTP-artigen Plastizität bei Patienten mit einer Schizophrenie der vorliegenden Studie erklären. 


\subsection{Progression der Defizite im Verlauf bei Patienten mit einer Schizophrenie}

Die in der vorliegenden Studie gezeigten Plastizitäts-Defizite der an einer Schizophrenie erkrankten Patienten konnten signifikant nur bei den chronisch kranken Patienten nachgewiesen werden. Patienten mit nur einer psychotischen Episode unterschieden sich hinsichtlich der Plastizitäts-Defizite nicht signifikant von den gesunden Kontrollprobanden.

Die Fragestellung, ob es sich bei der Schizophrenie um eine neurobiologisch progressive Erkrankung handelt, wurde innerhalb diverser vorangegangener Studien mit Hilfe unterschiedlicher Untersuchungstechniken analysiert (Lieberman 1999; Harrison 1999; Perez-Neri et al. 2006). Es besteht Grund zur Annahme, dass der Krankheitsverlauf der Schizophrenie bei mehreren Rezidiven häufig von einer allmählichen kognitiven Verschlechterung und einer zunehmenden Residualsymptomatik begleitet ist. Ein strukturelles Erklärungsmodell beschreibt als morphologisches Korrelat dieses ungünstigen Verlaufes eine progressive neuronale Degeneration mit zerebralem Volumenverlust (Church et al. 2002).

In verschiedenen bildgebenden Längsschnittsstudien konnte gezeigt werden, dass es entsprechend den unterschiedlichen Erkrankungsstadien bei an einer Schizophrenie erkrankten Patienten morphologisch zu progressiven Veränderungen neuronaler Strukturen kommt, was ebenso für einen fortschreitenden Prozess spricht (Cahn et al. 2009). Zudem konnte an Querschnittsstudien ein Zusammenhang zwischen der Dauer der aktiven Psychose und dem Ausmaß der Veränderungen des Gehirnvolumens bei Patienten mit einer Schizophrenie nachgewiesen werden. Je länger und je häufiger die Patienten eine aktive Psychose durchlebten, desto größer war der Volumenverlust der grauen Substanz beziehungsweise die Erweiterung des Ventrikelsystems (Cahn et al. 2009). 
Um progressive Defizite im Verlauf der Erkrankung fundiert untersuchen und beurteilen zu können, sind longitudinale Studien von wesentlicher Bedeutung, wie bereits oben erwähnt. MRT-Untersuchungen an Patienten mit einer Schizophrenie ergaben Volumenveränderungen (vor allem Volumenverlust der grauen Substanz beziehungsweise die Volumenzunahme der flüssigkeitsgefüllten Räume) des Gehirns insbesondere in den ersten Jahren der Erkrankung (Cahn et al. 2002; Ho et al. 2003). Weitere Untersuchungen konnten zeigen, dass der Volumenverlust der grauen Substanz nicht nur bereits in den frühen Stadien der Erkrankung (High-RiskPatienten beziehungsweise Übergang in eine Ersterkrankung) besteht, sondern auch bei chronisch erkrankten Patienten fortschreitet (Pantelis et al. 2005; Hulshoff Pol und Kahn 2008). Meta-Analysen longitudinaler Studien zur Untersuchung der morphologischen Gehirnveränderungen im Krankheitsverlauf der Schizophrenie wiesen darauf hin, dass diese Veränderungen einem dynamischen Verlauf unterliegen und allem Anschein nach spezifische Merkmale für die einzelnen Krankheitsstadien aufweisen (Borgwardt et al. 2011; Van Haren et al. 2012). Es scheint, dass diese progressiven Volumenverluste (vor allem der grauen Substanz) altersabhängig sind. Ab etwa einem Lebensalter von 45 Jahren scheint es im Vergleich zu Gesunden (entsprechend ihrem normalen neuronalen degenerativen Altersprozess) kaum noch morphologische Unterschiede des Gehirnvolumens zu geben (Van Haren et al. 2008). Wann die ersten strukturellen Veränderungen beginnen, ist noch unklar, zumindest sind diese bereits vor Krankheitsbeginn nachweisbar (Patienten im Prodromalstadium und Patienten mit hohem Risiko, eine Schizophrenie zu entwickeln) (Smieskova et al. 2010).

Neben der Dauer der Erkrankung gibt es weitere Faktoren wie die Schwere der Erkrankung und die Medikation, welche den Volumenverlust im Verlauf der Schizophrenie beeinflussen (Ho et al. 2011). 
Post-Mortem-Studien an Patienten mit einer Schizophrenie konnten ebenso signifikante neuronale Volumenreduktion (vor allem hippocampal) im Vergleich zu gesunden Kontrollpersonen nachweisen (Bogerts et al. 1993; Brisch et al. 2008). Dass Patienten mit schizophrener Erkrankung häufiger Hirnentwicklungsstörungen aufweisen, wird durch das häufigere Vorkommen von Befunden wie einer Erweiterung des Cavum septi pellucidi bei Patienten mit einer Schizophrenie gestützt (Brisch et al. 2007).

Des Weiteren besteht die Hypothese eines Zusammenhangs zwischen einer NMDARezeptor-Hypofunktion und einem progressiven Prozess in Bezug auf die kortikale Disinhibition bei Patienten mit einer Schizophrenie (Olney und Farber 1995; PerezNeri et al. 2006). Gegründet wird diese Hypothese auf der Vorstellung, dass eine Blockade der NMDA-Rezeptoren zu einer Reduktion kortikaler Inhibition führt, woraus eine gesteigerte exzitatorische glutamaterge Aktivität resultiert. Entsprechend der Hypothese kommt es folglich zu einem durch Übererregung bedingten Schaden neuronaler Strukturen. Dieser neuronale Zelltod stellt somit einen wesentlichen Aspekt eines neurodegenerativen Prozesses dar, welcher die Ursache und den natürlichen Verlauf des Krankheitsbildes der Schizophrenie mit bedingen könnte (Perez-Neri et al. 2006).

Gemäß den klinischen Symptome sowie den morphologischen und pathophysiologischen Veränderungen konnte im Allgemeinen bei den chronisch erkrankten Patienten im Vergleich zu den Ersterkrankten ein Progress der pathophysiologischen Veränderungen gezeigt werden. Dies bezieht sich vor allem auf eine stärkere Ausprägung der Symptome, der kognitiven Defizite, der Volumenveränderungen des Gehirns sowie der molekularbiologischen Veränderungen bei chronisch Kranken (Lieberman 1999). 
Damit würde die Schizophrenie nicht nur als eine Hirnentwicklungsstörung zu betrachten sein, sondern auch als eine neurodegenerative Erkrankung (Hardy und Gwinn-Hardy 1998).

Der Progress der bereits erläuterten morphologischen und funktionellen Veränderungen im Krankheitsverlauf scheint des Weiteren von äußeren und klinischen Faktoren mit bedingt zu sein. Diverse Untersuchungen beschreiben, dass die antipsychotische Therapie (Lieberman et al. 2005; Ho et al. 2011), eine Substanzabhängigkeit (zum Beispiel Cannabis) (Rais et al. 2008) sowie die Dauer und Anzahl der psychotischen Episoden (Wyatt 1991; Mc Glashan 2006; Cahn et al. 2009) im Sinne eines ,toxischen Effektes" Einfluss auf die im Verlauf der Erkrankung zunehmenden Veränderungen und Defizite haben.

Zusammenfassend konnte in den bereits erwähnten Untersuchungen verdeutlicht werden, dass es im Krankheitsverlauf der Schizophrenie zu einer Zunahme der morphologischen, funktionellen und klinischen Pathologien kommt, die neurophysiologisch mit den hier gezeigten Defizite der LTP-artigen Plastizität einhergehen können. Die in meiner Arbeit erhobenen Befunde, die signifikant eine Zunahme der Plastizitäts-Defizite bei chronisch erkrankten Patienten im Vergleich zu Ersterkrankten verdeutlichen, unterstützen im Einklang mit den oben genannten Vorbefunden die Annahme fortschreitender neurobiologischer Defizite bei Patienten mit einer Schizophrenie. 


\subsection{Dysfunktion des GABAergen Systems}

GABA entspricht dem wichtigsten inhibitorischen Neurotransmitter und eine Dysfunktion des GABAergen Systems wird als pathophysiologische Grundlage der Disinhibitionshypothese der Schizophrenie diskutiert (Benes et al. 1991; Benes et al. 2007).

Da zwischen den einzelnen Neurotransmittersystemen häufig ein Zusammenhang besteht, ist eine strikte Trennung der Untersuchung und der Erläuterung der einzelnen Hypothesen kaum möglich. Speziell in dieser Untersuchung ist der physiologische und pathologische Zusammenhang zwischen den Neurotransmittern GABA und Glutamat von wesentlicher Bedeutung und wird im Folgenden erläutert. Unter physiologischen Umständen wird GABA mit Hilfe der Glutamatdecarboxylase aus Glutamat synthetisiert. Post-mortale Untersuchungen an Schizophrenie erkrankten Patienten konnten Veränderungen des oben genannten Enzyms (GAD67) sowie eine Reduktion GABAerger Interneurone nachweisen (Benes et al. 1991; Benes 1998; Benes et al. 2007; Benes 2011; Lewis et al. 2005).

Post-mortem-Studien stellten weiterhin wiederholt einen Zusammenhang zwischen einer reduzierten GABAergen Funktion und Veränderungen des NMDA-Rezeptors bei Patienten mit einer Schizophrenie dar. So konnte gezeigt werden, dass bei den Patienten die Dichte an GABAergen Interneuronen, welche eine spezielle NMDARezeptor-Untereinheit exprimieren, im Vergleich zu den Gesunden reduziert ist (Woo et al. 2004; Coyle 2006).

Im Folgenden werden die Ergebnisse der einzelnen inhibitorischen, am ehesten durch GABA regulierten (SICI, CSP) und der faszilitatorischen Parameter (ICF) im Zusammenhang mit den Plastizitätsdefiziten diskutiert. 


\subsubsection{SICI als inhibitorischer Parameter}

Die vorliegende Studie zeigte einen signifikanten Unterschied der intrakortikalen Inhibition (SICI) innerhalb des Patientenkollektivs. Die vorliegende Studie ergab Veränderungen der SICI in beiden Stadien der Erkrankung (RO-SZ und ME-SZ), welche jedoch nur im frühen Krankheitsstadium (RO-SZ) mittels tDCS modulierbar ist. Im Vergleich zu den Patienten mit nur einer psychotischen Episode (RO-SZ), bei denen es zu einer signifikanten Zunahme der SICI nach anodaler tDCS kam, zeigten Patienten mit mehreren psychotischen Episoden (ME-SZ) sowie gesunde Kontrollpersonen keine Veränderungen der SICI durch anodale tDCS.

Die SICI (short-interval intracortical inhibition), welche am ehesten über $\mathrm{GABA}_{\mathrm{A}^{-}}$ Rezeptoren vermittelt wird, stellt ein Maß für die intrakortikale Erregbarkeit im motorischen Kortex dar (Kujirai et al. 1993; Ziemann 2004). Sie dient unter anderem der Untersuchung kortikaler Inhibition und GABAerger Neurotransmission (Ziemann 2004). Da die SICI in diversen unterschiedlichen psychiatrischen und neurologischen Störungen in verschiedenstem Ausmaß unspezifische Veränderungen (Bunse et al. 2014) aufweist, besteht nur eine geringe diagnostische Signifikanz (Rothwell et al. 2009). Veränderungen der SICI im Vergleich zu Gesunden sind daher eher als eine globale, unspezifische Störung der Erregbarkeit im motorischen Kortex zu bewerten.

Im Konsens mit verschiedenen Übersichtsarbeiten konnte gezeigt werden, dass die SICI in nahezu allen Untersuchungen bei Patienten mit einer Schizophrenie reduziert ist und dies in engem Zusammenhang mit einer gestörten GABAergen Neurotransmission steht (Hasan et al. 2013a; Radhu et al. 2013; Bunse et al. 2014).

Anodale tDCS, welche am ehesten LTP induziert und einer Fazilitation entspricht, sollte analog zu Vorbefunden bei Gesunden die SICI reduzieren (Nitsche et al. 2005). Der fehlende modulierende Effekt der tDCS auf die SICI bei Gesunden in unserer Studie könnte darin begründet liegen, dass tDCS nicht so GABA-sensitiv ist 
(Nitsche et al. 2004b) oder dass die Gesunden bereits eine hohe SICI zu Baseline hatten (sogenannter Floor-Effekt).

Bei den Patienten mit einer RO-SZ zeigte sich hier eine Zunahme der SICI nach anodaler tDCS. Ein möglicher Erklärungsansatz hierfür wäre die Vorstellung einer „Gegenmodulation" des GABAergen Systems bei den RO-SZ und damit Normalisierung der vorher pathologisch erniedrigten SICI durch die induzierte Neuroplastizität der tDCS. Der ausbleibende Effekt bei den ME-SZ könnte im Sinne einer mangelnden Fähigkeit der neuronalen Modulierbarkeit verstanden werden.

Chronisch kranke Patienten mit einer Schizophrenie zeigen damit keine signifikante Modulation der intrakortikalen Inhibition. Dies ist als Hinweis für eine verminderte Anpassungsfähigkeit im GABAergen System zu werten und reflektiert somit die seit längerem bestehende Annahme der kortikalen Disinhibition bei den ME-SZ (Daskalakis et al. 2002b; Fitzgerald et al. 2002; Wobrock et al. 2008; Bunse et al. 2014).

Da die SICI wahrscheinlich in ihren Funktionsmechanismen (neben anderen Neurotransmittern wie zum Beispiel Dopamin) vor allem über GABAerge Interneurone und $\mathrm{GABA}_{\mathrm{A}}$-Rezeptoren vermittelt wird (Ziemann 2004), lässt sich annehmen, dass die Ergebnisse Hinweis für eine gestörte GABAerge Neurotransmission sind. Dies würde somit einen weiteren Aspekt zum pathophysiologische Verständnis einer irreversibel beeinträchtigten $\mathrm{GABA}_{\mathrm{A}}$-ergen Dysfunktion bei chronisch kranken Patienten mit einer Schizophrenie liefern.

Im Einklang mit den Ergebnissen der vorliegenden Studie und diversen bereits erwähnten voran gegangenen Untersuchungen bestärkt sich die Annahme einer Dysfunktion der GABAergen Neurotransmission als pathophysiologisches Merkmal der Schizophrenie. 


\subsubsection{CSP als inhibitorischer Parameter}

Ein weiterer inhibitorischer Parameter, der in der vorliegenden Studie untersucht wurde, war die Messung der kortikalen Innervationsstille (CSP, englisch: cortical silent period). Die CSP ergab in der Baseline keine signifikanten Unterschiede sowohl zwischen den beiden Hauptgruppen (Gesunde versus Patienten) als auch zwischen den drei Untergruppen (Gesunde versus RO-SZ versus ME-SZ).

Im Überblick konnte jedoch ein numerischer Unterschied gezeigt werden. Im Vergleich zu den Gesunden war die CSP bei den Patienten mit einer Schizophrenie verlängert und im Innergruppenvergleich wiesen die RO-SZ eine tendenziell längere CSP auf als die ME-SZ.

Studien haben gezeigt, dass die CSP am ehesten $\mathrm{GABA}_{\mathrm{B}}$-vermittelt ist und eine lang anhaltende intrakortikale Inhibition widerspiegelt (Ziemann et al. 1993; Siebner et al. 1998). Die weiteren Untersuchungen ergaben sehr kontroverse Ergebnisse. Es gibt Hinweise, dass die Dauer der CSP (verkürzt oder verlängert) abhängig zu sein scheint von klinischen Faktoren wie der Dauer der Erkrankung und der pharmakologischen Therapie. Zentraler Schwerpunkt scheint hierbei ein CSPmodulierender Effekt der Antipsychotika (vor allem Clozapin) zu sein (Davey et al. 1997; Daskalakis et al. 2002b; Daskalakis et al. 2008b; Liu et al. 2009; Bunse et al. 2014). Zudem gibt es Hinweise für eine verlängerte CSP bei Patienten mit nur einer psychotischen Episode (RO-SZ) im Vergleich zu gesunden Kontrollpersonen (Hasan et al. 2012b; Bunse et al. 2014).

Der in der vorliegenden Arbeit fehlende signifikante Effekt könnte durch die Stichprobengröße und durch die antipsychotisch wirksamen Medikamente bedingt sein (Liu et al. 2009).

Im Einklang mit den Vorbefunden und den in der vorliegenden Arbeit gezeigten numerischen Unterschieden (verlängerte CSP vor allem bei RO-SZ) erlauben Veränderungen der CSP die Annahme von Dysfunktionen des $\mathrm{GABA}_{\mathrm{B}}$-Rezeptors. Dies würde ein Ungleichgewicht inhibitorischer Neurotransmission bei Patienten mit einer Schizophrenie bedingen, wobei diese Hypothese nur zurückhaltend formuliert 
werden kann. Dass die CSP bei den Ersterkrankten im Trend länger war als bei den mehrfach beziehungsweise chronisch Kranken, würde zur Hypothese passen, dass die verlängerte CSP Ausdruck einer kompensatorisch verstärkten $\mathrm{GABA}_{\mathrm{B}}$-ergen bei defizienter $\mathrm{GABA}_{\mathrm{A}}$-ergen Inhibition ist. Im Sinne einer besseren Neuroplastizität oder Modulationsfähigkeit besitzen die RO-SZ damit auch hier die besseren Kompensationsfähigkeiten.

\subsubsection{ICF als fazilitatorischer Parameter}

Die Untersuchungen der ICF (englisch: intracortikal facilitation) als einem intrakortikal fazilitatorischen Parameter konnten keine signifikanten Unterschiede sowohl zwischen den beiden Hauptgruppen (Gesunde versus Patienten) als auch zwischen den drei Untergruppen (Gesunde versus RO-SZ versus ME-SZ) nachweisen. Mit hoher Wahrscheinlichkeit wird die ICF über Glutamat und NMDARezeptoren vermittelt (Kujirai et al. 1993; Ziemann 2004).

Die Ergebnisse des aktuellen Forschungsstandes zur ICF sind bisher sehr variabel und unzureichend. Nur eine Arbeitsgruppe konnte bisher eine signifikant gesteigerte ICF bei Pateinten mit einer Schizophrenie im Vergleich zu Gesunden, als Zeichen einer kortikalen Disinhibition darstellen (Pascual-Leone et al. 2002). Auf Grund der insuffizienten Studienlage lassen sich nur allgemeine Hypothesen aufstellen. Es resultiert die These, dass Veränderungen erregender neuronaler Netzwerke einem weiteren pathophysiologischen Teilaspekt der Disinhibitionstheorie im Krankheitsbild der Schizophrenie entsprechen könnten. Eine mögliche Ursache für die kaum detektierbaren ICF-Veränderungen stellen die hohe Variabilität der ICF und die ausgeprägten inhibitorischen Defizite dar, welche möglicherweise die Defizite exzitatorischer Netzwerke überdecken (Hasan et al. 2013a).

Aus den Ergebnissen der vorliegenden Studie lässt sich insgesamt die Hypothese erstellen, dass Dysfunktionen des NMDA-Rezeptors und der GABAergen Neurotransmission im Einzelnen und deren Wechselspiel zu Defiziten LTP-artiger 
Plastizität bei Patienten mit einer Schizophrenie führen (Coyle 2006), was sich aber nicht in einer veränderten ICF widerspiegelt.

\subsection{Einordnung des Ergebnisses in die Dopamin-Hypothese}

Wie bereits in der Einleitung ausführlich dargestellt, wurde insbesondere aus der Beobachtung, dass Dopaminantagonisten die Symptome einer Schizophrenie verbessern und Agonisten verschlechtern, gefolgert, dass bei Patienten mit einer Schizophrenie eine hyperdopaminerge kortikale Aktivität vorliegt (Delay et al. 1952; Carlsson und Lindqvist 1963). Ergänzende und modulierende Studien erweiterten diese Hypothese und erhärteten zudem den Verdacht auf eine Hypoaktivität des dopaminergen Systems, die vor allem für die Negativsymptome verantwortlich sein könnte (Scatton et al. 1982). Zusammengefasst entstand die Theorie der regionalen Spezifität, welche zum Einen von einer dopaminergen Hyperaktivität (vor allem in mesolimbischen Strukturen) und zum Anderen von einer Hypoaktivität (vor allem im Tegmentum und frontalen kortikalen Strukturen) ausgeht (Howes und Kapur 2009). Der Neuromodulator Dopamin hat einen sehr vielfältigen Einfluss auf die Aktivität neuronaler Synapsen, mit der Folge einer komplexen Modulation synaptischer Funktionen. Insbesondere die Beeinflussung neuroplastischer Vorgänge über ein Wechselspiel mit glutamatergen Rezeptoren ist mit der dopaminergen Neurotransmission assoziiert (Manahan-Vaughan und Kulla 2003; Wolf et al. 2003).

Innerhalb von tDCS-Studien an gesunden Menschen konnte gezeigt werden, dass Dopamin im Sinne eines Neuromodulators von wesentlicher Bedeutung für die Induktion NMDA-abhängiger Neuroplastizität zu sein scheint (zum Beispiel MonteSilva et al. 2009). Durch dopaminerge Modulation der NMDA-Rezeptor-abhängigen kortikalen Erregbarkeit (über D1-Rezeptoren) beziehungsweise der GABAergen Inhibition (über postsynaptische D2-Rezeptoren) scheint der tDCS-induzierte Calciumeinstrom beeinflusst $\mathrm{zu}$ werden. Entsprechend der veränderten Konzentration an Kalzium kann es zu Veränderungen der neuronalen Plastizität 
kommen (Chen und Yang 2002; Monte-Silva et al. 2010). Zusammengefasst ergibt sich, dass Dopamin eine entscheidende Funktion für die Erhöhung der Calciumkonzentration auf ein bestimmtes Level hat und damit LTP-artige Veränderungen der Erregbarkeit induziert (Monte-Silva et al. 2010). Dabei hat Dopamin einen nicht linearen und dosisabhängigen inhibitorischen Effekt auf die LTP-artige Plastizität und nach Aktivierung von Dopamin besteht eine umgekehrt Uförmige Dosis-Wirkungsbeziehung auf LTP-artige Plastizität (Monte-Silva et al. 2009; Monte-Silva et al. 2010). Dieses Modell ist ebenfalls gut mit den Befunden unserer Studie vereinbar und könnte die gegenläufige Wirkung auf die SICI nach anodaler Stimulation bei den RO-SZ erklären, da hier eine noch hohe, unter Umständen auch fluktuierende dopaminerge Aktivität zu vermuten ist im Gegensatz zu den chronisch Erkrankten, bei denen sich schon ein stabileres Gleichgewicht durch die langanhaltende antipsychotische Behandlung eingestellt haben kann und bei denen möglicherweise schon ein dauerhaftes Defizit der LTP-artigen Plastizität besteht .

\subsection{Beurteilung der funktionellen Relevanz der Befunde}

Ein weiterer Aspekt, der hilft, das Krankheitsbild der Schizophrenie besser zu verstehen und sich an die Dopaminhypothese anschließt und zur Erklärung der Symptome herangezogen wird, ist die Theorie des gestörten Signal-zu-RauschVerhältnisses und die daraus resultierende gestörte Filterfunktion bei Patienten mit einer Schizophrenie. Diese gestörte Filterfunktion kann als Teilaspekt Symptome der Schizophrenie wie vor allem Defizite kognitiver Fähigkeiten und des Gedächtnisses (Rolls et al. 2008) sowie die Unfähigkeit zur Differenzierung zwischen relevanten und irrelevanten Sachverhalten erklären.

Für dieses gestörte Signal-zu-Rausch-Verhältnisses könnten auch Defizite der LTPartigen Plastizität mit verantwortlich sein. Dass Patienten mit einer Schizophrenie eine kortikale Disinhibition aufweisen, konnte sowohl in der vorliegenden, als auch 
in voran gegangenen Untersuchungen evident gezeigt werden (Übersichten bei Radhu et al. 2013; Bunse et al. 2014). Die reduzierte kortikale Inhibition, welche wir zwar mit unseren hier angewandten Methoden nur im Motorkortex nachweisen können, es aber Befunde für das Vorliegen auch in anderen Netzwerken gibt wie im sensorischen Gating (reduzierte P50), könnte das verstärkte kortikale Rauschen erklären. Eine dauerhafte (tonische) Hochregelung des Systems (kortikales Rauschen) könnte wiederum auch die Erklärung für die Reduktion von spikedependent Plastizität (erfasst mittels PAS) (Frantseva et al. 2008) und einer Abnahme der nicht-fokalen LTP-artigen Plastizität (erfasst mittels anodaler tDCS) sein. In Folge dieser fehlenden oder verminderten Neuroplastizität können Patienten, bei denen dieses Defizit chronifiziert, ihre Defizite der Informationsverarbeitung nicht mehr ausgleichen beziehungsweise Lernvorgänge anstoßen und es kommt zu einer bleibenden oder sogar verstärkten Abnahme der kognitiven Funktionen (Hasan et al. 2013).

Als Fazit könnte eine gestörte neuronale Filterfunktion die in der vorliegenden Arbeit gezeigten Defizite im Sinne einer reduzierten kortikalen Inhibition und einer Abnahme der LTP-artigen Plastizität bedingen. Klinisch würde sich dies beispielsweise in Defiziten der Filterung des sensorischen Inputs und in einer Minderung der kognitiven Exekutiv- und Gedächtnisfunktion äußern (Brenner et al. 2009; Hasan et al. 2011; Hasan et al. 2012a). 


\subsection{Limitationen dieser Studie}

Innerhalb der Studie wurden die meisten Patienten mit Antipsychotika behandelt, die ihre Wirkung vor allem an $5 \mathrm{HT}_{2}$ - und $\mathrm{D}_{2}$-Rezeptoren entfalten. Es ist bekannt, dass eine dopaminerge Modulation, sei sie antagonistisch oder agonistisch, einen entscheidenden Einfluss auf die mittels tDCS induzierte LTP-artige Plastizität hat und Nacheffekte moduliert (Nitsche et al. 2006; Monte-Silva et al. 2010). Nitsche et al. (2006) gelang es am gesunden menschlichen Kontrollpersonen nachzuweisen, dass vor allem eine $\mathrm{D}_{2}$-Rezeptor-Blockade die mittels anodaler tDCS induzierte LTP-artige Plastizität in ihrer Entstehung reduziert. Daraus ergibt sich die Vermutung, dass die antipsychotisch wirksame medikamentöse Therapie, speziell die mit $\mathrm{D}_{2}$-Antagonisten, ebenfalls einen Teilaspekt der in unserer Studie gefundenen neurophysiologischen Veränderungen im Sinne der Plastizitäts-Defizite erklären kann. Dass die antipsychotische Medikation alleine für die verminderte LTP-artige Plastizität verantwortlich ist, ist allerdings nicht wahrscheinlich.

Es gibt eine Vielzahl von Untersuchungen, die zeigen konnten, dass die Gabe von Antipsychotika kaum einen Einfluss auf die Ergebnisse von neurophysiologischen Studien an Patienten mit einer Schizophrenie hat. Die Forschungsgruppe um Fitzgerald et al. (2004) konnte sowohl bei medizierten als auch bei unmedizierten Patienten mit einer Schizophrenie Defizite der kortikalen Plastizität (LTD nach 1-Hz repetetiver transkranieller Magnetstimulation) nachweisen. Daskalakis et al. konnte LTP Defizite im motorischen Kortex sowohl bei medizierten als auch bei unmedizierten Patienten mit einer Schizophrenie nachweisen (Daskalakis et al. 2008a). Eine weitere Arbeit zeigte LTD-Defizite nach kathodaler Gleichstromstimulation sowohl bei medizierten Patienten mit einer Schizophrenie als auch bei deren erstgradigen Angehörigen (Hasan et al. 2013a). Aus diesen Arbeiten ist deswegen klar abzuleiten, dass antipsychotische Medikamente keinen entscheidenden Effekt auf die Plastizitäts-Defizite bei den Patienten mit einer Schizophrenie haben, sondern die hier gefundenen Defizite eher ein neurobiologisches Korrelat der Erkrankung repräsentieren (Hasan et al. 2013b). 
Weiterhin sollte beachtet werden, dass im Zentrum des Krankheitsbildes der Schizophrenie eine gesteigerte mesolimbische dopaminerge Neurotransmission steht. Die Behandlung mit Antipsychotika sollte hierbei den Dopaminspiegel bei den Patienten normalisieren und nicht auf ein hypodopaminerges Level einstellen, wie es in voran gegangenen Studien bei gesunden Probanden zu erwarten ist.

Dass die Einnahme von Antipsychotika allem Anschein nach einen geringen Einfluss auf die Ergebnisse der vorliegenden Studie hat, kann zudem unterstützt werden mit dem Hinweis, dass sowohl die Patienten mit nur einer psychotischen Episode (ROSZ) als auch die chronisch erkrankten Patienten (ME-SZ) mit Antipsychotika behandelt wurden und keine signifikanten Korrelationen zwischen den CPZÄquivalenten und den Untersuchungsergebnissen nachgewiesen werden konnten. Wären die Ergebnisse beeinflusst von der antipsychotischen Medikation, so hätten die daraus resultierenden Effekte sowohl bei den RO-SZ als auch bei den ME-SZ in ähnlicher Ausprägung nachweisbar sein müssen. Letztendlich ist davon auszugehen, dass die Unterschiede zwischen den Patienten mit nur einer psychotischen Episode und den chronisch Kranken hinsichtlich der LTP-artigen Plastizitätsdefizite nicht alleine durch die Einnahme von Antipsychotika erklärbar sind. Gewissheit können hier aber nur Studien mit unmedizierten Patienten in ausreichend hoher Fallzahl bringen.

Eine weitere Einschränkung der Studie stellt die Dauer der antipsychotisch wirksamen Therapie dar. Beim Innergruppenvergleich des gesamten Patientenkollektivs zeigten sich signifikante Unterschiede in der Behandlungsdauer mit den Antipsychotika. Entsprechend der Dauer der Erkrankung wurden chronisch erkrankte Patienten länger mit antipsychotisch wirksamen Medikamenten behandelt als die Patienten, welche in ihrem Krankheitsverlauf erst eine psychotische Episode vorwiesen. Daraus resultiert eine höhere kumulative antipsychotische Dosis bei den Patienten mit einer chronischen Schizophrenie. Limitierender Nachteil ist, dass in der 
Gruppe der chronisch erkrankten Patienten die Lebenskumulativdosis nicht berechnet werden konnte.

Dass Antipsychotika einen Effekt auf die Neuroplastizität haben können, gent auch aus den neuropathologischen und bildgebenden Studien hervor. Sowohl tierexperimentell als auch am Menschen wurde die Annahme bestärkt, dass die Gabe von Antipsychotika einen modulierenden Einfluss auf die gehirnmorphologischen Volumenveränderungen (vor allem Volumenverlust der grauen Substanz und Volumenzunahme der Seitenventrikel) hat (Dorph-Petersen et al. 2005; Ho et al. 2011). Hierbei gab es eine positive Korrelation zwischen der Dauer der Einnahme und der kumulativen Dosis der Antipsychotika und den kortikalen VolumenReduktionen bei Patienten mit einer Schizophrenie. Zudem gibt es Hinweise, dass Veränderungen der NMDA-Rezeptorfunktion und -expression, welche bei Patienten mit einer Schizophrenie beschrieben wurden (Funk et al. 2009; Errico et al. 2013), durch die Einnahme von Antipsychotika mit bedingt sein könnten (Duncan et al. 2006; Schwieler et al. 2008; Segnitz et al. 2011).

Ergänzend existieren aber auch Hinweise auf einen toxischen Effekt der multipel durchlebten psychotischen Episoden selbst auf den Verlauf der Erkrankung, welche wahrscheinlich zu progressiven Veränderungen führen und somit die PlastizitätsDefizite mit verursachen würden. Um den Einfluss der antipsychotisch wirksamen Medikamente genauer zu verifizieren und von weiteren möglichen Ursachen, wie dem toxischen Effekt der Psychose selbst, differenzieren zu können, sollten in zukünftigen Studien die Folgen der dauerhaften Einnahme von antipsychotisch wirksamen Medikamenten auf die kortikale Plastizität bei Patienten mit einer Schizophrenie im Längsschnitt untersucht werden.

Diese Studie ist eine experimentelle Querschnittsstudie. Sie umfasst eine definierte Auswahl von Personen aus einer festgelegten Zielpopulation. Risikofaktoren und deren Auswirkungen werden gleichzeitig zu einem festen Zeitpunkt erfasst. 
Um die LTP-artige Plastizität über einen längeren Zeitraum untersuchen zu können und um detaillierte Aussagen über den progressiven Prozess bei Patienten mit einer Schizophrenie machen zu können, wäre es von effektivem Nutzen, die Probanden in einem Inner-Subjekt-Vergleich im Design einer Längsschnittstudie in den unterschiedlichen Stadien der Erkrankung (zum Beispiel Prodromalstadium, Stadium der Ersterkrankung, der RO-SZ und der ME-SZ) zu untersuchen.

Eine weitere Limitation dieser Studie bezieht sich auf der Verteilung der Patienten innerhalb der Gruppe der RO-SZ. Diese Patienten hatten in ihrem Leben erst eine psychotische Episode, welche nicht länger als zweieinhalb Jahre zurücklag. Dieser Zeitraum ist länger als er üblicherweise für Ersterkrankte im engeren Sinne gilt. Diese werden im Allgemeinen noch im akuten Schub ihrer ersten psychotischen Episode oder nach der Stabilisierung untersucht und weisen so eine kürzere Dauer der Psychose auf als die hier untersuchten RO-SZ. Dementsprechend könnten bei den hier eingeschlossenen RO-SZ schon mehr krankheitsprogressive Veränderungen vorliegen als bei den eingeschlossenen ersterkrankten Patienten in anderen Studien.

Eine weitere Einschränkung bezieht sich auf die Altersdifferenzen der gesamten Probanden. Im Inter-Gruppen-Vergleich (Gesunde versus RO-SZ versus ME-SZ) zeigte sich ein signifikanter Altersunterschied. Dass die Patienten mit bereits mehr als einer psychotischen Episode (ME-SZ) ein höheres Durchschnittsalter hatten als die Patienten, welche nur eine psychotische Episode hatten (RO-SZ), ist zu erwarten und lässt sich anhand des Krankheitsverlaufes erklären.

Um diesen Effekt hinsichtlich der erfassten Ergebnisse im Vergleich zwischen den Gesunden und den chronisch Kranken vernachlässigen zu können, wurden zwei zusätzliche Untergruppen erstellt. Diese beiden Untergruppen (je eine aus der Gruppe der Gesunden und eine aus der Gruppe der ME-SZ) wurden entsprechend des Alters exakt gematcht. 
Statistisch würden einige der berichteten Signifikanzen nach der Korrektur für multiples Testen oder eine Adjustierung für post-hoch-Vergleiche nicht mehr das Signifikanzniveau erreichen. Um bei einer Korrektur für multiples Testen (alle abhängigen Variablen, Gruppen und Zeitpunkte) noch eine statistische Power auf einem Signifikanzniveau von $\mathrm{p}=0,05 \mathrm{zu}$ erreichen, müsste die Stichprobe deutlich vergrößert werden, was in der vorliegenden Arbeit nicht möglich war. Deswegen wurden nur weitere t-Tests durchgeführt, sofern die Varianzanalysen signifikante Interaktionen zeigten, und auf andere Vergleiche verzichtet. Vergleichbare Studien hatten ähnliche oder kleinere Stichprobengrößen und wählten einen ähnlichen Ansatz (zum Beispiel Oxley et al. 2004; Daskalakis et al. 2008a; Frantseva et al. 2008). Dennoch sollte die fehlende Bonferroni-Korrektur als deutliche Limitation dieser Studie verstanden werden und die vorliegenden Ergebnisse müssen in unabhängigen und größeren Stichproben repliziert werden. 


\section{Zusammenfassung und Ausblick}

Neuroplastizität beschreibt generell die Fähigkeit neuronaler Strukturen sich zu reorganisieren, das heißt, sich veränderten Umweltbedingungen sowohl in der Struktur als auch in der Funktion anzupassen. Hierbei beinhaltet Neuroplastizität sowohl Veränderungen der synaptischen Aktivität als auch der Konnektivität. Ein wesentlicher molekularer Mechanismus der veränderten synaptischen Aktivität ist dabei die Langzeitpotenzierung (LTP).

Eine dysfunktionale neuronale Plastizität wird als ein wichtiger Teilaspekt zur Erklärung der Pathophysiologie der Schizophrenie beschrieben. Die Schizophrenie ist eine der schwerwiegendsten psychiatrischen Erkrankungen, bei der sich sowohl das gesamte innere Erleben als auch die äußere Wahrnehmung und die Kognition der Patienten stark verändert, was insbesondere bei den schwereren Verläufen häufig zu einer erheblichen Belastung für die Betroffenen sowie deren Angehörigen führt. Die Plastizitätsdefizite bei Patienten mit einer Schizophrenie scheinen dabei im Zusammenhang mit den unterschiedlichen klinischen Ausprägungen und Verläufen der Erkrankung zu stehen.

Ziel der vorliegenden Studie war die erstmalige Untersuchung nicht-fokaler LTPartiger kortikaler Plastizität und kortikaler Erregbarkeit bei Patienten mit einer Schizophrenie im Vergleich zu Gesunden. Die Untersuchungen wurden auf der Basis der Hypothese durchgeführt, dass Patienten mit einer Schizophrenie Defizite der kortikalen Plastizität und der intrakortikalen Inhibition aufweisen, welche am stärksten bei Patienten mit einem chronischen Verlauf ausgeprägt sind.

Nicht-fokale kortikale LTP-artige Plastizität kann im motorischen Kortex mit anodaler transkranieller Gleichstromstimulation (tDCS) induziert werden. Untersuchungen am Tier und am Menschen beschreiben, dass diese Art der Plastizität viele Übereinstimmungen mit molekularer LTP hat und somit ein ideales Modellsystem für die Untersuchung von Plastizitätsvorgängen bei Probanden darstellt. 
In der vorliegenden Untersuchung wurden Patienten mit einer Schizophrenie in einem noch frühen Stadium der Erkrankung (Recent-Onset Schizophrenia, RO-SZ), in einem späteren Stadium (chronisch Kranke beziehungsweise mehrfach Erkrankte, ME-SZ) sowie eine gesunde Kontrollgruppe mit anodaler tDCS über dem linken Motorkortex stimuliert. Die Effekte dieser Stimulation auf die kortikale Erregbarkeit wurden dann mit verschiedenen Paradigmen der diagnostischen transkraniellen Magnetstimulation (TMS) untersucht (motorische Ruheschwellen, SICI, ICF, CSP). Wie erwartet, war bei allen Patienten im Vergleich zu den Gesunden eine reduzierte Short Interval Intracortical Inhibition im Sinne einer gestörten $\mathrm{GABA}_{\mathrm{A}}$-vermittelten kortikalen Inhibition nachweisbar. Weiterhin zeigten die Ergebnisse der vorgelegten Dissertation, dass, im Vergleich zu Ersterkrankten und Gesunden, chronisch erkrankte Patienten mit einer Schizophrenie eine signifikant reduzierte LTP-artige Plastizität aufweisen. Dies wird durch die unzureichende Erregbarkeitszunahme nach anodaler tDCS bei den chronisch kranken Patienten deutlich.

Damit weisen die in dieser Studie beobachteten Ergebnisse erstmals auf einen Zusammenhang zwischen den LTP-artigen Plastizitätsdefiziten und dem Krankheitsstadium der Schizophrenie hin. Störungen der NMDA-, GABA- und Dopamin-Rezeptoren sowie eine Dysregulation des Kalziumhaushaltes und von sekretorischen Proteasen sind als Erklärung dieser Plastizitätsdefizite zu diskutieren. Im klinischen Bezug lässt sich zusammenfassen, dass ersterkrankte Patienten mit einer Schizophrenie im Gegensatz zu den chronisch Erkrankten besser auf einen externen Stimulus ansprechen (noch erhaltene Neuroplastizität), also in einem früheren Krankheitsstadium die Modulierbarkeit inhibitorischer Funktionen noch gegeben ist. 
Therapeutisch wurde die tDCS aber bisher nur bei chronisch kranken Patienten mit einer Schizophrenie angewandt.

Die Ergebnisse diese Dissertation sollen dazu anregen, dieses Verfahren zukünftig als therapeutisches Mittel gerade auch bei Patienten in einem frühen Krankheitsstadium anzuwenden, um die Wahrscheinlichkeit eines Fortschreitens der Erkrankung in einen chronischen Verlauf zu reduzieren. Zur weiteren Abklärung der Anwendbarkeit von tDCS als Therapieoption bei ersterkrankten Patienten mit einer Schizophrenie sind zukünftig vor allem longitudinale Untersuchungen bei Ersterkrankten mit ausreichender Fallzahl von Bedeutung. 


\section{Literaturverzeichnis}

Andreasen NC, Nopoulos P, Magnotta V, Pierson R, Ziebell S, Ho BC (2011): Progressive brain change in schizophrenia: a prospective longitudinal study of first-episode schizophrenia. Biol Psychiatry $\underline{70}, 672-679$

Archer T (2010): Neurodegeneration in schizophrenia. Expert Rev Neurother $\underline{10}$, $1131-1141$

Bajbouj M, Gallonat J, Niehaus L, Lang UE, Roricht S, Meyer BU (2004): Abnormalities of inhibitory neuronal mechanisms in the motor cortex of patients with schizophrenia. Pharmacopsychiatry $\underline{37}, 74-80$

Benes FM (1998): Model generation and testing to probe neural circuitry in the cingulate cortex of postmortem schizophrenic brain. Schizophr Bull $\underline{24}$, $219-230$

Benes FM (2011): Regulation of cell cycle and DNA repair in Post-mitotic GABA neurons in psychotic disorders. Neuropharmacology $\underline{60}, 1232-1242$

Benes FM, Berretta S (2001): GABAergic interneurons: implications for understanding schizophrenia and bipolar disorder. Neuropsychopharmacology $\underline{25}, 1-27$

Benes FM, McSparren J, Bird ED, SanGiovanni JP, Vincent SL (1991): Deficits in small interneurons in prefrontal and cingulate cortices of schizophrenic and schizoaffective patients. Arch Gen Psychiatry $\underline{48}, 996$ - 1001 
Benes FM, Lim B, Matzilevich D, Walsh JP, Subburaju S, Minns M (2007): Regulation of GABA cell phenotype in hippocampus of schizophrenics and bipolars. Proc Natl Acad Sci USA 104, 10164 - 10169

Bliss TV, Lomo T (1973): Long-lasting potentiation of synaptic transmission in the dentate area of the anaesthetized rabbit following stimulation of the perforant path. J Physiol 232, $331-356$

Blum BP, Mann JJ (2002): The GABAergic system in schizophrenia. Int J Neuropsychopharmacol $\underline{5}, 159-179$

Bogerts B, Falkai P, Greve B, Schneider T, Pfeiffer U (1993): The neuropathology of schizophrenia: past and present. J Hirnforsch $\underline{34}, 193-205$

Borgwardt S, McGuire P, Fusar-Poli P (2011): Gray matters!--mapping the transition to psychosis. Schizophr Res $\underline{133}, 63-67$

Brenner CA, Kieffaber PD, Clemnetz BA, Johannesen JK, Shekhar A, O`Donnell BF, Hetrick WP (2009): Event-related potential abnormalities in schizophrenia: a failure to "gate in" salient information? Schizophr Res $\underline{113}$, $332-338$

Brisch R, Bernstein HG, Krell D, Stauch R, Trübner K, Dobrowolny H, Kropf S, Bielau H, Bogerts B (2007): Volumetric analysis of septal region in schizophrenia and affective disorder. Eur Arch Psychiatry Clin Neurosci 257, $140-148$ 
Brisch R, Bernstein HG, Stauch R, Dobrowolny H, Krell D, Truebner K, Meyer-Lotz G, Bielau H, Steiner J, Kropf S et al. (2008): The volumes of the fornix in schizophrenia and affective disorders: a post-mortem study. Psychiatry Res $\underline{164}, 265-273$

Bunse T, Wobrock T, Strube W, Padberg F, Palm U, Falkai P, Hasan A (2014): Motor Cortical Excitability Assessed by Transcranial Magnetic Stimulation in Psychiatric Disorders: A Systematic Review. Brain Stimul 7, 158 - 169

Bütefisch CM, Davis BC, Wise SP, Sawaki L, Kopylev L, Classen J, Cohen LG (2000): Mechanisms of use-dependent plasticity in the human motor cortex. Proc Natl Acad Sci USA 97, 3661 - 3665

Bütefisch CM, Wessling M, Netz J, Seitz RJ, Hömberg V (2008): Relationship between interhemispheric inhibition and motor cortex excitability in subacute stroke patients. Neurorehabil Neural Repair $\underline{22}, 4-21$

Cahn W, Hulshoff Pol HE, Lems EB, van Haren NE, Schnack HG, van der Linden JA, Schothorst PF, van Engeland H, Kahn RS (2002): Brain volume changes in first-episode schizophrenia: a 1-year follow-up study. Arch Gen Psychiatry $\underline{59}, 1002-1010$

Cahn W, Rais M, Stigter FP, van Haren NE, Caspers E, Hulshoff Pol HE, Xu Z, Schnack HG, Kahn RS (2009): Psychosis and brain volume changes during the first five years of schizophrenia. Eur Neuropsychopharmacol $\underline{19}$, $147-151$

Carlson A (2006): The neurochemical circuitry of schizophrenia. Pharmacopsychiatry $\underline{39}, 10-14$ 
Carlsson A, Lindqvist M (1963): Effect of chlorpromazine or haloperidol on formation of 3Methoxytyramine and normetanephrine in mouse brain. Acta Pharmacol Toxicol (Copenh) $\underline{20}, 140-144$

Chen KC, Yang YK, Howes O, Lee ICH, Landau S, Yeh TL, Chiu NT, Chen PS, Lu RB, David AS u.a. (2013): Striatal dopamine transporter availability in drugnaive patients with schizophrenia: a case-control SPECT study with [(99m)Tc]-TRODAT-1 and a meta-analysis. Schizophr Bull $\underline{39}, 378$ - 386

Chen L, Yang CR (2002): Interaction of dopamine D1 and NMDA receptors mediates acute clozapine potentiation of glutamate EPSPs in rat prefrontal cortex. J Neurophysiol 무, 2324 - 2336

Chen R (2000): Studies of human motor physiology with transcranial magnetic stimulation. Muscle Nerve Suppl $\underline{9}, 26-32$

Chen R (2004): Interactions between inhibitory and excitatory circuits in the human motor cortex. Exp Brain Res $\underline{154}, 1$ - 10

Chen R, Corwell B, Yaseen Z, Hallett M, Cohen LG (1998): Mechanisms of cortical reorganization in lower-limb amputees. J Neurosci $\underline{18}, 3443$ - 3350

Church SM, Cotter D, Bramon E, Murray RM (2002): Does schizophrenia result from developmental or degenerative processes? J Neural Transm Suppl $\underline{63}$, $129-147$

Ciompi L (1980): The natural history of schizophrenia in the long term. $\mathrm{Br} \mathrm{J}$ Psychiatry $\underline{136}, 413-420$ 
Classen J, Wolters Am Stefan K, Wycislo M, Sandbrink F, Schmidt A, Kunesch E (2004): Paired associative stimualtion. Suppl Clin Neurophysiol 57, $563-569$

Coyle JT (2006): Glutamate and schizophrenia: beyond the dopamine hypothesis. Cell Mol Neurobiol 26, $365-384$

Creutzfeldt OD, Fromm GH, Kapp H (1962): Influence of transcortical d-c currents on cortical neuronal activity. Exp Neurol $\underline{5}, 436-452$

Csernansky JG (2007): Neurodegeneration in schizophrenia: evidence from in vivo neuroimaging studies. ScientificWorldJournal ㅁ, 135 - 143

Daskalakis ZJ, Christensen BK, Fitzgerald PB, Chen R (2002a): Transcranial magnetic stimulation: a new investigational and treatment tool in psychiatry. $\mathbf{J}$ Neuropsychiatry Clin Neurosci 14, 406 - 415

Daskalakis ZJ, Christensen BK, Chen R, Fitzgerald PB, Zipursky RB, Kapur S (2002b): Evidence for impaired cortical inhibition in schizophrenia using transcranial magnetic stimulation. Arch Gen Psychiatry $\underline{59}, 347$ - 354

Daskalakis ZJ, Christensen BK, Chen R, Fitzgerald PB, Zipursky RB, Kapur S (2003): Effect of antipsychotics on cortical inhibition using transcranial magnetic stimulation. Psychopharmacology (Berl) $\underline{170}, 255$ - 262

Daskalakis ZJ, Christensen BK, Fitzgerald PB, Chen R (2008a): Dysfunctional neural plasticity in patients with schizophrenia. Arch Gen Psychiatry $\underline{65}$, $378-385$ 
Daskalakis ZJ, Christensen BK, Fitzgerald PB, Moller B, Fountain SI, Chen R (2008b): Increased cortical inhibition in persons with schizophrenia treated with clozapine. J Psychopharmacol 22, 203 - 209

Davey NJ, Puri BK, Lewis HS, Lewis SW, Ellaway PH (1997): Effects of antipsychotic medication on electromyographic response to transcranial magnetic stimulation of the motor cortex in schizophrenia. $\mathbf{J}$ Neurol Neurosurg Psychiatry $\underline{63}, 468-473$

Davies CH, Starkey SJ, Pozza MF, Collingridge GL (1991): GABA autoreceptors regulate the induction of LTP. Nature $\underline{349}, 609-611$

Day BL, Dressler D, Maertens de Noordhout A, Marsden CD, Nakashima K, Rothwell JC, Thompson PD (1989): Electric and magnetic stimulation of human motor cortex: surface EMG and single motor unit responses. J Physiol $\underline{412}, 449-473$

De Peri L, Crescini A, Deste G, Fusar-Poli P, Sacchetti E, Vita A (2012): Brain structural abnormalities at the onset of schizophrenia and bipolar disorder: a meta-analysis of controlled magnetic resonance imaging studies. Curr Pharm Des $\underline{18}, 486-494$

Delay J, Deniker P, Harl JM (1952): [Therapeutic use in psychiatry of phenothiazine of central elective action (4560 RP)]. Ann Med Psychol (Paris) 110, $112-117$ 
Deutsche Gesellschaft für Psychiatrie, Psychotherapie und Nervenheilkunde DGPPN (Hrsg.). S3 Praxisleitlinien Psychiatrie und Psychotherapie. Band 1 Behandlungsleitlinie Schizophrenie. Steinkopff-Verlag, Darmstadt, November 2005

Devanne H, Lavoie BA, Capaday C (1997): Input - output properties and gain changes in the human corticospinal pathway. Exp Brain Res 114, 329 - 338

Di Lazzaro V, Oliviero A, Profice P, Saturno E, Pilato F, Insola A (1998): Comparison of descending volleys evoked by transcranial magnetic and electric stimulation in conscious humans. Electroencephalogr Clin Neurophysiol $\underline{109}, 397-401$

Dollfus S, Petit M (1991): Evaluation trial on the efficacy of neuroleptics on the outcome of schizophrenia. Encephale 17, $247-253$

Dorph-Petersen KA, Pierri JN, Perel JM, Sun Z, Sampson AR, Lewis DA (2005): The influence of chronic exposure to antipsychotic medications on brain size before and after tissue fixation: a comparison of haloperidol and olanzapine in macaque monkeys. Neuropsychopharmacology $\underline{30}, 1649-1661$

Duncan GE, Moy SS, Lieberman JA, Koller BH (2006): Typical and atypical antipsychotic drug effects on locomotor hyperactivity and deficits in sensorimotor gating in a genetic model of NMDA receptor hypofunction. Pharmacol Biochem Behav $\underline{85}, 481$ - 491

Eastwood SL, Harrison PJ (2006): Cellular basis of reduced cortical reelin expression in schizophrenia. Am J Psychiatry $\underline{163}, 540$ - 542 
Eichhammer P, Langguth B, Zowe M, Kleinjung T, Jacob P, Sand P, Hajak G (2004): GABA-B-associated neuropsychiatric disorders. Psychiatr Prax $\underline{31}$, $44-46$

Ellison-Wright I, Bullmore E (2009): Meta-analysis of diffusion tensor imaging studies in schizophrenia. Schizophr Res $\underline{108}, 3-10$

Endicott J, Spitzer RL, Fleiss JL, Cohen J (1976): The Global Assessment Scale: A procedure for measuring overall severity of psychiatric disturbance. Archives of General Psychiatry $\underline{33}, 766-771$

Errico F, Napolitano F, Squillace M, Vitucci D, Blasi G, de Bartolomeis A, Bertolino A, D`Aniello A, Usiello A (2013): Decreased levels of D-aspartate and NMDA in the prefrontal cortex and striatum of patients with schizophrenia. $\mathbf{J}$ Psychiatr Res $\underline{47}, 1432-1437$

Fitzgerald PB, Brown TL, Daskalakis ZJ, Kulkarni J (2002): A transcranial magnetic stimulation study of inhibitory deficits in the motor cortex in patients with schizophrenia. Psychiatry Res $\underline{114}, 11-22$

Fitzgerald PB, Brown TL, Marston NA, Oxley T, De Castella A, Daskalakis ZJ, Kulkarni J (2004): Reduced plastic brain responses in schizophrenia: a transcranial magnetic stimulation study. Schizophr Res $\underline{71}, 17$ - 26

Fornito A, Yücel M, Pantelis C (2009): Reconciling neuroimaging and neuropathological findings in schizophrenia and bipolar disorder. Curr Opin Psychiatry $\underline{22}, 312-319$ 
Frantseva MV, Fitzgerald PB, Chen R, Möller B, Daigle M, Daskalakis ZJ (2008): Evidence for impaired long-term potentiation in schizophrenia and its relationship to motor skill learning. Cereb Cortex $\underline{18}$, 990 - 996

Fritsch B, Reis J, Martinowich K, Schambra HM, Ji Y, Cohen LG, Lu B (2010): Direct current stimulation promotes BDNF-dependent synaptic plasticity: potential implications for motor learning. Neuron $\underline{66}, 198-204$

Funk AJ, Rumbaugh G, Harotunian V, McCullumsmith RE, Meador-Woodruff JH (2009): Decreased expression of NMDA receptor-associated proteins in frontal cortex of elderly patients with schizophrenia. Neuroreport $\underline{20}$, $1019-1022$

Gallinat J: Einfluss von Neuregulin 1 auf zerebrale Funktion, Kognition und Neurochemie bei Schizophrenie. Vortrag DGPPN Kongress Berlin 21. November 2007

Gallinat J, Gudlowski Y (2008): Die Glutamathypothese der Schizophrenie. Nervenheilkunde 27, $317-325$

Glahn DC, Laird AR, Ellison-Wright I, Thelen SM, Robinson JL, Lancaster JL, Bullmore E, Fox PT (2008): Meta-analysis of gray matter anomalies in schizophrenia: application of anatomic likelihood estimation and network analysis. Biol Psychiatry $\underline{64}, 774-781$

Goldman-Rakic PS, Selemon LD (1997): Functional and anatomical aspects of prefrontal pathology in schizophrenia. Schizophr Bull 23, $437-458$ 
Grafe P: Nozizeption und Schmerz; in: Physiologie; hrsg. v. Deetjen P, Speckmann EJ, Hescheler J; Urban \& Fischer Verlag/Elsevier GmbH; München 2005; $76-90$

Green MF (1996): What are the functional consequences of neurocognitive deficits in schizophrenia? Am J Psychiatry 153, 321 - 330

Gupta S, Kulhara P (2010): What is schizophrenia: A neurodevelopmental or neurodegenerative disorder or a combination of both? A critical analysis. Indian J Psychiatry $\underline{52}, 21-27$

Gurden H, Takita M, Jay TM (2000): Essential role of D1 but not D2 receptors in the NMDA receptor-dependent long-term potentiation at hippocampal-prefrontal cortex synapses in vivo. J Neurosci $\underline{20}, \mathrm{RC} 106$

Gustavsson A, Svensson M, Jacobi F, Allgulander C, Alonso J, Beghi E, Dodel R, Ekman M, Faravelli C, Fratiglioni L et al. (2011): Cost of disorders of the brain in Europe 2010. Eur Neuropsychopharmacol 21, 718 - 779

Guy W, Bonato RR: Clinical Global Impressions (CGI); in: Manual for the ECDEU Assessment Battery; hrsg. v. Guy W, Bonato RR; Chevy Chase, National Institute of Mental Health; Rockville 1976

Habl G, Schmitt A, Zink M, von Wilmsdorff M, Yeganeh-Doost P, Jatzko A, Schneider-Axmann T, Bauer M, Falkai P (2012): Decreased reelin expression in the left prefrontal cortex (BA9) in chronic schizophrenia patients. Neuropsychobiology $\underline{66}, 57-62$ 
Hansel C, Artola A, Singer W (1996): Different threshold levels of postsynaptic [Ca2+]i have to be reached to induce LTP and LDP in neocortical pyramidal cells. J Physiol Paris $\underline{90}, 317$ - 319

Hardy J, Gwinn-Hardy K (1998): Genetic classification of primary neurodegenerative disease. Science $\underline{282}, 1075-1079$

Harrison (1999): The neuropathology of schizophrenia. A critical review of the data and their interpretation. Brain $\underline{122}, 593-624$

Hasan A, Nitsche MA, Rein B, Schneider-Axmann T, Guse B, Gruber O, Falkai P, Wobrock T (2011): Dysfunctional long-term potentiation-like plasticity in schizophrenia revealed by transcranial direct current stimulation. Behav Brain Res $\underline{224}, 15-22$

Hasan A, Nitsche MA, Herrmann M, Schneider-Axmann T, Marshall L, Gruber O, Falkai P, Wobrock T (2012a): Impaired long-term depression in schizophrenia: a cathodal tDCS pilot study. Brain Stimul $\underline{5}, 475-483$

Hasan A, Wobrock T, Grefkes C, Labusga M, Levold K, Schneider-Axmann T, Falkai P, Müller H, Klosterkötter J, Bechdolf A (2012b): Deficient inhibitory cortical networks in antipsychotic-naïve subjects at risk of developing firstepisode psychosis and first-episode schizophrenia patients: a cross-sectional study. Bio Psychiatry $\underline{72}, 744-751$

Hasan A, Falkai P, Wobrock T (2013a): Transcranial brain stimulation in schizophrenia: Targeting cortical excitability, connectivity and plasticity. Curr Med Chem 20, 405 - 413 
Hasan A, Misewitsch K, Nitsche MA, Gruber O, Padberg F, Falkai P, Wobrock T (2013b): Impaired motor cortex responses in non-psychotic first-degree relatives of schizophrenia patients: a cathodal tDCS pilot study. Brain Stimul $\underline{6}, 821-829$

Hashimoto T, Bazmi HH, Mirnics K, Wu Q, Sampson AR, Lewis DA (2008): Conserved regional patterns of GABA-related transcript expression in the neocortex of subjects with schizophrenia. Am J Psychiatry 165, 479-489

Haukvik UK, Hartberg CB, Agartz I (2013): Schizophrenia--what does structural MRI show? Tidsskr Nor Laegeforen $\underline{133}, 850$ - 853

Hebb DO (1949): The organization of behavior. A neuropsychological theory. New York: Wiley

Heinrichs RW, Zakzanis KK (1998): Neurocognitive deficit in schizophrenia: a quantitative review of the evidence. Neuropsychology $\underline{12}, 426-445$

Ho BC, Andreasen NC, Nopoulos P, Arndt S, Magnotta V, Flaum M (2003): Progressive structural brain abnormalities and their relationship to clinical outcome: a longitudinal magnetic resonance imaging study early in schizophrenia. Arch Gen Psychiatry $\underline{60}, 585$ - 594

Ho BC, Andreasen NC, Ziebell S, Pierson R, Magnotta V (2011): Long-term antipsychotic treatment and brain volumes: a longitudinal study of firstepisode schizophrenia. Arch Gen Psychiatry $\underline{68}, 128$ - 137 
Hoe M, Nakagami E, Green MF, Brekke JS (2012): The causal relationships between neurocognition, social cognition and functional outcome over the time in schizophrenia: a latent difference score approach. Psychol Med $\underline{42}, 1-13$

Howes OD, Kapur S (2009): The dopamine hypothesis of schizophrenia: version III - the final common pathway. Schizophr Bull $\underline{35}, 549$ - 562

Howes OD, Egerton A, Allan V, McGuire P, Stokes P, Kapur S (2009): Mechanisms underlying psychosis and antipsychotic treatment response in schizophrenia: insights from PET and SPECT imaging. Curr Pharm Des 15, 2550 - 2559

Hulshoff Pol HE, Kahn RS (2008): What happens after the first episode? A review of progressive brain changes in chronically ill patients with schizophrenia. Schizophr Bull $\underline{34}, 354-366$

Jablensky A (1995): Schizophrenia: recent epidemiologic issues. Epidemiol Rev 17, $10-20$

Kaneko K, Kawai S, Fuchigami Y (1996): The effect of currnet direction induced by transcranial magnetic stimulation on the corticospinal excitability in human brain. Electroencephalogr Clin Neurophysiol 101, 478 - 482

Kay SR, Fiszbein A, Opler LA (1987): The positive and negative syndrome scale (PANSS) for schizophrenia. Schizophr Bull 13, 261 - 277

Klär AA, Ballmaier M, Leopold K, Häke I, Schaefer M, Brühl R, Schubert F, Gallinat J (2010): Interaction of hippocampal volume and N-acetylaspartate concentration deficits in schizophrenia: a combined MRI and 1H-MRS study. Neuroimage $\underline{53}, 51-57$ 
Klosterkötter J (2013): Prevention of psychotic disorders. Nervenarzt $\underline{84}$, $1302-1309$

Konradi C, Heckers S (2003): Molecular aspects of glutamate dysregulation: implications for schizophrenia and its treatment. Pharmacol Ther $\underline{97}$, $153-179$

Kujirai T, Carania MD, Rothwell JC, Day BL, Thompson PD, Ferbert A, Wroe S, Asselman P, Marsden CD (1993): Corticospinal inhibition in human motor cortex. J Physiol 417, 501 - 519

Lakatosova S, Ostatnikova D (2012): Reelin and its complex involvement in brain development and function. Int J Biochem Cell Biol 44, 1501 - 1504

Lang N, Rothkegel H, Reiber H, Hasan A, Sueske E, tergau F, Ehrenreich H, Wuttke W, Paulus W (2011): Circadian modulation of GABA-mediated cortical inhibition. Cereb Cortex 21, 2299 - 2306

Large M, Smith G, Sharma S, Nielssen O, Singh SP (2011): Systematic review and metaanalysis of the clinical factors associated with the suicide of psychiatric in-patients. Acta Psychiatr Scand 124, 18 - 29

Larkum ME, Kaiser KM, Sakmann B (1999): Calcium electrogenesis in distal apical dendrites of layer 5 pyramidal cells at a critical frequency of backpropagating action potentials. Proc Natl Acad Sci USA ㅁ6, 14600 - 14604 
Laursen TM, Munk-Olsen T, Nordentoft M, Mortensen PB (2007): Increased mortality among patients admitted with major psychiatric disorders: a register-based study comparing mortality in unipolar depressive disorder, bipolar affective disorder, schizoaffective disorder, and schizophrenia. J Clin Psychiatry $\underline{68}, 899-907$

Lewis DA, Hashimoto T, Volk DW (2005): Cortical inhibitory neurons and schizophrenia. Nat Rev Neurosci $\underline{6}, 312-324$

Lieberman JA (1999): Is schizophrenia a neurodegenerative disorder? A clinical and neurobiological perspective. Biol Psychiatry 46, 729 - 739

Lieberman JA, Bogerts B, Degreef G, Ashtari M, Lantos G, Alvir J (1992): Qualitative assessment of brain morphology in acute and chronic schizophrenia. Am J Psychiatry 149, 784 - 794

Lieberman JA, Tollefson GD, Charles C, Zipursky R, Sharma T, Kahn RS, Keefe RS, Green AI, Gur RE, McEvoy J et al. (2005): Antipsychotic drug effects on brain morphology in first-episode psychosis. Arch Gen Psychiatry $\underline{62}$, $361-370$

Liebetanz D, Nitsche MA, Tergau F, Paulus W (2002): Pharmacological approach to the mechanisms of transcranial DC-stimulation-induced after-effects of human motor cortex excitability. Brain $\underline{125}, 2238-2247$

Lisman J (1989): A mechanism for the Hebb and the anti-Hebb processes underlying learning and memory. Proc Natl Acad Sci USA $\underline{86}, 9574$ - 9578 
Lisman JE (2001): Three $\mathrm{Ca}^{2+}$ levels affect plasticity differently: the LTP zone, the LTD zone and no man`s land. J Physiol 532, 285

Liu SK, Fitzgerald PB, Daigle M, Chen R, Daskalakis ZJ (2009): The relationship between cortical inhibition, antipsychotic treatment, and the symptoms of schizophrenia. Biol Psychiatry $\underline{65}, 503-509$

Loebel AD, Lieberman JA, Alvir JM, Mayerhoff DI, Geisler SH, Szymanski SR (1992): Duration of psychosis and outcome in first-episode schizophrenia. Am J Psychiatry 149, 1183 - 1188

Luby ED, Cohen BD, Rosenbaum G, Gottlieb JS, Kelley R (1959): Study of a new schizophrenomimetic drug; sernyl. AMA Arch Neurol Psychiatry $\underline{81}$, $363-369$

Malenka RC (1991): The role of postsynaptic calcium in the induction of long-term potentiation. Mol Neurobiol $\underline{5}, 289-295$

Malenka RC (2003): The long-term potential of LTP. Nat Rev Neurosci 4, 923 - 926

Malenka RC, Bear MF (2004): LTP and LTD: an embarrassment of riches. Neuron $\underline{44}, 5-21$

Manahan-Vaughan D, Kulla A (2003): Regulation of depotentiation and long-term potentiation in the dentate gyrus of freely moving rats by dopamine D2-like receptors. Cereb Cortex $\underline{13}, 123-135$

Margolis RL, Chuang DM, Post RM (1994): Programmed cell death: implications for neuropsychiatric disorders. Biol Psychiatry $\underline{35}, 946$ - 956 
McGlashan TH (2006): Is active psychosis neurotoxic? Schizophr Bull $\underline{32}, 609-613$

Mesholam-Gately RI, Giuliano AJ, Goff KP, Faraone SV, Seidman LJ (2009): Neurocognition in first-episode schizophrenia: a meta-analytic review. Neuropsychology $\underline{23}, 315-336$

Mills KR, Boniface SJ, Schubert M (1992): Magnetic brain stimulation with a double coil: the importance of coil orientation. Electroencephalogr Clin Neurophysiol $\underline{85}, 17-21$

Misonou H, Mohapatra DP, Park EW, Leung V, Zhen D, Misonou K, Anderson AE, Trimmer JS (2004): Regulation of ion channel localization and phosphorylation by neuronal activity. Nat Neurosci $\underline{7}, 711-718$

Monte-Silva K, Kuo MF, Thirugnanasambandam N, Liebetanz D, Paulus W, Nitsche MA (2009): Dose-dependent inverted U-shaped effect of dopamine (D2-like) receptor activation on focal and nonfocal plasticity in humans. J Neurosci $\underline{29}$, $6124-6131$

Monte-Silva K, Liebetanz D, Grundey J, Paulus W, Nitsche MA (2010): Dosagedependent non-linear effect of L-dopa on human motor cortex plasticity. J Physiol $\underline{588}, 3415-3424$

Mössner R, Schuhmacher A, Schulze-Rauschenbach S, Kühn KU, Rujescu D, Rietschel M, Zobel A, Franke P, Wölwer W, Gaebel W (2008): Further evidence for a functional role of the glutamate receptor gene GRM3 in schizophrenia. Eur Neuropsychopharmacol 18, 768 - 772 
Müller WE: Pharmakologische und neurobiologische Grundlagen; in: Neuroleptika. Medizinisch-pharmakologisches Kompedium Band 13; hrsg. v. Möller HJ, Müller N, Bandelow B; Wissenschaftliche Verlagsgesellschaft $\mathrm{mbH}$; Stuttgart 2001

Nakamura H, Kitagawa H, Kawaguchi Y, Tsuji H (1996): Direct and indirect activation of human corticospinal neurons by transcranial magnetic and electrical stimulation. Neurosci Lett $\underline{210}, 45-48$

Nevian T, Sakmann B (2006): Spine Ca2+ signaling in spike-timing-dependent plasticity. J Neurosci 26, $11001-11013$

Nitsche MA, Paulus W (2000): Excitability changes induced in the human motor cortex by weak transcranial direct current stimulation. J Physiol 527, $633-639$

Nitsche MA, Paulus W (2001): Sustained excitability elevations induced by transcranial DC motor cortex stimulation in humans. Neurology $\underline{57}$, $1899-1901$

Nitsche MA, Paulus W (2007): Transkranielle Gleichstromstimulation; in: Das TMSBuch; hrsg. v. Siebner HR, Ziemann U; Springer Verlag; Heidelberg 2007, $533-542$

Nitsche MA, Fricke K, Henschke U, Schlitterlau A, Liebetanz D, Lang N, Henning S, Tergau F, Paulus W (2003): Pharmacological modulation of cortical excitability shifts induced by transcranial direct current stimulation in humans. J Physiol 553, 293 - 301 
Nitsche MA, Nitsche MS, Klein CC, Tergau F, Rothwell JC, Paulus W (2003a): Level of action of cathodal DC polarisation induced inhibition of the human motor cortex. Clin Neurophysiol 114, $600-604$

Nitsche MA, Schauenburg A, Lang N, Liebetanz D, Exner C, Paulus W, Tergau F (2003b): Facilitation of implicit motor learning by weak transcranial direct current stimulation of the primary motor cortex in the human. J Cogn Neuosci $\underline{15}, 619-626$

Nitsche MA, Grundey J, Liebetanz D, Lang N, Tergau F, Paulus W (2004a): Catecholaminergic consolidation of motor cortical neuroplasticity in humans. Cereb Cortex 14, $1240-1245$

Nitsche MA, Liebetanz D, Schlitterlau A, Henschke U, Fricke K, Frommann K, Lang N, Henning S, Paulus W, Tergau F (2004b): GABAergic modulation of DC stimulation-induced motor cortex excitability shifts in humans. Eur $\mathbf{J}$ Neurosci $\underline{19}, 2720-2726$

Nitsche MA, Seeber A, Frommann K, Klein CC, Rochford C, Nitsche MS, Fricke K, Liebetanz D, Lang N, Antal A et al. (2005): Modulating parameters of excitability during and after transcranial direct current stimulation of the human motor cortex. J Physiol $\underline{568}, 291$ - 303

Nitsche MA, Lampe C, Antal A, Liebetanz D, Lang N, Tergau F, Paulus W (2006): Dopaminergic modulation of long-lasting direct current-induced cortical excitability changes in the human motor cortex. Eur $\mathrm{J}$ Neurosci $\underline{23}$, $1651-1657$ 
Nitsche MA, Cohen LG, Wassermann EM, Priori A, Lang N, Antal A, Paulus W, Hummel F, Boggio PS, Fregni F, Pascual-Leone A (2008): Transcranial direct current stimulation: State of the art 2008. Brain Stimul 1, 206- 223

Nitsche MA, Kuo MF, Karrasch R, Wächter B, Liebetanz D, Paulus W (2009): Serotonin affects transcranial direct current-induced neuroplasticity in humans. Biol Psychiatry $\underline{66}, 503-508$

Nudo RJ, Milliken GW, Jenkins WM, Merzenich MM (1996): Use-dependent alterations of movement representations in primary motor cortex of adult squirrel monkeys. J Neurosci $\underline{15}, 785-807$

Oldfield RC (1971): The assessment and analysis of handedness: the Edinburgh inventory. Neuropsychologia $\underline{9}, 600-604$

Olney JW, Farber NB (1995): Glutamate receptor dysfunction and schizophrenia. Arch Gen Psychiatry 2, $998-1007$

Orth M, Benecke R: Kortikale Innervationsstille; in: Das TMS-Buch; hrsg. v. Siebner HR, Ziemann U; Springer Verlag; Heidelberg 2007, 159 - 165

Oxley T, Fitzgerald PB, Brown TL, de Castella A, Daskalakis ZJ, Kulkarni J (2004): Repetitive transcranial magnetic stimulation reveals abnormal plastic response to premotor cortex stimulation in schizophrenia. Biol Psychiatry $\underline{56}$, $628-633$ 
Pantelis C, Yucel M, Wood SJ, Velakoulis D, Sun D, Berger G, Stuart GW, Yung A, Phillips L, McGorry PD (2005): Structural brain imaging evidence for multiple pathological processes at different stages of brain development in schizophrenia. Schizophr Bull 31, 672 - 696

Pariante CM, Dazzan P, Danese A, Morgan KD, Brudaglio F, Morgan C, Fearon P, Orr K, Hutchinson G, Pantelis C u. A. (2005): Increased pituitary volume in antipsychotic-free and antipsychotic-treated patients of the AEsop first-onset psychosis study. Neuropsychopharmacology $\underline{30}, 1923$ - 1931

Pascual-Leone A, Manoach DS, Birnbaum R, Goff DC (2002): Motor cortical excitability in schizophrenia. Biol Psychiatry $\underline{52}, 24-31$

Paz RD, Tardito S, Atzori M, Tseng KY (2008): Glutamatergic dysfunction in schizophrenia: from basic neuroscience to clinical psychopharmacology. Eur Neuropsychopharmacol $\underline{18}, 773-786$

Perez-Costas E, Melendez-Ferro M, Roberts RC (2010): Basal ganglia pathology in schizophrenia: dopamine connections and anomalies. J Neurochem $\underline{113}$, $287-302$

Perez-Neri I, Ramirez-Bermudez J, Montes S, Rios C (2006): Possible mechanisms of neurodegeneration in schizophrenia. Neurochem Res $\underline{31}, 1279$ - 1294

Purpura DP, McMurtry JG (1965): Intracellular activities and evoked potential changes during polarization of motor cortex. J Neurophysiol 28, $166-185$

Pycock CJ, Kerwin RW, Carter CJ (1980): Effect of lesion of cortical dopamine terminals on subcortical dopamine receptors in rats. Nature $\underline{286}, 74-76$ 
Radhu N, de Jesus DR, Ravindran LN, Zanjani A, Fitzgerald PB, Daskalakis ZJ (2013): A meta-analysis of cortical inhibition and excitability using transcranial magnetic stimulation in psychiatric disorders. Clin Neurophysiol $\underline{124}, 1309-1320$

Rais M, Cahn W, Van Haren N, Schnack H, Caspers E, Hulshoff Pol H, Kahn R (2008): Excessive brain volume loss over time in cannabis-using first-episode schizophrenia patients. Am J Psychiatry $\underline{165}, 490$ - 496

Rizzo V, Siebner HS, Morgante F, Mastroeni C, Girlanda P, Qartarone A (2009): Paired associative stimulation of left and right human motor cortex shapes interhemispheric motor inhibition based on a Hebbian mechanism. Cereb Cortex $\underline{19}, 907-915$

Rogers JT, Rusiana I, Trotter J, Zhao L, Donaldson E, Pak DT, Babus LW, Peters M, Banko JL, Chavis P et al. (2011): Reelin supplementation enhances cognitive ability, synaptic plasticity, and dendritic spine density. Learn Mem $\underline{18}, 558-$ 564

Rolls ET, Loh M, Deco G, Winterer G (2008): Computational models of schizophrenia and dopamine modulation in the prefrontal cortex. Nat Rev Neurosci $\underline{9}, 696-709$

Rothwell JC, Day BL, Thompson PD, Kujirai T (2009): Short latency intracortical inhibition: one of the most popular tools in human motor neurophysiology. $\mathrm{J}$ Physiol $\underline{587}, 11-12$ 
Rothwell JC, Hallett M, Berardelli A, Eisen A, Rossini P, Paulus W (1999): Magnetic stimulation: motor evoked potentials. The International Federation of Clinical Neurophysiology. Electroencephalogr Clin Neurophysiol Suppl $\underline{52}, 97-103$

Saykin AJ, Shtasel DL, Gur RE, Kester DB, Mozley LH, Stafiniak P, Gur RC (1994): Neuropsychological deficits in neuroleptic naïve patients with firstepisode schizophrenia. Arch Gen Psychiatry 1ㅗ, 124 - 131

Scatton B, Worms P, Lloyd KG, Bartholini G (1982): Cortical modulation of striatal function. Brain Res 232, $331-343$

Schiller J, Helmchen F, Sakmann B (1995): Spatial profile of dendritic calcium transients evoked by action potentials in rat neocortical pyramidal neurones. $\mathbf{J}$ Physiol $\underline{487}, 583-600$

Schwieler L, Linderholm KR, Nilsson-Todd LK, Erhardt S, Engberg G (2008): Clozapine interacts with the glycine site of the NMDA receptor: electrophysiological studies of dopamine neurons in the rat ventral tegmental area. Life Sci $\underline{83}, 170-175$

Segnitz N, Ferbert T, Schmitt A, Gass P, Gebicke-Haerter PJ, Zink M (2011): Effects of chronic oral treatment with aripiprazole on the expression of NMDA receptor subunits and binding sites in rat brain. Psychopharmacology (Berl) $\underline{217}, 127-142$ 
Shenton ME, Wible CG, McCarley RW: A review of magnetic resonance imaging studies of brain abnormalities in schizophrenia. In: Brain Imaging in Clinical Psychiatry; hrsg. v. Krishnan K, Doraiswamy P; Marcel Dekker, Inc; New York 1997; $297-380$

Shimazu H, Maier MA, Cerri G, Kirkwood PA, Lemon RN (2004): Macaque ventral premotor cortex exerts powerful facilitation of motor cortex outputs to upper limb motoneurons. J Neurosci 24, 1200 - 1211

Siebner HR, Ziemann U: Hirnstimulation - Physiologische Grundlagen; in: Das TMS-Buch; hrsg. v. Siebner HR, Ziemann U; Springer Verlag; Heidelberg $2007 ; 27-45$

Siebner HR, Dressnandt J, Auer C, Conrad B (1998): Continous intrathecal baclofen infusions induced a marked increase of the transcranially evoked silent period in a patient with generalized dystonia. Muscle Nerve 21, 1209 - 1212

Smieskova R, Fusar-Poli P, Allen P, Bendfeldt K, Stieglitz RD, Drewe J, Radue EW, McGuire PK, Riecher-Rössler A, Borgwardt SJ (2010): Neuroimaging predictors of transition to psychosis--a systematic review and meta-analysis. Neurosci Biobehav Rev $\underline{34}, 1207$ - 1222

Stefan K, Kunesch E, Cohen LG, Benecke R, Classen J (2000): Induction of plasticity in the human motor cortex by paired associative stimulation. Brain $\underline{123}, 572-584$

Stefan K, Kunesch E, Benecke R, Cohen LG, Classen J (2002): Mechanisms of enhancement of human motor cortex excitability induced by interventional paired associative stimulation. J Physiol $\underline{543}, 699-708$ 
Stefansson H, Steinthorsdottir V, Thorgeirsson TE, Gulcher JR, Stefansson K (2004): Neuregulin 1 and schizophrenia. Ann Med $\underline{36}, 62$ - 71

Straub RE, Jiang Y, MacLean CJ, Ma Y, Webb BT, Myakishev MV, Harris-Kerr C, Wormley B, Sadek H, Kadambi B u. A. (2002): Genetic variation in the 6p22.3 gene DTNBP1, the human ortholog of the mouse duysbindin gene, is associated with schizophrenia. Am J Hum Genet $\underline{71}, 337$ - 348

Tandon N, Shah J, Keshaven MS, Tandon R (2012): Attenuated psychosis and the schizophrenia prodrome: current status of risk identification and psychosis prevention. Neuropsychiatry (London) 2 , $345-353$

Tebartz van Elst L, Valerius G, Büchert M, Thiel T, Rüsch N, Bubl E, Henning J, Ebert D, Olbrich HM (2005): Increased prefrontal and hippocampal glutamate concentration in schizophrenia: Evidence from a magnetic resonance spectroscopy study. Biol Psychiatry $\underline{58}, 724-730$

Van Haren NE, Hulsfoff Pol HE, Schnack HG, Cahn W, Mandl RC, Collins DL, Evans AC, Kahn RS (2007): Focal gray matter changes in schizophrenia across the course of the illness: a 5-years follow-up study. Neuropsychopharmacology $\underline{32}, 2057-2066$

Van Haren NE, Hulsfoff Pol HE, Schnack HG, Cahn W, Brans R, Carati I, Rais M, Kahn RS (2008): Progressive brain volume loss in schizophrenia over the course of the illness: evidence of maturational abnormalities in early adulthood. Biol Psychiatry $\underline{63}, 106-113$ 
Van Haren NE, Cahn W, Hulsfoff Pol HE, Kahn RS (2012): The course of brain abnormalities in schizophrenia: can we slow the progression? J Psychopharmacol $\underline{26}, 8-14$

Van Rossum JM (1966): The significance of dopamine-receptor blockade for the machanism of action of neuroleptic drugs. Arch Int Pharmacodyn Ther $\underline{160}$, $492-494$

Waddington JL, Youssef HA, Kinsella A (1995): Sequential cross-sectional and 10year prospective study of severe negative symptoms in relation to duration of initially untreated psychosis in chronic schizophrenia. Psychol Med $\underline{25}$, $849-857$

Weinberger DR (1999): Cell biology of the hippocampal formation in schizophrenia. Biol Psychiatry $\underline{45}, 395-402$

Werhahn KJ, Fong JKY, Meyer BU, Priori A, Rothwell JC, Day BL, Thompson PD (1994): The effect of magnetic coil orientation on the latency of surface EMG and single motor unit responses in the firstdorsal interosseous muscle. Electroencephalogr Clin Neurophysiol 93, 138 - 146

Werhahn KJ, Kunesch E, Noachtar S, Benecke R, Classen J (1999): Differential effects on motorcortical inhibition induced by blockade of GABA uptake in humans. J Physiol 517, 591 - 597

Wobrock T, Pajonk FG, D`Amelio R, Falkai P (2005): Schizophrenie und Sucht. Psychoneuro $\underline{31}, 433-440$ 
Wobrock T, Kadovic D, Falkai P (2007): Cortical excitability in schizophrenia. Sudies using transcranial magnetic stimulation. Nervenarzt $\underline{78}, 753-754$

Wobrock T, Schneider M, Kadovic D, Schneider-Axmann T, Ecker UK, Retz W, Rösler M, Falkai P (2008): Reduced cortical inhibition in first-episode schizophrenia. Schizophr Res $\underline{105}, 252-261$

Wobrock T, Schneider-Axmann T, Retz W, Rösler M, Kadovic D, Falkai P, Schneider M (2009): Motor circuit abnormalities in first-episode schizophrenia assessed with transcranial magnetic stimulation. Phyrmacopsychiatry $\underline{42}, 194-201$

Wolf ME, Mangiavacchi S, Sun X (2003): Mechanisms by which dopamine receptors may influence synaptic plasticity. Ann N Y Acad Sci 1003, $241-249$

Woo TU, Walsh JP, Benes FM (2004): Density of glutamic acid decarboxylase 67 messenger RNA-containing neurons that express the N-methyl-D-aspartate receptor subunit NR2A in the anterior cingulate cortex in schizophrenia and bipolar disorder. Arch Gen Psychiatry $\underline{61}, 649$ - 657

Woods SW (2003): Chlorpromazine equivalent doses for the newer atypical antipsychotics. J Clin Psychiatry $\underline{64}, 663-667$

Wright IC, Rabe-Hesketh S, Woodruff PW, David AS, Murray RM, Bullmore ET (2000): Meta-analysis of regional brain volumes in schizophrenia. Am J Psychiatry $\underline{157}, 16-25$ 
Wyatt RJ (1991): Neuroleptics and the natural course of schizophrenia. Schizophr Bull 17, $325-351$

Ziemann U (2004): TMS and drugs. Clin Neurophysiol 115, 1717 - 1729

Ziemann U, Netz J, Szelényi A, Hömberg V (1993): Spinal and supraspinal mechanisms contribute to the silent period in the contracting soleus muscle after transcranial magnetic stimulation of human motor cortex. Neurosci Lett $\underline{156}, 167-171$ 


\section{Danksagung}

Bedanken möchte ich mich bei Herrn Privatdozent Dr. T. Wobrock für die Anregungen und Ideen sowie für die Bereitstellung aller benötigten Geräte, die maßgeblich zum Gelingen dieser Arbeit geführt haben.

Mein besonderer Dank gilt meinem Betreuer Dr. A. Hasan für die außerordentlich sachkundige sowie uneingeschränkte und geduldige Unterstützung. Jede Phase dieser Arbeit wurde von ihm intensiv, professionell und warmherzig begleitet.

Allen anderen Mitarbeitern der Abteilung Psychiatrie und Psychotherapie danke ich für die Hilfsbereitschaft, organisatorische Unterstützung und die jederzeit freundschaftliche Arbeitsatmosphäre. 


\section{Publikationen:}

Wesentliche Ergebnisse dieser Dissertation wurden unter dem Titel "Dysfunctional long-term potentiation-like plasticity in schizophrenia revealed by transcranial direct current stimulation" in der Fachzeitschrift Behavioural Brain Research (Publikationsjahr: 2011, 224(1):15-22, Impact Factor 2011: 3.417) unter der Autorenreihenfolge "Alkomiet Hasan, Michael A. Nitsche, Bettina Rein, Thomas Schneider-Axmann, Birgit Guse, Oliver Gruber, Peter Falkai, Thomas Wobrock" publiziert.

Eine weitere Arbeit mit einem Teil der Daten aus der Dissertation sowie weiteren Daten und Analysen wurde am 10.09.2014 unter dem Titel "BDNF-Val66Metpolymorphism impact on cortical plasticity in schizophrenia patients: a proof-ofconcept study" in der Fachzeitschrift The International Journal of Neuropsychopharmacology (IntJNP-14-0237.R1, Impact Factor 2014: 5.264) unter der folgenden Autorenreihenfolge "Wolfgang Strube, Michael A. Nitsche, Thomas Wobrock, Tilmann Bunse, Bettina Rein, Maximiliane Herrmann, Andrea Schmitt, Vanessa Nieratschker, Stephanie H. Witt, Marcella Rietschel, Peter Falkai, Alkomiet Hasan" zur Publikation angenommen. 


\section{Lebenslauf}

Geboren wurde ich am 08. Oktober 1985 in Quedlinburg als drittes Kind von Sigrid Monika Hertel und Eberhard Michael Rein. Ich besuchte von 1992 bis 1996 die Neustädter Grundschule in Quedlinburg und anschließend wechselte ich auf das GutsMuths-Gymnasium in Quedlinburg, wo ich im Juli 2005 das Zeugnis der allgemeinen Hochschulreife erlangte. Im August 2005 begann ich die Ausbildung zur Gesundheits- und Krankenpflegerin im Klinikum Dorothea Christiane Erxleben in Quedlinburg, welche ich im Oktober 2006 beendete. Zum Wintersemester 2006/2007 begann ich das Studium der Humanmedizin an der Georg-August-Universität Göttingen. Es folgte ein regulärer Studienverlauf mit Bestehen des Ersten Abschnittes der Ärztlichen Prüfung im September 2008. Der Zweite Abschnitt der Ärztlichen Prüfung folgte erfolgreich im Oktober 2012.

Von Dezember 2009 bis August 2010 war ich im TMS-Labor in der Abteilung Psychiatrie und Psychotherapie der Medizinischen Fakultät der Universität Göttingen unter der Leitung von PD Dr. med. T. Wobrock tätig.

Am 01.12.2012 trat ich meine Assistenzarztstelle in der Klinik für Allgemein-, Viszeral- und Gefäßchirurgie im Harzklinikum Quedlinburg an. Nach einer einjährigen Elternzeit setzte ich im August 2014 die Facharztweiterbildung für Viszeralchirurgie in Quedlinburg fort. 